Florida International University FIU Digital Commons

\title{
Vascular reactivity of isolated rat mesenteric arterioles in the presence and absence of ouabain
}

Rohit Chawla

Florida International University

DOI: $10.25148 /$ etd.FI14060152

Follow this and additional works at: https://digitalcommons.fiu.edu/etd

Part of the Biomedical Engineering and Bioengineering Commons

\section{Recommended Citation}

Chawla, Rohit, "Vascular reactivity of isolated rat mesenteric arterioles in the presence and absence of ouabain" (2006). FIU Electronic Theses and Dissertations. 2120.

https://digitalcommons.fiu.edu/etd/2120 
FLORIDA INTERNATIONAL UNIVERSITY

Miami, Florida

VASCULAR REACTIVITY OF ISOLATED RAT MESENTERIC ARTERIOLES IN

THE PRESENCE AND ABSENCE OF OUABAIN

A thesis submitted in partial fulfillment of the

requirements for the degree of

MASTER OF SCIENCE

in

BIOMEDICAL ENGINEERING

by

Rohit Chawla

2006 
To: Dean Vish Prasad

College of Engineering and Computing

This thesis, written by Rohit Chawla, and entitled Vascular Reactivity of Isolated Rat Mesenteric Arterioles in the Presence and Absence of Ouabain, having been approved in respect to style and intellectual content, is referred to you for judgment.

We have read this thesis and recommend that it be approved.

Richard T. Schoephoerster

Wei-Chiang Lin

Nikolaos M. Tsoukias, Major Professor

Date of Defense: July 20, 2006

The thesis of Rohit Chawla is approved.

Dean Vish Prasad

College of Engineering and Computing

Interim Dean Stephan L. Mintz

University Graduate School

Florida International University, 2006 


\section{DEDICATION}

This work is dedicated to my parents Ravi Chawla and Sneh lata Chawla and my brother Rahul who have always been a source of love and inspiration for me. 


\section{ACKNOWLEDGMENTS}

First of all, I would like to thank my research mentor Dr Nikolaos Tsoukias without whose support and guidance, this research thesis would have been impossible. His dedication to research and hardworking character has been a source of inspiration for me. His guidance at every step of this research endeavour helped ensure timely completion of this study. I would like to thank him for not just being a mentor but also a friend throughout the years of my masters' degree.

Secondly, I would like to thank my thesis committee members Dr Richard Schoephoerster and Dr Wei-Chiang Lin. I thank Dr Schoephoerster for giving me admission to his department and his guidance during my thesis. I thank Dr Lin for his valuable guidance during the thesis as well as for sharing his rats.

Lastly, I would like to thank all my lab buddies Manu Kanwar, Dr. Adam Kapela, Haroldo Silva, Jennifer Hall, Sara Nofallah and Roxana Ordonez. I thank them for their help during my research and providing a healthy lab environment to work in. I also thank Siobhain Gallocher for helping me with statistical analysis. 
ABSTRACT OF THE THESIS

VASCULAR REACTIVITY OF ISOLATED RAT MESENTERIC ARTERIOLES IN

THE PRESENCE AND ABSENCE OF OUABAIN

by

Rohit Chawla

Florida International University, 2006

Miami, Florida

Professor Nikolaos M. Tsoukias, Major Professor

The microvasculature plays a significant role in the regulation of blood pressure and regional blood supply. Cardiotonic steroids like the adrenal cortical hormone (ouabain) have been proposed to play a role in some forms of hypertension. The purpose of this study was to determine the effect of different agonists on arteriolar diameter in the presence and absence of ouabain.

In Vitro studies on isolated intact rat mesenteric arterioles were performed by administering different concentrations of the vasoconstrictor norepinephrine (NE) and the vasorelaxant acetylcholine (Ach) in the presence and absence of ouabain. NE induced constriction was not significantly enhanced in the presence of ouabain. Ach completely reversed NE-induced constriction without ouabain, which was significantly impaired in ouabain presence $(p<0.01)$. NOS inhibition reduced the Ach-mediated relaxation significantly in the absence of ouabain $(p<0.01)$ whereas it was not significantly affected in ouabain presence. $\mathrm{K}^{+}$Channel blockade almost completely abolished Ach-induced relaxation in presence and absence of ouabain. 
1.0 INTRODUCTION .1

2.0 HYPERTENSION .2

2.1 OUABAIN ACTION MECHANISM: BLAUSTEIN'S HYPOTHESIS ........... 3

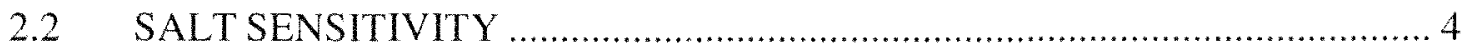

$2.3 \mathrm{CA}^{2+}$ HOMEOSTASIS IN SALT SENSITIVE HYPERTENSION .................... 5

3.0 MICROCIRCULATORY PHYSIOLOGY, CALCIUM, ENDOTHELIUM-

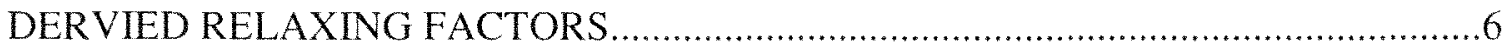

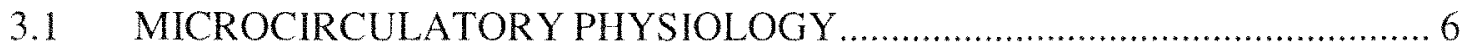

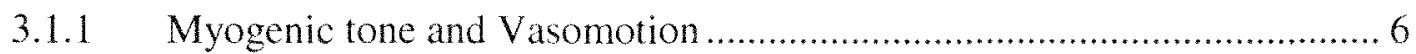

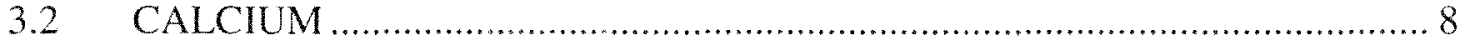

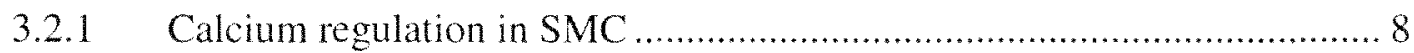

3.2.2 Calcium regulation in ECs ............................................................ 16

3.2.3 Integration and Coordination of responses in the vascular wall: Gap

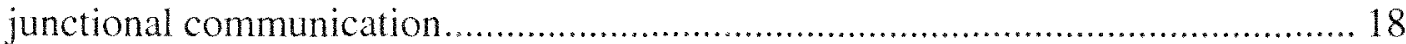

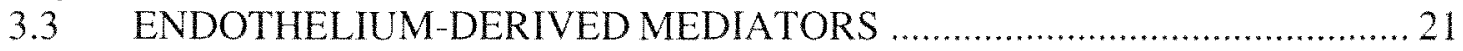

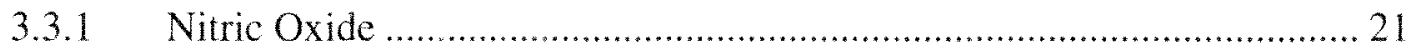

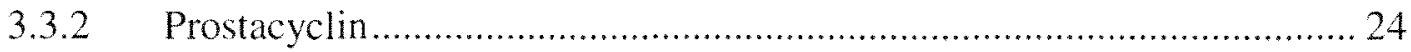

3.3.3 Endothelium Derived Hyperpolarizing Factor..................................... 25

3.3.4 Mediators responsible for EDHF induced dilation in rat mesenteric

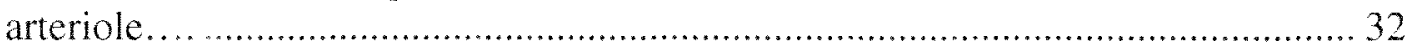

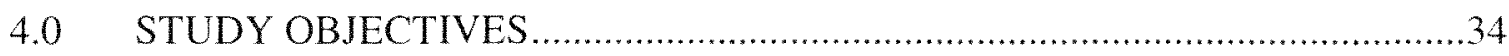

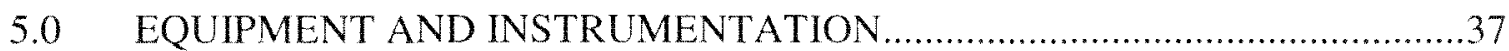

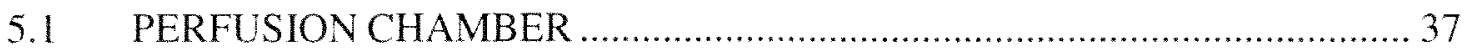

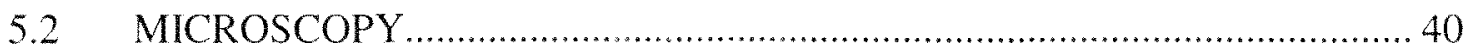

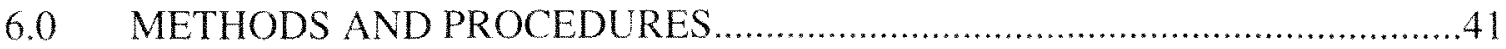

6.1 CONTROL SOLUTION

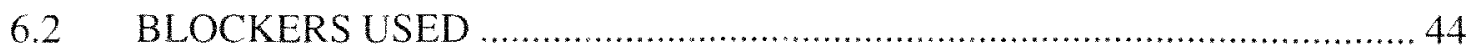


6.3 EXPERIMENTAL SET UP FOR APPLICATION OF AGONISTS TO

SMOOTH MUSCLE AND ENDOTHELIUM

6.4 BRIGHT FIELD IMAGING, DIAMETER MEASUREMENTS,

RECORDING MOVIES FOR VASOMOTION …................................................ 50

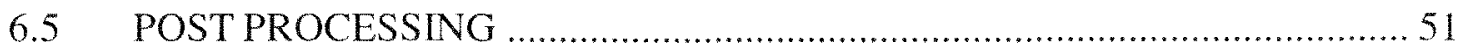

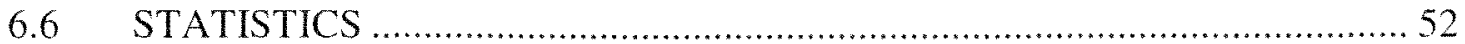

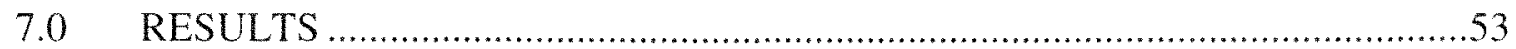

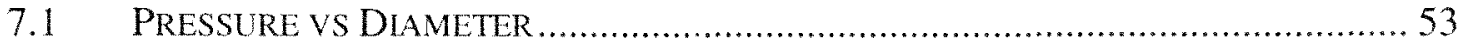

7.2 CONTROL STUDIES OF VASCULAR REACTIVITY .............................................. 55

7.2.1 Effect of Vasoconstrictor NE on vessel diameter................................... 55

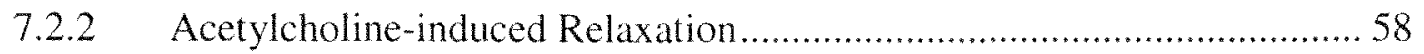

7.2.3 Effect of Indomethacin on Ach induced relaxation................................6 60

7.2.4 Effect of eNOS blockade on Ach-induced relaxation.............................6. 62

7.2.5 Effect of blocking EDHF pathway in Ach-induced relaxation.................. 63

7.3 EFFECT OF OUABAIN ON VASCULAR REACTIVITY ...........................................6 65

7.3.1 Effect of Ouabain on NE induced constriction-response curve ................66 66

7.3.2 Ach-induced dilation in the presence of Ouabain ................................... 70

7.3.3 Effect of EDHF blockade on Ach induced relaxation in presence of

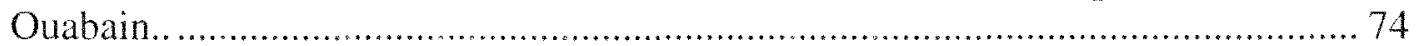

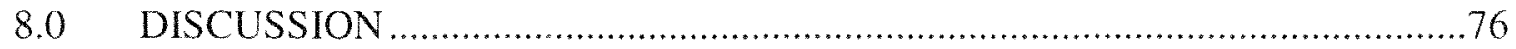

9.0 CONCLUSION

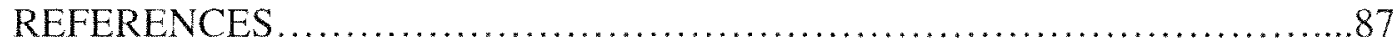




\section{LIST OF FIGURES}

FIGURE

PAGE

Figure 1: Blaustein's hypothesis for the effect of ouabain-induced $\mathrm{Na}^{+} / \mathrm{K}^{+}$pump on $\mathrm{Ca}^{2+}$ homeostasis. (Blaustein et al, 1977) ........................4

Figure.2: Various ion channels, pumps and exchangers in a smooth muscle cell of rat mesenteric arteriole.

Figure 3: Various ion channels, pumps and exchangers present in EC of rat mesenteric artery........................................ 17

Figure 4: Integrated SMC and EC cell ........................................21

Figure 5: A detailed figure showing the effect of EDHF action mechanism through $\mathrm{SK}_{\mathrm{Ca}}$ and $\mathrm{IK}_{\mathrm{Ca}}$ channels in rat mesenteric artery .........................36

Figure.6: Perfusion chamber (Living Systems Instrumentation, Model CH/SH 1).....38

Figure 7: Rat mesenteric arcade spread in control solution at $5^{\circ} \mathrm{C}$

Figure 8: Bright field image of a cannulated rat mesentery microartery secured with the help of two microsutures (imaged using Olympus $4 \mathrm{X}$ objective)

Figure 10: Diameter response to increase in intra-luminal pressure from 0 to $80 \mathrm{mmHg}$ in isolated intact rat mesenteric arteriole.

Figure 11: Concentration-response curve for NE induced constriction in isolated rat mesenteric rat arterioles.

Figure 12: Application of NE in the concentration range $0.4 \mu \mathrm{M}-1 \mu \mathrm{M}$ often resulted in vasomotion.

Figure 13: Concentration response curve for Ach-induced relaxation in isolated intact rat mesenteric arterioles preconstricted with $1 \mu \mathrm{M} \mathrm{NE}$

Figure 15: Concentration response curve for Ach-induced relaxation in isolated intact rat mesenteric arterioles preconstricted with $1 \mu \mathrm{M} \mathrm{NE}$ in the presence of e-NOS blocker (L-Name).

Figure 17: Effect of ouabain on NE induced vasoconstriction in isolated rat mesenteric artery...

Figure 18: Effect of NCX blockade with $2 \mu \mathrm{M} \mathrm{KB}-\mathrm{R} 7943$ on NE induced constriction in the presence of ouabain. 
Figure 20: Effect of NOS blockade on Ach-induced relaxation response in the presence of $100 \mathrm{nM}$ Ouabain............................................. 74 
presence and absence of ouabain. Also, the effect of ouabain on Ach-mediated relaxation was studied by comparing the relaxation responses in the presence and absence of ouabain. Further blockade of individual relaxing pathways (Cyclooxygenase pathway, NO-mediated pathway as well as EDHF-mediated pathway) was done with and without ouabain to further elucidate the pathway through which ouabain exerts its effect.

\subsection{HYPERTENSION}

Hypertension is an endemic disease in Western countries and is defined as a state when diastolic blood pressure (BP) $>90 \mathrm{mmHg}$ and/or systolic $(\mathrm{BP})>140 \mathrm{mmHg}$. This is a very important health issue as hypertension is a major risk factor for premature death and diability from heart attack, heart failure, stroke and many other afflictions. (92). Within United States, approximately $20 \%$ of the population is hypertensive whereas more than $50 \%$ of individuals over the age of 60 are hypertensive. Different factors are responsible for hypertension in the body including reduced functioning of the kidneys causing an increase in extracellular fluid leading to increased BP (54), genetics, adrenal cortical hormone, ouabain and other cardiotonic steroids. Some forms of hypertension are associated with an increase in ouabain levels. During hypertension, the blood pressure is higher due to reduced vessel diameter compared to normal conditions. This can be due to enhanced constriction of vessels to vasoconstrictors or impaired relaxation to vasorelaxants present in the body. The vessel diameter is regulated by an elaborate network of signaling pathways between the endothelial cells (EC) and smooth muscle cells (SMC) which form the vascular wall. 


\subsection{OUABAIN ACTION MECHANISM: BLAUSTEIN'S HYPOTHESIS}

Cardiotonic steroids, including the adrenal cortical hormone ouabain, have been proposed to play a critical role in linking salt intake to hypertension. Almost half of the patients with essential hypertension have increased levels of ouabain $(52,86)$ and chronic high salt intake causes an elevation in the concentration of cardiotonic steroids in plasma $(56,57)$. Several animal models of salt sensitive hypertension have also elevated levels of cardiotonic steroids $(55,56)$. The mechanisms of ouabain-induced inhibition of relaxation remain controversial. In rat thoracic aorta, ouabain caused impairment of relaxation to sodium nitroprusside (NO donor). Removal of the endothelium had no effect on the inhibition of relaxation and suggested involvement of effector pathways in SMC rather than endothelium $(116,117)$. On the other hand, ouabain-induced impairment of EC-dependent relaxation, reported in human resistance arteries, was attributed to compromised synthesis or release of EDRF (137).

Almost thirty years ago Blaustein (10) proposed that cardiotonic steroids affect vascular resistance through inhibition of the $\mathrm{Na}^{+} / \mathrm{K}^{+}$ATPase. The $\mathrm{Na}^{+} / \mathrm{K}^{+}$ATPase pump present in the SMC plasma membrane is responsible for the removal of $3 \mathrm{Na}^{+}$ions from the SMC. High levels of ouabain blocks this pump thereby leading to an accumulation of $\mathrm{Na}^{+}$inside the cell. The $\mathrm{Na}^{+} / \mathrm{Ca}^{2+}$ exchanger (also present in SMC plasma membrane) is responsible for the removal of $\mathrm{Ca}^{2+}$ from the cell along with intrusion of $\mathrm{Na}^{+}$ions inside the cell. Thus, the increase in intracellular $\mathrm{Na}^{+}$due to high ouabain levels lead to reversal of the $\mathrm{Na}^{+} / \mathrm{Ca}^{2+}$ exchanger (NCX) thereby increasing cytosolic $\mathrm{Ca}^{2+}$. The $\mathrm{Ca}^{2+}$ accumulation is amplified by the $\mathrm{Ca}^{2+}$ buffering system of the SR. Blaustein's hypothesis is illustrated 
below in Fig 5. The left part of the figure shows a normal SMC and the right part illustrates the effect of high ouabain levels on $\mathrm{SMC} \mathrm{Ca}^{2+}$.

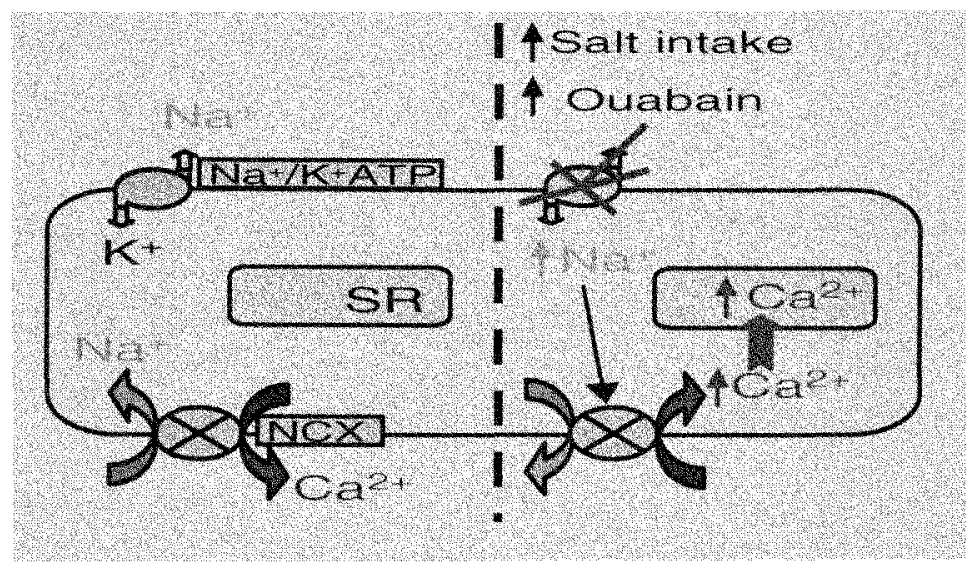

Figure 1: Blaustein's hypothesis for the effect of ouabain-induced $\mathrm{Na}^{+} / \mathrm{K}^{+}$pump on $\mathrm{Ca}^{2+}$ homeostasis. (Blaustein et al, 1977)

Until recently, this hypothesis has been examined only indirectly in different hypertensive models producing inconclusive results for the role of NCX activity in hypertension $(3,4,89,98,99)$. Recently inhibitors of NCX have been developed and provide the tools for directly assessing this mechanism in SMC. SEA0400 is a specific inhibitor of NCX, developed by Matsuda and colleagues that preferentially blocks the reverse mode (i.e. $\mathrm{Ca}^{2+}$ entry mode) of $\mathrm{NCX}(90)$. Recent experimental data utilizing this new inhibitor as well as transgenic animal models support Blaustein's hypothesis and provide evidence for the importance of NCX activity in salt sensitive hypertension (68).

\subsection{SALT SENSITIVITY}

Salt sensitivity appears in a significant percentage of the population and represents a major public health problem. It is associated with endothelial dysfunction and increased cardiovascular risk. The mechanisms that contribute to such susceptibility 
remain largely unresolved. The mechanisms by which salt intake elevates blood pressure have also not been elucidated. Neurohormonal effects (28), alterations to the transmembrane $\mathrm{Na}^{+} / \mathrm{Ca}^{2+}$ transport (84), activation of the renin-angiotensin system and inhibition of the L-arginine-NO system (115) have emerged as major components in the pathophysiology of salt sensitivity. The L-arginine-NO system appears to be downregulated in Salt Sensitive (SS) hypertension. Impaired endothelium-derived vasodilation has been reported in SS humans $(94)$ and animals $(59,60)$. Increased NO production by administration of L-arginine in Dahl SS rats abrogates salt sensitivity (21, 63) and chronic NO blockade induces SS hypertension in control rats (97). The mechanisms that link SS to a decreased NO activity have not been resolved completely. Recent studies suggest decreased expression of eNOS $(59,60,115)$, increased NO scavenging by $\mathrm{O}_{2}^{-}$and decoupling of eNOS by increased levels of peroxynitrite in SS hypertension.

\section{$2.3 \mathrm{Ca}^{2+}$ HOMEOSTASIS IN SALT SENSITIVE HYPERTENSION}

$\mathrm{Ca}^{2+}$ mobilization plays a central role in the regulation of vascular tone and blood flow. In the ECs the intracellular concentration of free $\mathrm{Ca}^{2+}$ regulates release of vasoactive substance, while in the SMCs $\mathrm{Ca}^{2+}$ is the major determinant of contractility. Alterations in the mechanisms of its regulatory control may contribute to the pathogenesis of hypertension. Prior investigations have suggested altered $\mathrm{Ca} 2+$ dynamics in salt sensitivity and a direct effect of salt intake on $\mathrm{Ca}^{2+}$ dynamics in some vessels. Depressed endothelial $\mathrm{Ca}^{2+}$ responses to acetylcholine in the aorta of aldosterone-salt hypertensive rats have been reported (83). Altered $\mathrm{EC} \mathrm{Ca}^{2+}$ dynamics may be responsible 
for impaired endothelium dependent relaxations observed in different vascular beds (137). Further investigations are required to examine if this phenomenon appears in different vessels and particularly in microcirculatory vessels.

\subsection{MiCROCIRCULATORY PHYSIOLOGY, CALCIUM, ENDOTHELIUM- DERVIED RELAXING FACTORS}

\subsection{MICROCIRCULATORY PHYSIOLOGY}

Microcirculation is the flow of blood through the smallest vessels of the body as arterioles, capillaries and venules. These microvessels with diameters $<300 \mu \mathrm{m}$ are termed as resistance vessels as they offer maximum resistance to blood flow thereby playing a significant role in blood flow regulation. Various in-vitro studies on microcirculatory physiology have been performed on intact vessels as well as cultured cells. Studies on intact vessels preserve the presence of gap junctions and ion channels as present in the body and are free from neuronal and hormonal control. These studies also allow to study the coordination of responses between endothelial cells (EC) and smooth muscle cells (SMC). Thus, in-vitro studies on intact rat mesenteric arterioles provide a valuable tool to understand microcirculatory physiology.

\subsubsection{Myogenic tone and Vasomotion}

Blood vessels respond to intra-luminal pressure increase with constriction. This behavior, known as myogenic response, is independent of neural, hormonal and metabolic influences and is inherent to $\operatorname{SMC}(27,69)$. The myogenic response involves an increase in smooth muscle cell (SMC) $\mathrm{Ca}^{2+}$ concentration and a corresponding decrease in vessel diameter. An increase in transmural vessel pressure from $10-30 \mathrm{mmHg}$ 
results in an increase in vessel diameter in rat microvessel. However upon further increase in pressure to the physiological range of $40-60 \mathrm{~mm} \mathrm{Hg}$, an initial increase in the vessel diameter is followed by constriction (27). All vessels less than $150 \mu \mathrm{m}$ develop and maintain basal tone (27). Although the resting diameter continuously increases with increase in transluminal pressure, the slope of the pressure vs. diameter curve decreases with increase in pressure and tends to plateau. $(5,111)$ This mechanism allows the blood vessels to adapt to changes in blood pressure and avoid indefinite expansion with pressure. (111)

Microvessels may also show rapid oscillations in diameter upon stimulation with agonists like potassium chloride $(\mathrm{KCl})$ and norepinephrine $(\mathrm{NE})(121)$. This phenomenon of repeated diameter oscillations in microvessels is termed as vasomotion. Vasomotion is not linked to physiological rhythms like heartbeat or breathing but is considered as an intrinsic cellular phenomenon caused due to a rapid increase and decrease in SMC $\mathrm{Ca}^{2+}$ concentrations $(51,53,79)$. Vasomotion is suggested as a defense mechanism to counteract local hypoxic conditions as well as assist in efficient repartition of blood flow (103). Previous reports have suggested the presence of a small $\mathrm{SMC} \mathrm{Ca}{ }^{2+}$ threshold for the onset of vasomotion and its abolishment at high agonist concentrations (121). Various studies have suggested the importance of careful handling of the vessels to reproduce vasomotion in-vitro, as it depends on the proper functioning of gap junctions and ion channels which can be easily disrupted due to over-stretching of the vessel. 


\subsection{CALCIUM}

$\mathrm{Ca}^{2+}$ is one of the most important physiological regulators which performs many functions at both micro and macro levels. (9) At the macro- scale $\mathrm{Ca}^{2+}$ is the structural component of bones and teeth. However, at the micro-scale, it assists in various physiological processes like maintenance of vascular tone, intra/intercellular signaling, gene expression, fertilization, learning and memory, metabolism, contraction, relaxation, vesicle trafficking and apoptosis (9).

In the SMC, intracellular $\mathrm{Ca}^{2+}$ plays an important part in regulation of SMC contraction and relaxation (27). In general, increase in $\mathrm{SMC} \mathrm{Ca}^{2+}$ concentration results in contraction whereas a decrease in $\mathrm{Ca}^{2+}$ concentration causes vasorelaxation. SMC contraction and relaxation regulates the microvessel diameter, which in turn, regulates blood flow rate.

\subsubsection{Calcium regulation in SMC}

$\mathrm{Ca}^{2+}$ concentration in the SMC can be increased by influx of extracellular $\mathrm{Ca}^{2+}$ through $\mathrm{Ca}^{2+}$ channels present in the plasma membrane or by opening of intracellular $\mathrm{Ca}^{2+}$ stores like the sarcoplasmic reticulum (SR). Influx of $\mathrm{Ca}^{2+}$ through $\mathrm{Ca}^{2+}$ channels can also influence the opening of intracellular $\mathrm{Ca}^{2+}$ stores leading to a further increase in SMC $\mathrm{Ca}^{2+}$; a phenomenon termed as $\mathrm{Ca}^{2+}$ induced $\mathrm{Ca}^{2+}$ release (CICR) $(50,71)$. Potassium channels can hyperpolarize SMC leading to closure of voltage gated calcium channels, thereby reducing $\mathrm{Ca}^{2+}$ concentration in the SMC. Various channels, pumps and exchangers present in the rat mesenteric arteriolar SMC are shown in Fig.2: 


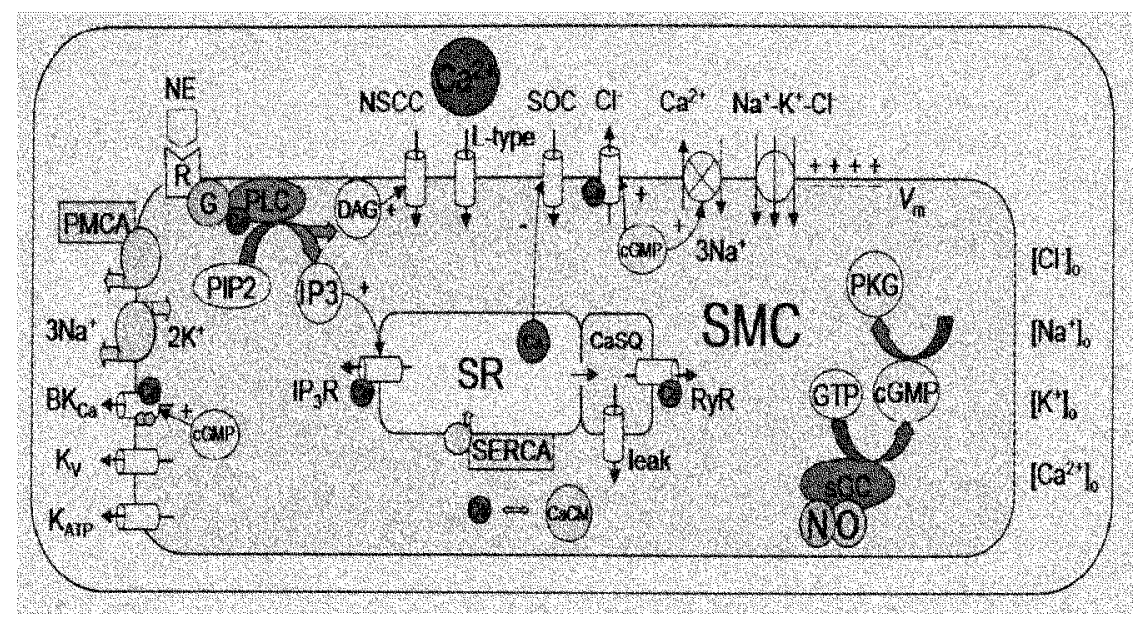

Figure.2: Various ion channels, pumps and exchangers in a smooth muscle cell of rat mesenteric arteriole.

\section{$\mathrm{Na}^{+} / \mathrm{K}^{+}$ATPase}

The surface membrane of almost every animal cell expresses hundreds or even millions of copies of $\mathrm{Na}^{+} / \mathrm{K}^{+}$ATPases. This sodium pump rejects sodium towards the extracellular space and accumulates potassium in the intracellular medium thereby maintaining the sodium and potassium ionic gradients at the expense of ATP produced by the cell. These ionic gradients drive many co- and counter transporters allowing intake of glucose and amino acids, regulation of cell volume, $\mathrm{pH}$ and calcium homeostasis and are responsible for the electrical activity of all excitable cells. $\mathrm{Na}^{+} / \mathrm{K}^{+}$ATPases are electrogenic as three sodium ions are extruded out of the cell while two potassium ions are transported. The activity of the pump contributes to the regulation of cell membrane potential. (45)

$\mathrm{Na}^{+} / \mathrm{K}^{+}$ATPase pump is composed of a noncovalently linked $\alpha$ subunit and a glycosilated $\beta$ subunit. Four isoforms of $\alpha$ subunit $(\alpha 1$ to $\alpha 4)$ and three isoforms of the $\beta$ subunit $(\beta 1$ to $\beta 3)$ are found in mammalian cells. In mammalian arteries both vascular 
SMC and EC express $\alpha 1$ isoform of $\mathrm{Na}^{+} / \mathrm{K}^{+}$ATPase. This isoform is almost completely activated at the physiological concentration of extracellular potassium $(5 \mathrm{mM})$ and in the rat is poorly sensitive to ouabain $\left(\mathrm{IC}_{50}>10\left(^{5}\right)\right.$ ). However depending on the species, both SMC and EC can have $\alpha 2$ and/or $\alpha 3$ isoforms which are activated by potassium in the concentration range $3-15 \mathrm{mM}$ and are more sensitive to inhibitory action of ouabain. The rat mesenteric arteriolar SMC contains only $\alpha 1, \alpha 2$ and $\alpha 3$ isoforms. $(72,135)$

\section{$\mathrm{Na}^{+} / \mathrm{Ca}^{2+}$ exchanger}

SMC plasma membrane contains $\mathrm{Na}^{+} / \mathrm{Ca}^{2+}$ exchangers (NCX), which are involved in regulation of intracellular $\mathrm{Ca}^{2+}$. NCX is reported to have three major roles. Firstly, it plays a dominant role in the net removal of $\mathrm{Ca}^{2+}$ when cytoplasmic $\mathrm{Ca}^{2+}$ $\left(\left[\mathrm{Ca}^{2+}\right]_{\mathrm{cyt}}\right)$ level is high leading to cell activation. Although, $\mathrm{Ca}^{2+}$ entry via $\mathrm{Ca}^{2+}$ selective channels is much more dominant, $\mathrm{NCX}$ also mediates the entry of some $\mathrm{Ca}^{2+}$ during cell activation and depolarization. It also modulates the resting $\left[\mathrm{Ca}^{2+}\right]_{\mathrm{cy}}$, even though more than one half of the $\mathrm{Ca}^{2+}$ removal under resting conditions may be mediated by low capacity high affinity ATP driven $\mathrm{Ca}^{2+}$ pump. $(80,136)$

$\mathrm{Na}^{+} / \mathrm{Ca}^{2+}$ exchanger is a bi-directional electrogenic ion transporter protein which couples the translocation of $3 \mathrm{Na}^{+}$in one direction to the translocation of $1 \mathrm{Ca}^{2+}$ in the other (12). The $\mathrm{Na}^{+} / \mathrm{Ca}^{2+}$ exchanger uses energy of the $\mathrm{Na}^{+}$electrochemical gradient to extrude intracellular $\mathrm{Ca}^{2+}$ (12). The extracellular $\mathrm{Na}^{+}$concentration is higher than the intracellular $\mathrm{Na}^{+}$concentration and hence provides a gradient for $\mathrm{Na}^{+}$movement. $\mathrm{Na}^{+} / \mathrm{K}^{+}$ ATPase pump blockade causes an increase in intracellular $\mathrm{Na}^{+}$concentration which reverses the operating direction of $\mathrm{NCX}$ thereby resulting in translocation of $\mathrm{Na}^{+}$outside the cell and $\mathrm{Ca}^{2+}$ into the cell leading to intracellular $\mathrm{Ca}^{2+}$ increase. 


\section{Potassium Channels in the Vascular SMC Wall}

Ion Channels are membrane protein complexes that allow selected ionic species to diffuse through lipid cell membrane. Potassium channels, which selectively pass potassium ions, are the largest and the most diverse type of ion channels. They play a critical role in regulating cell membrane potential, smooth muscle calcium and hence smooth muscle relaxation. $\mathrm{K}^{+}$Channels are classified into four subgroups which are discussed below

\section{Voltage gated potassium channels ( $\mathrm{Kv}$ channels)}

In SMC, the voltage activated potassium current is an important component of the outward potassium conductance and can be divided into two different types based on its inactivation properties: the delayed rectifier current $(\mathrm{KDR})$ and the rapidly inactivating transient outward current (KTO). Depending on the species and the tissue studied, the vascular SMC can have both or either of $\mathrm{K}_{\mathrm{V}}$ channels. However in $\mathrm{EC}, \mathrm{K}_{\mathrm{V}}$ channels are rarely expressed. The activity of this channel plays a predominant role in the control of the cell membrane potential and thus the tone of vascular smooth muscle. Depolarization of the cell membrane, which can be caused by physical (intraluminar pressure-induced myogenic tone) or neurohormonal mediators (e.g. norepinephrine, endothelin, angeotensin II) leads to the activation of these channels which serves as a useful protective mechanism in restoring membrane potential and preventing excessive contraction of the smooth muscle and thus vasospasm. This protective mechanism is referred to as the voltage-dependent brake. (65) 


\section{Calcium activated potassium channels}

This family of calcium channels is divided into two subfamilies, small and intermediate conductance calcium activated potassium channels (also known as $\mathrm{SK}_{\mathrm{Ca}}$ and $\mathrm{IK}_{\mathrm{Ca}}$ respectively) and the large conductance calcium activated channels (also known as $\mathrm{BK}_{\mathrm{Ca}}$ ). Only $\mathrm{BK}_{\mathrm{Ca}}$ channels are present on $\mathrm{SMC}$ plasma membrane whereas $\mathrm{SK}_{\mathrm{Ca}}$ and $\mathrm{IK}_{\mathrm{Ca}}$ are present on $\mathrm{EC}$ plasma membrane in rat mesenteric arterioles.

\section{Large conductance calcium activated potassium channels $\left(\mathrm{BK}_{\mathrm{Ca}}\right)$}

$\mathrm{BK}_{\mathrm{Ca}}$ channels are both voltage and calcium regulated potassium channels indicating that they play an important role in limiting the entry of calcium and the cell excitability. Its activity is increased when depolarizing voltages are applied and when the intracellular calcium concentration is increased. The calcium sensitivity of $\mathrm{BK}_{\mathrm{Ca}}$ lies in the region of negatively charged aspirate residues situated in the intracellular C-terminal called the "Ca ${ }^{2+}$ bowl". $\mathrm{BK}_{\mathrm{Ca}}$ has been found to be present in the vascular smooth muscle and not in the endothelium in rat mesenteric artery. (62)

\section{Voltage operated $\mathrm{Ca}^{2+}$ channels}

Vascular smooth muscle cells have voltage gated $\mathrm{Ca}^{2+}$ channels (VGCC) which are further classified as $\mathrm{L}$-type $\mathrm{Ca}^{2+}$ channels and $\mathrm{T}$-type $\mathrm{Ca}^{2+}$ channels. VGCC plays an important role in influx of extracellular $\mathrm{Ca}^{2+}$ into the $\operatorname{SMC}(9,70)$. SMC in the rat mesentery resistance arteries are reported to possess mostly L-type VGCC. Depolarization of SMC by $20-35 \mathrm{mV}$ increases the opening probability of VGCC by $10-$ 15 times. (9) Vasoactive agents like $\mathrm{KCl}$ cause an increase in $\mathrm{SMC} \mathrm{Ca}^{2+}$ by opening VGCC thereby causing influx of $\mathrm{Ca}^{2+}$ from the extracellular medium into the SMC (121). Direct modulation of VGCC can also result from stretching of the vessel (9). 


\section{Receptor operated $\mathrm{Ca}^{2+}$ channels}

Ion channels present in SMC plasma membrane that open in response to binding of an extracellular ligand are termed as receptor operated channels. These channels contribute to the influx of extracellular $\mathrm{Ca}^{2+}$ into the cell (9). The cell surface receptors include G-protein linked receptors and receptor tyrosine kinase (RTK). The major external stimuli that activate these channels are transmitters like ATP, acetylcholine, NE and glutamate (9). Upon stimulation, the signals generated include IP3, which is generated by hydrolysis of phosphatidylinositol-4,5-biphosphate $\left(\mathrm{PIP}_{2}\right)$ by phospholipase $\mathrm{C}$ enzymes (PLC $\beta$ and PLC $\gamma$ ), cyclic ADP ribose (cADPR) and nicotinic acid dinucleotide phosphate (NAADP) (9). The signals generated also promote the release of $\mathrm{Ca}^{2+}$ from the intracellular stores.

\section{Plasma membrane $\mathrm{Ca}^{2+}$-ATPase (PMCA)}

$\mathrm{Ca}^{2+}$ adenosine triphosphatase or PMCA pumps are present on the SMC plasma membrane and play the most important role in the removal of intracellular $\mathrm{Ca}^{2+}(9,70)$. However, the PMCA is responsible for sustained release of $\mathrm{Ca}^{2+}$ from the cell unlike the $\mathrm{Na}^{+} / \mathrm{Ca}^{2+}$ exchangers, which are responsible for acute removal of intracellular $\mathrm{Ca}^{2+}$. PMCA is constituted from two distinct domains, an ATP binding cytoplasmic domain and a $\mathrm{Ca}^{2+}$ binding transmembrane domain. Phosphorylation of Asparate residue (Asp351) by terminal phosphate of ATP causes a conformational change of both the PMCA domains which, in turn, is responsible for transport of $\mathrm{Ca}^{2+}$ across the membrane. Release of $\mathrm{Ca}^{2+}$ acts as a signaling mechanism for hydrolysing Asp351-Phosphate group and also returns the pump to its original state. Four different isoforms of PMCA exist (PMCA 1, PMCA 2, PMCA 3, PMCA 4) of which PMCA 1 is the most abundant and 
present in rat mesenteric SMC. (70) PMCA pumps use the energy derived from the hydrolysis of ATP to Adenosine diphosphate (ADP) to remove $\mathrm{Ca}^{2+}$ from the cytoplasm thereby causing SMC relaxation in rat mesenteric arterioles.

\section{Store operated $\mathrm{Ca}^{2+}$ channels}

Depletion of intracellular stores like SR in the SMC results in opening of store operated $\mathrm{Ca}^{2+}$ channels (SOC) present in SMC plasma membrane. Agonists like norepinephrine stimulate SMC thereby causing an increase in SMC intracellular $\mathrm{Ca}^{2+}$ by releasing $\mathrm{Ca}^{2+}$ from $\mathrm{SR}$ through $\mathrm{IP}_{3}$ pathway (Figl). This increase in $\mathrm{Ca}^{2+}$ leads to $\mathrm{SMC}$ contraction. As $\mathrm{Ca}^{2+}$ is removed from the cell, the refilling of $\mathrm{SR}$ is explained by the presence of SOC as it allows the influx of $\mathrm{Ca}^{2+}$ from the extracellular space upon depletion of SR.

\section{$\mathrm{Ca}^{2+}$ channels present in SMC intracellular stores}

\section{Release through ryanodine receptors $(\mathrm{Ry} R)$}

$\mathrm{SR}$ is the main intracellular $\mathrm{Ca}^{2+}$ store present in the arterial SMC (9) and its membrane contains the ryanodine receptors (RyR) family. The major activator of $R y R$ is $\mathrm{Ca}^{2+}$ and it can act both from the lumenal and cytoplasmic side of the RyR channel. RyR activation is regulated by CADPR, which is generated by nicotinamideadeninedinucleotide (NAD) (9). An increase in $\mathrm{Ca}^{2+}$ present inside SR results in increased sensitivity of RyR on the SR surface. CADPR also increases the sensitivity of RyR on the SR surface (71).

Increase in cytoplasmic $\mathrm{Ca}^{2+}$ which can result from activation of $\mathrm{VGCC}$ or by a receptor mediated mechanism causes activation of $\mathrm{RyR}$ thereby releasing $\mathrm{Ca}^{2+}$ from the SR. In SMC, this calcium induced calcium release (CICR) primarily has an amplifying 
effect on the increase in cytoplasmic $\mathrm{Ca}^{2+}$ concentration (71). The $\mathrm{Ca}^{2+}$ release from the SR through RyR receptors can result in transient increases in cytoplasmic $\mathrm{Ca}^{2+}$ levels termed as $\mathrm{Ca}^{2+}$ sparks (71). $\mathrm{Ca}^{2+}$ release from the $\mathrm{SR}$ by $\mathrm{RyR}$ channels can also directly activate the $\mathrm{Ca}^{2+}$ activated potassium channels ( $\mathrm{K}_{\mathrm{Ca}}$ channels) This causes SMC hyperpolarization leading to inhibition of VGCC thus inhibiting contraction (27).

\section{Release through $\mathrm{IP}_{3}$ receptors}

In addition to RyR, $S R$ also contains $\mathrm{IP}_{3}$ receptors $\left(\mathrm{IP}_{3} \mathrm{R}\right)$. Previous studies have reported the existence of two types of SR in the SMC; one contains only RyR and other both RyR and $\mathrm{IP}_{3} \mathrm{R}$ (9). IP $\mathrm{P}_{3}$ is generated by hydrolysis of membrane-associated phosphatidylinositol-4, 5-biphosphate $\left(\mathrm{PIP}_{2}\right.$ ) by phospholipase $\mathrm{C}$ enzymes (PLC $\beta$ and PLC $\gamma$ ). Vasoactive agents like NE act by stimulation of PLC through membrane associated $G$ protein. The reaction converts $\mathrm{PIP}_{2}$ to $\mathrm{DAG}$ and $\mathrm{IP}_{3}(9)$ (Fig1). $\mathrm{Ca}^{2+}$ is the main regulator of the $I P_{3} R$ as an increase in luminal $S R \mathrm{Ca}^{2+}$ increases the $I_{3} R$ sensitivity thereby opening the $\mathrm{IP}_{3} \mathrm{R} \mathrm{Ca}^{2+}$ channels. Previous reports on dependence of cytoplasmic $\mathrm{Ca}^{2+}$ levels on the $\mathrm{IP}_{3} \mathrm{R}$ sensitivity have been conflicting. Low $\mathrm{Ca}^{2+}$ concentration $(100-300 \mathrm{nM})$ in the cytoplasm is stimulatory for the $\mathrm{IP}_{3} R$ but above $300 \mathrm{nM}$ $\mathrm{Ca}^{2+}$ becomes inhibitory and results in closure of $\mathrm{IP}_{3} \mathrm{R}$ gated $\mathrm{Ca}^{2+}$ channels (9). The relationship of $\mathrm{Ca}^{2+}$ levels and $I P_{3} \mathrm{R}$ activation has been reported to be sigmoidal (9). The $\mathrm{Ca}^{2+}$ release from the $\mathrm{SR}$ as a result of $\mathrm{IP}_{3} \mathrm{R}$ activation has an amplifying effect on the cytosolic $\mathrm{Ca}^{2+}$ concentration which causes SMC contraction. DAG along with $\mathrm{Ca}^{2+}$ released from the intracellular stores activates protein kinase $\mathrm{C}$. The activation of protein kinase $\mathrm{C}$ allows persistence of $\mathrm{Ca}^{2+}$ dependent responses. Rapid hydrolysis of $\mathrm{IP}_{3}$ and deactivation of $I P_{3} R$ results in termination of $\mathrm{Ca}^{2+}$ release from the $\mathrm{SR}$. 


\section{SERCA pumps}

Sarcoplasmic reticulum $\mathrm{Ca}^{2+}$ ATPase pumps (SERCA pumps), which are present on the SR membrane, sequester $\mathrm{Ca}^{2+}$ intracellular stores like SR and hence contribute to decrease cytoplasmic $\mathrm{Ca}^{2+}(9,31)$. After $\mathrm{Ca}^{2+}$ is released from SR, SERCA pumps facilitate refilling of the SR as well as regulate intracellular $\mathrm{Ca}^{2+}$ levels. Similar to PMCA, SERCA pumps also use the energy derived from the hydrolysis of ATP to ADP to transfer $\mathrm{Ca}^{2+}$ from the cytoplasm in to the intracellular stores.

\section{$\mathrm{Ca}^{2+}$ buffering}

$\mathrm{Ca}^{2+}$ buffering in the SMC also plays a role in intracellular $\mathrm{Ca}^{2+}$ regulation. Intracellular $\mathrm{Ca}^{2+}$ exists as a complex with different proteins like calmodulin and troponin and is reversibly converted to free $\mathrm{Ca}^{2+}$. Most of the cytosolic $\mathrm{Ca}^{2+}(>90 \%)$ exist as a complex with intracellular proteins. The amplitude and duration of the $\mathrm{Ca}^{2+}$ signal as well as spatial spreading of local $\mathrm{Ca}^{2+}$ signal depend on these cytosolic buffers. (9)

\subsubsection{Calcium regulation in ECs}

Endothelial cells (ECs) are located at the interface between blood and vessel wall smooth muscle cells (SMCs), playing an essential multifunctional role in both normal body homeostasis and various pathological conditions (1, 130). ECs are responsible for immunological response regulation, blood coagulation state, blood-tissue permeability, vessel repair, angiogenesis, and vascular tone modulation (130). They often respond to mechanochemical stimuli by either releasing different physiological signals or altering surface molecule expression and adhesion, gene expression, cytoskeletal remodeling, cell growth and angiogenesis (102). Endothelial control of vascular tone occurs by regulating the contractility of the surrounding blood vessel SMCs, therefore modulating blood flow 
and arterial pressure by altering the caliber of arteries and arterioles, most notably in microvessels $(68,102)$.

In ECs, $\left[\mathrm{Ca}^{2+}\right]_{i}$ elevations lead to production of vasoactive substances, for instance prostanoids and $\mathrm{NO}$, the latter being generated by $\mathrm{Ca}^{2+}$-dependent activation of endothelial NO synthases (102). The initial rise in $\left[\mathrm{Ca}^{2+}\right]_{i}$ due to agonist stimulation commonly takes place via intracellular store $\mathrm{Ca}^{2+}$ release and the subsequent plateau is supported by extracellular $\mathrm{Ca}^{2+}$ entry $(1,102)$. Calcium store depletion and the electrochemical driving force regulate $\mathrm{Ca}^{2+}$ influx from the extracellular medium. Fig.3 illustrates the various channels, pumps and exchangers present in the EC which play a role in regulation of vascular tone and calcium homeostasis. In this study, the potassium channels present in the EC are important as they form the basis for the action of EDHF pathway. Among the calcium activated potassium channels, only $\mathrm{SK}_{\mathrm{Ca}}$ and $\mathrm{IK}_{\mathrm{Ca}}$ potassium channels are present in $\mathrm{EC}$ of rat mesenteric arteries whereas only $\mathrm{BK}_{\mathrm{Ca}}$ channels are present in the SMC. Also, the SOC, NSCC, $\mathrm{Na}^{+} / \mathrm{K}^{+}$ATPase pump and NCX are common to both SMC and EC plasma membrane and have been explained earlier.

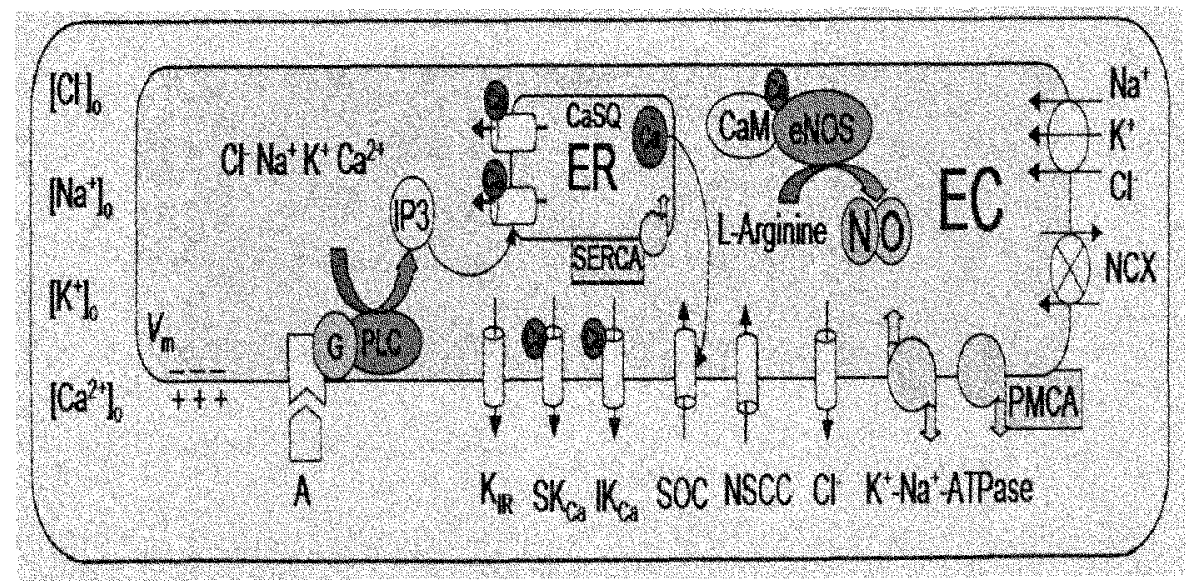

Figure 3; Various ion channels, pumps and exchangers present in EC of rat mesenteric artery 
Channels which are present only on the EC plasma membrane are explained below:

\section{Small and Intermediate conductance calcium -activated potassium channels}

The $\mathrm{SK}_{\mathrm{Ca}}$ are sensitive to an increase in intracellular calcium concentration $(0.6$ $0.7 \mu \mathrm{M})$ and are virtually voltage independent. They have small conductance to calcium compared to the $\mathrm{IK}_{\mathrm{Ca}}$ and $\mathrm{BK} \mathrm{Ca}$. The calcium sensitivity of the $\mathrm{SK}_{\mathrm{Ca}}$ channel is attributed to the association of the calcium binding protein calmodulin with the $\alpha$ subunit (138). This channel is blocked by toxins like apamin but is unaffected by charybdotoxin. The IK $\mathrm{Ca}$ has conductance intermediate between $\mathrm{SK}_{\mathrm{Ca}}$ and $\mathrm{BK} \mathrm{Ca}$ and is insensitive to apamin or iberiotoxin but is blocked by charybdotoxin, Tram-34 and Tram-39. Rat mesenteric arteriolar endothelium is found to have SKca and IKca only. (16, 17, 23, 32, 34, 37, 46, $62,64,77,78,105,106,125,129)$

\section{Inward rectifier potassium channels $\left(K_{I R}\right)$}

These channels contribute to the hyperpolarization of the vascular smooth muscle leading to relaxation. These channels are sensitive to the extracellular potassium in the concentration range of 1 to $20 \mathrm{mM}$ and increase potassium entry into the cell causing the smooth muscle to hyperpolarize. These channels are present in almost all endothelial cells and contribute significantly to membrane potentials. Enothelial $\mathrm{K}_{\mathrm{IR}}$ channels are activated not only by potassium but also by shear stress. In SMC, the expression of $K_{I R}$ increases as the diameter of the artery decreases. (104)

\subsubsection{Integration and Coordination of responses in the vascular wall: Gap junctional communication}

Integration and coordination of responses among the various cells composing a tissue is essential for the proper function of any given organ, including the blood vessel 
wall. Cells can communicate by the release of various hormones, mediators etc as well as by direct electrical and chemical intercellular communications by means of gap junction channels. The coupling between smooth muscle cells, endothelial cells and endothelial/smooth muscle allows the transfer of signal between the various cells,

\section{Longitudinal cell-cell communication}

The communication signal can be in the form of ions diffusing across SMC through homocellular gap junctions. It can also be movement of $\mathrm{Ca}^{2+}$ and $\mathrm{IP}_{3}$ through the gap junctions and hence directly affect the contraction of far laying $\mathrm{SMC}$ in response to a highly localized application of a vasoconstrictor $(41,122-124)$. Studies conducted by Peng et al. (110) concluded that intracellular communication between SMC as seen in longitudinal signaling over long distances (several millimeters) along the vessel length is too fast to be explained by diffusion of chemical species like $\mathrm{Ca}^{2+}$ or $\mathrm{IP}_{3}$. There is evidence for longitudinal signaling to be electrical in nature (110). The synchronous contractions seen in SMC during a longitudinal response support the presence of an electrical signal traveling along the vessel length which is believed to travel on the cell plasma membrane. The electrical signal can result in membrane depolarization (110). Membrane depolarization can result in opening of VGCC (both L-Type and T-Type), which would cause an influx of extra cellular $\mathrm{Ca}^{2+}$. A synchronous increase of $\mathrm{Ca}^{2+}$ along the vessel length would result in synchronous contractions as seen during a vasomotor response (110).

\section{Radial cell-cell communication}

In cultured cells, heterocellular diffusion of $\mathrm{Ca}^{2+}$ and $\mathrm{IP}_{3}$ has been determined to be slow, (123) however the geometry of arterioles allows a rapid diffusion of molecules 
across a concentration gradient between the SMC and EC (123). Arterioles comprise of a layer of smooth muscle cells around a monolayer of endothelial cells. There is evidence for existence of connexin based heterocellular gap junctions between the two cell types (81). The EC volume has been determined to be less than $10 \%$ of the SMC volume (33). This unique geometry allows a single endothelial cell to be in contact with a maximum of $20 \mathrm{SMC}$. The diffusion time for $\mathrm{Ca}^{2+}$ from a SMC to an $\mathrm{EC}$ is believed to be less than $100 \mathrm{~ms}$ (41). This diffusion time is based upon a 2-micron diffusion distance and an estimate of $\mathrm{Ca}^{2+}$ diffusion coefficient in cytosolic extracts. The small diffusion time for $\mathrm{Ca}^{2+}$ and $\mathrm{IP}_{3}$ (IP 3 has a higher diffusion coefficient than $\mathrm{Ca}^{2+}$ ), the close apposition of the two cell types and presence of heterocellular gap junctions allows a rapid diffusion of $\mathrm{Ca}^{2+}$ and $\mathrm{IP}_{3}$ from SMC to EC. The unique geometry also favors rapid endothelium mediated signaling to the overlaying SMC. Stimulation by an agonist can increase calcium and $\mathrm{IP}_{3}$ in one cell (EC or SMC) which can diffuse to the other cell type through gap junctions/ ion channels. This way of signaling is termed as chemical intercellular communication. Also the $\mathrm{K}^{+}$ions can diffuse to the intercellular space causing the hyperpolarization of one cell. This cell (EC or SMC) can hyperpolarize the other cell by electrical coupling through gap junctions/ ion channels. Thus stimulation of one cell can effect the functioning of the other cell. This coupling of the two cell types is very important as the stimulation of one cell type causes an effect on the other cell type thereby regulating the vessel diameter. Fig 4 shows the coupling of the EC and SMC cell types as in the vascular wall. 


\section{EC}

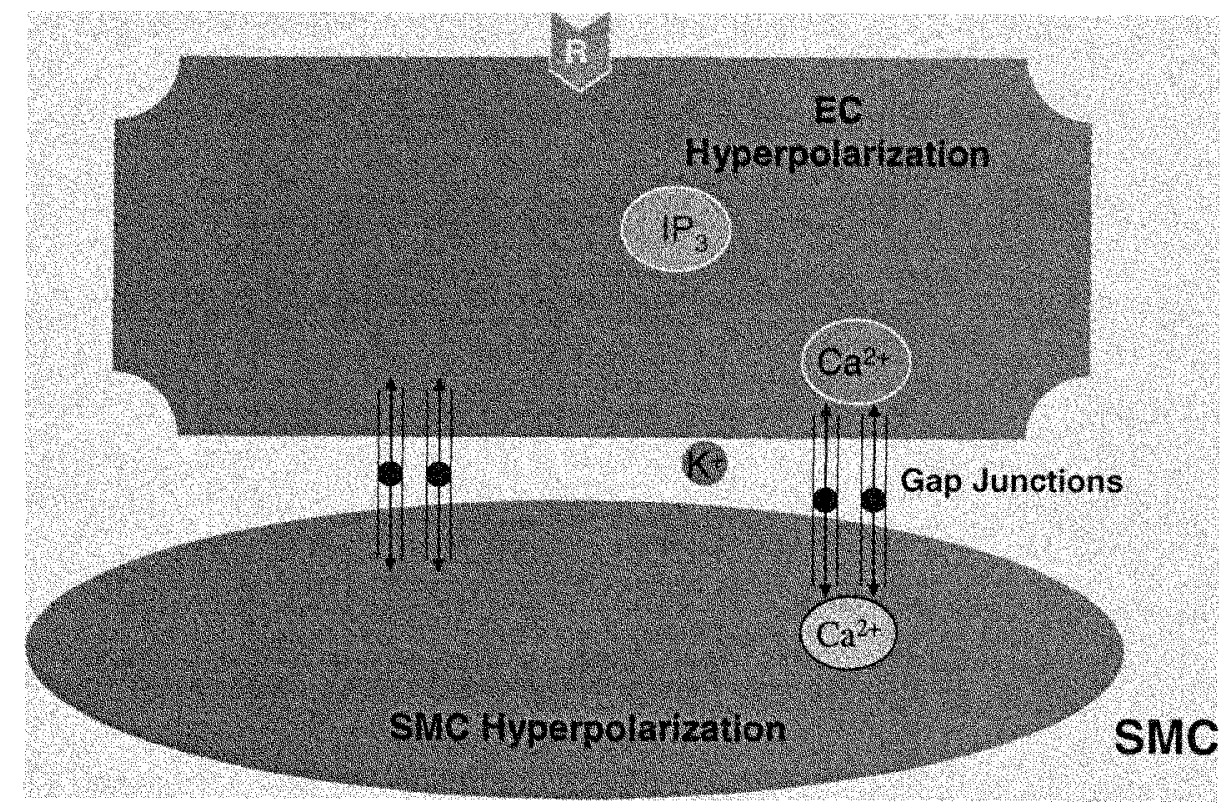

Figure 4: Integrated SMC and EC cell

\subsection{ENDOTHELIUM-DERIVED MEDIATORS}

Endothelial cells sense changes (hemodynamic, agonists) in the microenvironment of the vessels and transmit signals to the nearby SM cells to regulate vascular tone. The Endothelium controls the vascular tone by the release of nitric oxide (NO) $(48,67,107)$, prostanoids (107) and endothelium derived hyperpolarizing factor (EDHF) $(19,20,24)$. These three vasoactive factors are collectively termed as endothelium derived relaxing factors (EDRF). These EDRF's diffuse to the adjacent smooth muscle layer causing the microvessel to relax. 


\subsubsection{Nitric Oxide}

Murrel established nitroglycerine as a treatment for angina in 1897. It took the scientific community more than 100 years to identify NO as the smooth muscle relaxing factor in nitroglycerine. In 1980, Furchgott showed that an intact vascular endothelium is a requirement for acetylcholine (Ach) induced relaxation in isolated rat aorta (48). This study provided evidence supporting NO as an EDRF (47). The works of Ignarro, Moncanda and Furchgott further supported the role of nitric oxide as an EDRF $(47,48$, 66). In 1988, Moncanda discovered that NO is synthesized in the endothelium from LArginine, a reaction catalyzed by NOS. Bredt and Snyder successfully cloned the enzyme nNOS in 1991.

In the last two decades, the study of NO has received considerable interest among the scientific community. NO was declared as the molecule of the year in 1992 by magazine "The Science". Another major stimulus to the NO research was in 1998 when the Nobel Prize was shared among Robert F. Furchgott, Louis J. Ignarro and Ferid Murad for work on understanding the physiological role of NO in the vasculature.

\section{NO role in physiology and pathology}

NO plays a pivotal role in numerous physiological processes such as angiogenesis, reproduction, inflammation, neurotransmission, platelet and leukocyte adhesion, host defense response, apoptosis, regulation of vascular tone, blood flow etc $(2$, $47,66)$. It is also involved in various pathophysiological processes like septic shock, atherosclerosis, ischemia/reperfusion injury and carcinogenesis $(2,47,66)$. The high reactivity of this molecule, which is due to an unshared pair of electron, is responsible for the complex role of NO in all the physiological and pathological processes. 


\section{NO production and action mechanism}

NO is produced in vivo as a free radical by the action of the enzyme nitric oxide synthase (NOS). Three different isoforms of NOS exist which are either expressed constitutively or their expression is induced by cytokines $(109,113)$. Inducible NOS (iNOS) produces NO in the nano to micromolar range. Endothelial NOS (eNOS) and neuronal NOS (nNOS) are constitutively expressed and produce NO in the pico to nanomolar range. Endothelial cells (EC) use eNOS to produce NO and maintain vascular homeostasis (49). nNOS produces NO during neurotransmission in central and peripheral neuronal cells.

In the endothelium, $\mathrm{NO}$ is produced by the oxidation reaction of guanidino nitrogen of L-Arginine to L-citrulline in the presence of eNOS which is a NOS isoform present in the EC. NO is produced by the EC in response to agonist and hemodynamic stimulation. NO produced in the EC diffuses to the overlaying smooth muscle cells and increases the cyclic guanine monophosphate (cGMP) concentration by a two step reaction kinetics (141). NO diffuses from the EC to SMC across cell membranes and reacts with soluble guanylate cyclase ( $\mathrm{SGC}$ ) to form a 5 cordinate sGC-NO complex. The catalytically active 5 coordinate sGC-NO converts guanine triphosphate (GTP) into cGMP. The increase in cGMP in the SMC results in an increase in protein kinase G (PKG), which decreases the intracellular concentration of free $\mathrm{Ca}^{2+}$. A decrease in free intracellular $\mathrm{Ca}^{2+}$ has an inhibitory effect upon activation of myosin light chain kinase (MLCK) and hence results in relaxation of SMC. Relaxation of SMC results in an increase in vessel diameter and hence in increased blood flow (141). 
activation of sGC though a wide range (23-250 nM) of NO concentration needed for $\mathrm{sGC}$ activation has been reported $(6,25,127,141)$. The in-vitro deactivation life of sGC is 10 100 minutes in the absence of $\mathrm{NO}$ scavengers like myoglobin (87) but the in-vivo deactivation life of $\mathrm{sGC}$ is less than 2 minutes (107). This allows the SMC to return to pre-NO release contracted state after termination of NO production.

\subsubsection{Prostacyclin}

Prostacyclin ( $\mathrm{PGI}_{2}$ ) was first discovered in 1976 and was characterized as an endogenous anticoagulator for platelets as well as a strong vasodilator (13). This novel lipid mediator generated by vascular tissues was the most abundant product of arachidonic acid in vascular tissues and was later named as prostacyclin. Like many other lipid mediators of the eicosanoid family derived from arachidonic acid, PGI2 is produced by the cyclooxygenase $(\mathrm{COX})$ system. Cyclooxygenase is an integral membrane protein found in microsomal membranes. It was first purified in 1976, cloned by three separate groups in 1988 and is known as cyclooxygenase-1 or COX-1. $(74,75,132)$ However in 1991, several other laboratories identified the product of the second gene with cyclooxygenase and peroxidase activities, which was named cyclooxygenase-2 or PGHsynthase-2 (COX-2) $(40,93)$.

\section{Prostacyclin production and action mechanism}

$\mathrm{PGI}_{2}$ is produced by the COX system. Arachidonic acid is converted to prostaglandin $\mathrm{H}_{2}\left(\mathrm{PGH}_{2}\right)$ by $\mathrm{COX}$ which is further converted to $\mathrm{PGI}_{2}$ by the action of $\mathrm{PGI}_{2}$ synthase (PGIS) (133). $\mathrm{PGI}_{2}$ is produced in the body by either COX-1 or COX-2 coupled to PGIS (126). Although, $\mathrm{PGI}_{2}$ is a primary product of COX-2 in certain systems

$(11,14,91)$, the situation vanes depending on the cell types (82). PGI 2 exerts its 
vasodilator effect in various vascular beds by hyperpolarizing the SMC through one of the $\mathrm{K}^{+}$channels present in the SMC plasma membrane. The signaling pathway of $\mathrm{PGI}_{2}$ incorporates a G protein-coupled cell surface receptor termed as IP (17). Activation of IP stimulates adenylyl cyclase leading to an increased production of intracellular cAMP which in turn activates protein kinase A cascade, or calcium mobilization via phospholipase $\mathrm{C}$ activation $(17,18)$. Both endothelial and smooth muscle cells have the capacity to generate $\mathrm{PGI}_{2}$ via PGIS which acts upon vascular tissues and platelets as a potent vasodilator. However, in rat mesenteric arterioles, $\mathrm{PGI}_{2}$ is unable to exert a hyperpolarizing effect and hence it is unexpected to exert any vasodilation. However, to confirm the role of $\mathrm{PGI}_{2}$-mediated relaxation in rat mesenteric vessels, $\mathrm{COX}-1$ inhibitor (Indomethacin) is used in this study.

\subsubsection{Endothelium Derived Hyperpolarizing Factor}

Earlier pharmacological studies using various inhibitors of metabolism of arachidonic acid suggested that atleast three different pathways were involved in causing vasodilation. However, at that time only prostacyclin pathway was clearly identified (95). De Mey (29) first proposed the existence of a third pathway as the endotheliumdependent relaxations to acetylcholine obtained in the presence of indomethacin (COX-1 blocker) were abolished by mepacrine (inhibitor of phospholipase A2) whereas the responses to thrombin and ATP were unaffected. Later, Rubanyi (119) and Rubanyi and Vanhouette (120) showed that under different conditions, the biphasic endothelium dependent relaxation to acetylcholine exhibited different susceptibility to antioxidants or to inhibitors of the arachidonic acid cascades, thereby providing an evidence for the involvement of different relaxing factors. 
In the late 1970s, Kuriyama and Suzuki observed that acetylcholine produced a contraction and a simultaneous hyperpolarization in rabbit and pig coronary and mesenteric arteries (76). Later, Nikitina determined that acetylcholine was able to produce an endothelium dependent relaxation along with smooth muscle hyperpolarization (101). Thus, it was concluded that endothelium dependent relaxations and hyperpolarizations were more or less resistant to inhibitors of cyclooxygenase and NO synthase. $(8,26,58,118)$ suggesting an additional pathway that involved the hyperpolarization of the smooth muscle which was attributed as EDHF.

\section{Role in Physiology and Pathology}

The physiological role of EDHF seems to be more prominent in smaller arteries and arterioles than in larger arteries. This observation has been made in a number of vascular beds, including those from the mesenteric, cerebral and stomach $(125,129,131$, 140). Because of the fundamental role of these smaller vessels in the control of vascular resistance, EDHF seems to play a significant role in the regulation of vascular resistance and thus in the control of blood flow during normal physiologic conditions.

Another physiologic role for EDHF may be in conducted dilations of arterioles. When an artery or arteriole is stimulated to dilate at a particular site, the dilation can be transferred several millimeters upstream and downstream from the foci. This phenomenon is termed conducted vasomotor response (124). This conducted dilation is involved in efficient regulation of blood flow within a microvascular network. For example, optimum blood flow control in the exercising muscle requires an overall coordination of vascular resistances. There can be a risk of insufficient delivery of oxygen during times of maximum exercise in the absence of a functional conducted 
dilator response. The conducted dilation is an important aspect of this coordinated response and is required to maximize blood flow control. Local stimulation of endothelial cells with Ach evokes conducted vasodilation. (124). This phenomenon is endothelium dependent which cannot be completely attributed to $\mathrm{NO}$ as in some blood vessels NO inhibits conducted vasodilations (108). This supports the role of EDHF in conducted vasodilations.

EDHF is also found to play a role in initiation and maintenance of vasomotion. Vasomotion is the rhythmic change in arterial or venous diameter which is likely to contribute to the harmonious and efficient distribution of blood flow. EDHF may also help prevent spasm and compensate for disappearance of NO-mediated relaxations under hypoxic conditions. (58)

After many pathologic conditions, dilation produced by endothelium derived NO can be significantly reduced. The reduced dilation can be due to a number of factors like excessive production of reactive oxygen species, which inactivate nitric oxide, and/or dysfunction in eNOS generation of nitric oxide. (22) In contrast, EDHF is resistant to reactive oxygen species. EDHF has been reported to be upregulated after a variety of pathologic conditions when nitric oxide-mediated dilations have been attenuated. The upregulation seems to occur after ischemia-reperfusion, traumatic injury, congestive heart failure, coronary artery disease, hypercholesterolemia, and angioplasty.

The effect of the pathologic condition on the EDHF response can be due to many factors. In some pathologic conditions, EDHF production can be down-regulated, whereas in other cases it can be up-regulated. (44) In addition, the effect of the pathologic condition on the EDHF dilation could be related to the vessel size, the vascular bed, or 
the severity and duration of the pathologic condition. In those pathologic conditions where EDHF is upregulated, it is considered as a protective mechanism that compensates for insufficient endothelium-derived nitric oxide. A number of studies suggest that there is a balance in the nitric oxide and EDHF response. $(61,73,96)$ When the nitric oxidemediated dilation is impaired during pathologic conditions, EDHF is up-regulated sufficiently to maintain normal dilation. Thus, the relative contributions of nitric oxide and EDHF to the overall dilation are adjusted accordingly for the response to remain relatively unchanged.

\section{EDHF Action Mechanism}

EDHF-mediated responses involve an increase in the intracellular calcium concentration causing the opening of calcium-activated potassium channels $\left(\mathrm{SK}_{\mathrm{Ca}}\right.$ and $\mathrm{IK}_{\mathrm{Ca}}$ only in case of rat mesenteric arterioles) present in the endothelial cells leading to their hyperpolarization. This results in an endothelium-dependent hyperpolarization of the smooth muscle cells, which can be propagated by direct electrical coupling through myo-endothelial gap junctions/ion channels and/or the accumulation of potassium ions in the intercellular space. Potassium ions hyperpolarize the smooth muscle cells by activating inward rectifying potassium channels and $/$ or $\mathrm{Na}^{+} / \mathrm{K}^{+}$-ATPase. EDHF causes smooth muscle to hyperpolarize by $15-30 \mathrm{mV}(88,140)$. The smooth muscle hyperpolarization causes relaxation by decreasing the concentration of cytoplasmic free $\mathrm{Ca}^{2+}$ by closing the voltage-operated $\mathrm{Ca}^{2+}$ channels in the smooth muscle cell membrane. The cytoplasmic concentration of free $\mathrm{Ca}^{2+}$ is a major determinant of the contractile state of smooth muscle. In addition to regulating $\mathrm{Ca}^{2+}$ concentrations, the sensitivity to cytoplasmic $\mathrm{Ca}^{2+}$ can be regulated by kinases and phosphatases to alter the contractile 
state of vascular smooth muscle. However, it is not known whether EDHF affects vascular smooth muscle sensitivity to $\mathrm{Ca}^{2+}$.

\section{EDHF-Types}

The acronym EDHF can be misleading as it implies that a single diffusible substance mediates this type of endothelium dependent relaxation. In fact, there can be many endothelium-derived factors including $\mathrm{NO}$ and prostacyclin, which can hyperpolarize the smooth muscle thus acting as an EDHF. Hence, the endothelium mediator which produces hyperpolarization and relaxation should be named adequately rather than being denominated as EDHF. The various endothelium-derived factors which may play a role of EDHF are as follows:

\section{Prostacyclin}

Prostacyclin is the major metabolite of arachidonic acid produced by cyclooxygenase in endothelial cells. It activates IP receptors on vascular smooth muscle thereby causing relaxation in many vascular beds. It can cause hyperpolarization depending on the artery and the species by opening one or more types of potassium channels. Thus, ATP-sensitive potassium channels (K-ATP), large conductance calciumactivated potassium channels $\left(B K_{C a}\right)$, inwardly rectifying potassium channels $\left(K_{\mathrm{IR}}\right)$ and/or voltage activated potassium channels $\left(\mathrm{K}_{V}\right)$ can play a role in causing prostacyclininduced relaxation. Hence, in many cases the prostanoid can be regarded as an EDHF. As most of the available inhibitors of cyclooxygenase abolish the production of prostaglandins in vascular tissues, any endothelium dependent hyperpolarization observed in the presence of one of these inhibitors (Indomethacin) will be independent of prostacyclin. 
NO also can hyperpolarize vascular smooth muscle cells by activating, potassium channels such as K-ATP, $\mathrm{BK}_{\mathrm{Ca}}, \mathrm{K}_{\mathrm{IR}}$, and/or $\mathrm{Kv}$. NO interacts with other ionic channels of the smooth muscle, including chloride and cationic channels as well. NO also influences the membrane potential of the smooth muscle cells indirectly in an autocrine fashion. However, similar to prostacyclin, the effect of NO as an EDHF can be considered abolished in the presence of NOS blockers like L-Name.

\section{Potassium ions}

Hyperpolarization of the endothelial cells can help achieve hyperpolarization and relaxation of the underlying vascular smooth muscle cells through potassium ions. The activation of endothelial $\mathrm{IK}_{\mathrm{Ca}}$ and/or $\mathrm{SK}_{\mathrm{Ca}}$ causes an efflux of potassium ions from inside the cell. This efflux of potassium in the abluminal direction can lead to its accumulation in the small intercellular space between endothelial and smooth muscle cells. The concentration of $\mathrm{K}^{+}$ions diffused to the intercellular space can be sufficient to activate $\mathrm{K}_{\mathrm{IR}}$ and/or the $\mathrm{Na}^{+} / \mathrm{K}^{+}$pump on the SMC. Therefore, potassium ions could contribute to EDHF-mediated responses. (100)

\section{Metabolites of Arachidonic Acid}

\section{Products of cytochrome $\mathbf{P 4 5 0}$ monooxygenase}

Epoxyeicosatrienoic acids (EETs), derived from cytochrome P450 2C or 2J epoxygenases as well as their epoxide hydrolase metabolites dihydroxyeicosatrienoic acids, have been reported to induce vasodilation in many blood vessels $(42,43,114)$. EETs cause arterial SMC hyperpolarization in coronary arteries thereby enhancing the open-state probability of $\mathrm{BK}_{\mathrm{Ca}}$ channels. EETs can also activate SMC vanilloid transient 
receptor potential channel (TRPV4), which facilitates in increasing the frequency of calcium sparks and transient outward currents. This EET-dependent activation of a calcium-signaling complex (TRPV4-ryanodine receptors- $\mathrm{BK}_{\mathrm{Ca}}$ ) causes SMC hyperpolarization and relaxation. (36)

EETs can play a role in regulating endothelial calcium homeostasis through their action on store-operated $\mathrm{Ca}^{2+}$ channels in response to calcium store depletion (139) The endothelial $\left[\mathrm{Ca}^{2+}\right]_{i}$ controls the activation of endothelial $\mathrm{K}^{+}$channels $\left(\mathrm{IK}_{\mathrm{Ca}}\right.$ and $\mathrm{SK}_{\mathrm{Ca}}$ in rat mesenteric arterioles). EETs may also regulate the activity of endothelial $\mathrm{K}_{\mathrm{Ca}}$ independently (7).

\section{Products of Lipooxygenases}

Endothelial cells can express different lipoxygenases depending on conditions (physiological and/or pathophysiological). These lipoxygenases can metabolize arachidonic acid into relaxing and contracting substances. Thus, 12-(S)-HETE is released from the endothelium by various stimulating factors and functions by activating $\mathrm{BK}_{\mathrm{Ca}}$ on the smooth muscle cells (39) leading to SMC hyperpolarization and relaxation.

\section{Hydrogen Peroxide $\left(\mathrm{H}_{2} \mathrm{O}_{2}\right)$}

Both endothelial and smooth muscle cells generate significant amounts of reactive oxygen species. Superoxide is reduced to $\mathrm{H}_{2} \mathrm{O}_{2}$ by superoxide dismutase, and can have dilator or constrictor properties and hence can either hyperpolarize or depolarize smooth muscle. (38) However, evidence supporting role of $\mathrm{H}_{2} \mathrm{O}_{2}$ as an EDHF and its action mechanism is very limited. For example, the type (i.e. $\mathrm{IK}_{\mathrm{Ca}} \mathrm{SK}_{\mathrm{Ca}}$ or $\mathrm{BK} \mathrm{K}_{\mathrm{Ca}}$ ) and location (i.e. endothelial or the smooth muscle cells) of potassium channels that are activated by $\mathrm{H}_{2} \mathrm{O}_{2}$ is not yet known. Also, it is unclear whether $\mathrm{H}_{2} \mathrm{O}_{2}$ diffuses to activate potassium 
channels on the smooth muscle or it acts as an intracellular messenger to activate endothelial potassium channels. Likewise, although $\mathrm{H}_{2} \mathrm{O}_{2}$ is produced in response to an increase in endothelial $\left[\mathrm{Ca}^{2+}\right]_{i},(139)$ it is uncertain whether this pathway is linked to activation of endothelial $\mathrm{IK}_{\mathrm{Ca}}$ and $\mathrm{SK}_{\mathrm{Ca}}$ or an independent phenomenon. Moreover, $\mathrm{H}_{2} \mathrm{O}_{2}$ does not relax or hyperpolarize all vascular smooth muscle cells and hence more research needs to be carried out to substantiate its role as an EDHF by using specific $\mathrm{K}^{+}$channel blockers and studying $\mathrm{H}_{2} \mathrm{O}_{2}$ induced hyperpolarization and relaxation.

\section{C-Type Natriuretic Peptide}

C-type natriuretic peptide (CNP) causes relaxation and hyperpolarization of arterial and venous smooth muscle cells by opening $\mathrm{BK}_{\mathrm{Ca}}$ and hence is proposed to act as an EDHF (134). Experiments in rat arteries suggest that acetylcholine releases CNP from EC activating NPR-C receptors on vascular smooth muscle. Hyperpolarization of the smooth muscle cell is obtained by the cyclic-GMP-independent activation of a G-protein regulated inward-rectifier potassium channel (GIRK). However, more experimentation is required to validate its role as an EDHF. For example, the role of CNP-dependent activation of NPR-C in vascular smooth muscle cells in producing a cyclic GMPindependent, pertussis toxin-sensitive signaling is unknown. The expression and activity of GIRK has been well-characterized in neurons and cardiac myocytes, but the protein expression and characterization of this channel in vascular smooth muscle cells is still unclear. Finally it is not known whether CNP can activate GIRK in any cell type.

\subsubsection{Mediators responsible for EDHF induced dilation in rat mesenteric arteriole}

Thus from the above discussion of six different EDHF mediators we can conclude that role of NO and prostacyclin as an EDHF is abolished in presence of NOS and COX 
blocker. Thus, in this study NO and prostacyclin does not exert an EDHF effect. The $\mathrm{K}^{+}$ ions can exert an EDHF effect only in presence of $\mathrm{IK}_{\mathrm{Ca}}$ and $\mathrm{SK}_{\mathrm{Ca}}$ present in the rat endothelium as stated earlier and hence in the presence of apamin ( $\mathrm{SK}_{\mathrm{Ca}}$ blocker) and TRAM-34 ( IK $\mathrm{Ka}_{\mathrm{Ca}}$ blocker), the $\mathrm{K}^{+}$ions cannot cause EDHF mediated dilation. EETs and products of lipooxygenases can exert EDHF effect through either BKCa channels which are not present in rat mesenteric arterioles or through other $\mathrm{K}^{+}$channels present in $\mathrm{EC}$ which are blocked in this study. Thus, the contribution of metabolites of arachidonic acids mediated dilation in this study is expected to be completely eliminated.

Role of $\mathrm{H}_{2} \mathrm{O}_{2}$ as an EDHF has not been observed in rat mesenteric arterioles. Although it is believed to exert an effect through potassium channels, its action mechanism is still unclear. Thus, in this study it is not expected to exert any effect in the presence of $\mathrm{SK}_{\mathrm{Ca}}$ and $\mathrm{IK}_{\mathrm{Ca}}$ blockers. As CNP induces $\mathrm{SMC}$ hyperpolarization through $\mathrm{G}$ protein regulated inward-rectifier potassium channel (GIRK) present on SMC, this pathway is not expected to exert any effect as previous studies eliminate the presence of $\mathrm{K}_{\mathrm{IR}}$ on rat mesenteric arterioles SMC membrane. Thus, when the endothelial cells of rat mesenteric arteriole are stimulated with Ach, there is an increase in EC calcium which leads to opening of $I \mathrm{~K}_{\mathrm{Ca}}$ and $\mathrm{SK}_{\mathrm{Ca}}$ channels. As the potassium concentration is higher within the cell, therefore potassium diffuses out of the EC into the inter cellular space resulting in EC hyperpolarization. This hyperpolarization is transferred to the SMC either directly through gap junctions or through the acceleration of $\mathrm{Na}^{+} / \mathrm{K}^{+}$ATPase pump (by additional intercellular $\mathrm{K}^{+}$ions).

The $\mathrm{Na}^{+} / \mathrm{K}^{+}$ATPase pump removes $3 \mathrm{Na}^{+}$and intrudes $2 \mathrm{~K}^{+}$ions. Thus, each cycle of this pump is responsible for the removal of one positive charge from the SMC. 
Hence, acceleration of this pump leads to SMC hyperpolarization as more positive charge diffuses out of the SMC. SMC hyperpolarization leads to the closure of L-Type voltage gated $\mathrm{Ca}^{2+}$ channels. This leads to a decrease in SMC intracellular concentration causing dilation. Thus, we can conclude that in rat mesenteric arterioles, presence of specific blockers of $\mathrm{IK}_{\mathrm{Ca}}$ and $\mathrm{SK}_{\mathrm{Ca}}$, are expected to be abolish all the EDHF mediated dilations. This is shown in Fig 5 .

\subsection{STUDY OBJECTIVES}

This study attempts to elucidate the role of high levels of adrenal cortical hormone, ouabain on vascular reactivity. Previous studies on vascular reactivity in the presence of ouabain are very limited and have been performed in bigger diameter vessels like rat thoracic rings, human arteries etc $(30,137)$. Blood pressure is primarily regulated in the microvasculature and hence reactivity studies on microvessels provide a better tool to study the role of various agonists in blood flow regulation and regional blood supply. Also, as gap junctions between the SMC and EC are important in intercellular communication, studies on cultured cells may provide limited information for the complex interactions. Also, some of the studies have been performed at very high concentrations of ouabain $(\sim \mu \mathrm{M})$ which is many folds higher than physiological and even pathological level. This might be to study the enhanced effect of ouabain as at lower ouabain concentraions, experimental determination of ouabain induced difference in vascular reactivity might be difficult.

An in-vitro system of carefully isolated microvessels should preserve the gap junctions/ion channels in the two cell types and facilitate studying the simultaneous effect 
of agonists on both endothelium and smooth muscle layers. Microarteries (from malesprague dawley rats) in the diameter range of $250-400$ microns (pressurized at $50 \mathrm{mmHg}$ ) were chosen for this study, as microarteries in this diameter range are primarily resistance arteries with little or no compliance and provide significant resistance to blood flow (27). The in-vitro system established for this study is also independent of neuronal and hormonal control. The concentration of ouabain used in this study is $100 \mathrm{nM}$ which is more close to physiological levels than many other studies. The effect of ouabain on rat mesenteric microvessel has not been published and hence this study will provide data from rat mesenteric arterioles.

Objective\#1: This study aims to measure the effect of NE on arteriolar diameter in the presence and absence of ouabain. NE increases SMC Ca ${ }^{2+}$ through $\mathrm{IP}_{3}$ pathway. Ouabain blocks the $\mathrm{Na}^{+} / \mathrm{K}^{+}$ATPase pump leading to further increase in $\mathrm{SMC} \mathrm{Ca}^{2+}$ by reversing the operational mode of $\mathrm{Na}^{+} / \mathrm{Ca}^{2+}$ exchanger.

Objective \#2: This study attempts to investigate the effect of Ach on arteriolar diameter in the presence and absence of ouabain. Ach is a known vasodilator and acts by stimulating endothelial release of NO, cycloxegenase-derived products and EDHF factors.

Objective \#3: This study will investigate the relative contribution of endotheliumderived mediators in Ach-induced relaxation in the presence and absence of ouabain. Achinduced relaxation will be studied by blocking individual pathways. 


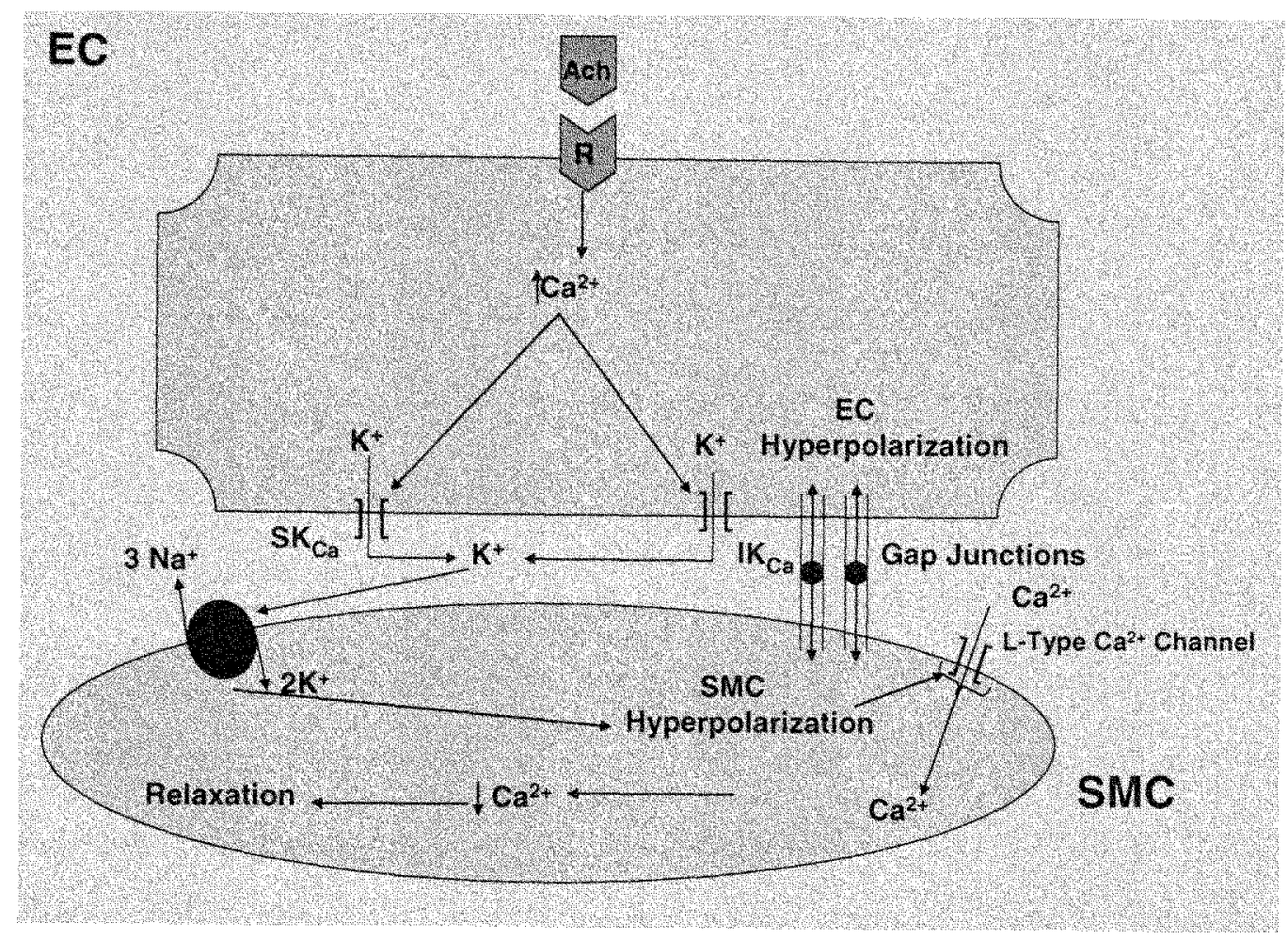

Figure 5: A detailed figure showing the effect of EDHF action mechanism through $\mathrm{SK}_{\mathrm{Ca}}$ and $\mathrm{IK}_{\mathrm{Ca}}$ channels in rat mesenteric artery.

\section{CHOICE OF ANIMAL AND TISSUE}

Male Sprague Dawley rats weighing 250-300 g and 2-3 month old were chosen as the animal subject in order to facilitate comparison of the results of this study with available literature. Sprague Dawley rats are easily available and can be housed at the animal care facility at Florida International University (FIU). The study is performed on intact rat mesenteric arteries as these are high resistance arteries with small diameters (250-400 microns) and hence they play a significant role in blood flow regulation. The mesenteric artery is easily accessible and well studied. 


\subsection{EQUIPMENT AND INSTRUMENTATION}

\subsection{PERFUSION CHAMBER}

The perfusion chamber used in this study was obtained from Living Systems Instrumentation, VT, USA (Model $\mathrm{CH} / / \mathrm{SH}$ ). The chamber allows to mount intact microvessel with the help of glass cannulas. The vessel chamber allows three dimensional movements of cannulas. The transparent round glass coverslip (150-200 microns) allows bright field measurements of the microvessel. The prefabricated chamber has a self-heating thermistor controlled by a temperature controller (Model TC-01, Living Systems Instrumentations, VT, USA), which helps maintain a constant bath temperature $\left(37^{\circ} \mathrm{C}\right)$ during experimentation. The chamber has a bath volume of $5 \mathrm{ml}$ which is suitable to cover the microvessel. The inlet and outlet port of the vessel chamber allows replacing the superfusate solution and regulating superfusate level in the bath.

The chamber was connected with silicon tubings (Cole Parmer, IL) and used borosilicate glass cannulas (Model GC-12, Living Systems Instrumentation, VT) with an internal tip diameter of 100-200 microns. The smooth beveled tip cannulas allow easy cannulation of the microvessel resulting in minimal damage to the endotheium. 


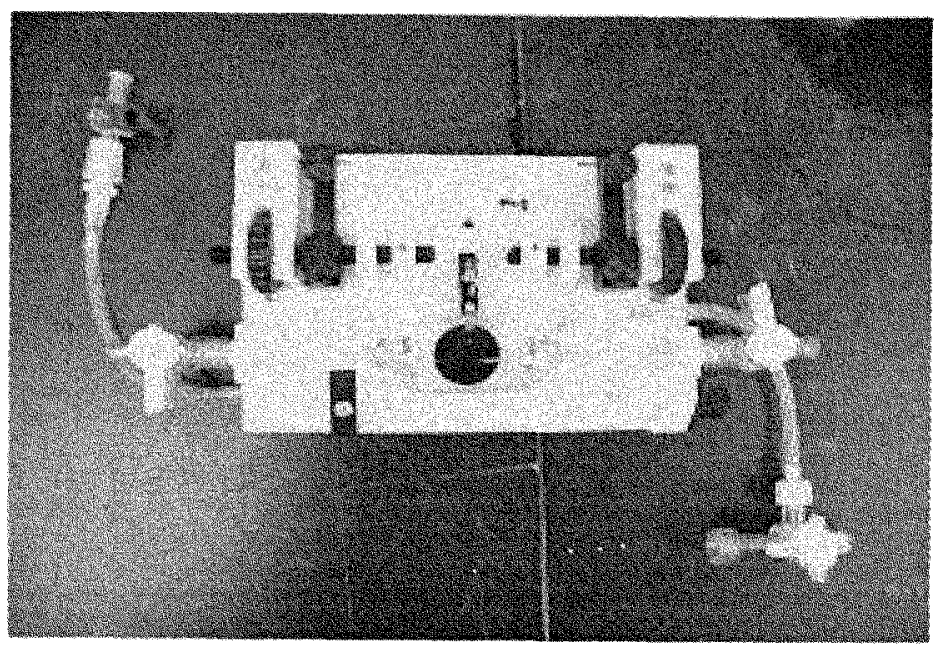

Figure.6: Perfusion chamber (Living Systems Instrumentation, Model CH/SH 1)

Pressure transducers (Model PT/F, Living Systems Instrumentation, VT) were used in line with perfusion systems (Bioscience Tools, CA USA) to monitor perfusion pressure on both ends of the vessel. The pressure transducers were connected to pressure servo controller (Model PM/4, Living Systems Instrumentation, VT (pressure range: 0$200 \mathrm{mmHg}$ )) to facilitate regulation of perfusion pressure and perfusate flow. Fast and accurate measurement of perfusion pressure is critical for the operation of servo control mechanisms as well as for vessel viability.

\section{Temperature control}

The self heated vessel chamber is fitted with a thermistor sensor (tip dia $1.2 \mathrm{~mm}$, Living systems Instrumentations, VT, USA) which helps maintaining and measuring temperature of the bath solution. The thermistor sensor allows real time measurement of bath temperature by sending the temperature signal to the temperature controller (Model TC-01, Living Systems Instrumentation, VT, USA). The temperature controller can maintain bath temperature within a set range $\left( \pm 3^{\circ} \mathrm{C}\right)$ during the course of experiment. 
The bath temperature is set to physiological temperature i.e. $37^{\circ} \mathrm{C}$ which is important to obtain vessel response to different stimuli as well as maintain vessel viability during the course of experimentation.

\section{Pressure Servo Controller}

The pressure servo controller is used along with the peristaltic pump to regulate pressure and flow through the perfusion lines and the vessel. The servo controller can be used in either automatic or manual mode. The two different modes facilitate to test for leaks in the vessel. Also, the intra-luminal pressure is regulated with the servo controller working in automatic mode. The peristaltic pump can operate in pressure as well as flow mode. It can regulate pressure in the range $0-200 \mathrm{mmHg}$ and flow in the range $3 \mu \mathrm{L} / \mathrm{min}$ $2.5 \mathrm{ml} / \mathrm{min}$. The pump is used in the pressure mode along with servo controller to regulate the intra-luminal pressure of the vessel.

\section{Flow Pump}

A peristaltic pump (Model FC (Living Systems Instrumentation, VT, USA) was used to superfuse different solutions in the vessel chamber. The flow rate of the pump was set to $5 \mathrm{ml} / \mathrm{min}$ so as to replace the bath volume in 1 minute. An alternate method also used for superfusing solutions was by adding solutions directly to the bath using a syringe. Another pump (Model 77120-62, Masterflex,USA) was connected with the outlet port of the vessel chamber to remove the superfusate simultaneously. This is required for rapid exchange of bath solution as well as maintaining constant bath level to avoid spilling of the solution on the objectives of the microscope. The flow rates of both the pumps were kept the same so that the bath volume remains constant during experimentation. However, the studies were done under no flow condition and hence the 
pumps were used to replace the bath solutions only. This was done to study only the effect of agonists on vascular reactivity. Hence, performing the studies in the absence of flow provide a better tool to eliminate the effect of flow on vessel responses.

\subsection{MICROSCOPY}

Nikon dissection microscope (Model SMZ645) was employed for microdissection i.e. removal of fat from the mesenteric microvessel and identifying artery from vein. The same microscope was also employed for adjusting the two cannulas at the same level, cannulating the microarteries and suturing the microarteries to the glass cannulas. Olympus fluorescent microscope (Motorized Inverted Research Microscope IX-81, USA) was used in bright field mode. The microscope components critical for bright field experiments were:

\section{Olympus shutter, Olympus lamp and Camera}

Olympus shutter was used to control exposure time of the light from Olympus lamp (IX-2 UCB) onto the vessel. The exposure time was set so that the vessel can be seen clearly on the screen and hence the diameter measurements can be performed using the IPLab 3.6.3 software.

The Olympus lamp (IX-2 UCB) was used to provide visible light to the vessel. The intensity of the light was controlled manually from the microscope or from the software IPLab 3.6.3.

Cooled mono 12 bit Retiga Q imaging camera (Model EXi) is employed for image acquisition. The camera was operated at a gain of 1557 and an offset of 2048 . The 
gain and offset for the camera were maintained to acquire consistent and comparable results

\section{Objective}

Objective with magnification of $4 \mathrm{X}$ was used to record images for this study. The objectives have to be focused to get a clear picture of the vessel. The focusing is done manually using the microscope. The various specifications of the used objective are

\begin{tabular}{|l|l|l|l|}
\hline Magnification & Numerical Aperture & Working distance (mm) & Depth of field \\
\hline $4 \mathrm{X}$ & 0.16 & 8.2 & 55.5 \\
\hline
\end{tabular}

Table 1: Important objective (4X) characteristics

\section{IPLab 3.6.3 for windows}

Software IPLab3.6.3 Windows version (Scanalytics, VA, USA) was used to control the microscope and the associated hardware. IPLab3.6.3 allows control of shutter, filter wheel, camera and objectives. The diameter measurements were recorded with the help of the software manually as well as with the script for measuring diameter in bright field mode.

\subsection{METHODS AND PROCEDURES}

\subsection{CONTROL SOLUTION}

Hyclone cell culture grade water (Hyclone, Utah, USA) was used in preparing control solution for the study. The control solution was prepared to make the solution physiological in terms of osmolarity and $\mathrm{pH}$. This is necessary for to obtain vessel response as the cells can die if placed in non-physiological solution. The composition of the control solution is given in the table below. 


\begin{tabular}{|l|l|}
\hline Salt & \multicolumn{1}{|c|}{ Concentration (mM) } \\
\hline $\mathrm{NaCl}$ & 118.7 \\
\hline $\mathrm{KCl}$ & 5 \\
\hline $\mathrm{CaCl}_{2}$ & 2.5 \\
\hline $\mathrm{MgSO}_{4}$ & 1.2 \\
\hline $\mathrm{KH}_{2} \mathrm{PO}_{4}$ & 1.2 \\
\hline $\mathrm{HEPES}$ & 20 \\
\hline Glucose & 5 \\
\hline
\end{tabular}

Table 2: Composition of the control solution

The various salts and concentrations used to prepare the solution were obtained from protocols used by other studies. The control solution was filtered before experimentation to remove any impurity from the salts and avoid contamination during experiments. The prepared solution was checked for osmolarity and pH before each experiment to ensure the solution had a physiological osmolarity range (280-300mOsm) and $\mathrm{pH}$ range $(7.4 \pm 0.05)$. This is important for keeping the cells functional and obtaining response from the vessel. The $\mathrm{pH}$ was adjusted using $1 \mathrm{M} \mathrm{NaOH}$ solution. The osmolarity was measured using the osmometer (Advanced Instruments, USA) and $\mathrm{pH}$ using the $\mathrm{pH}$ meter (Fischer Scientific, USA).

\section{VASOACTIVE AGENTS}

All the chemicals and drugs were obtained from sigma chemicals, USA except for KB-R7943 which was purchased from Calbiochem, USA. Fresh solutions were prepared before every experiment and serial dilutions were made to obtain the required concentrations. 


\section{$\mathrm{NE}$ as a vasoconstrictor}

Norepinephrine (NE) was used as an agonist for vasoconstriction in a concentration range of $0.1 \mu \mathrm{M}$ to $10 \mu \mathrm{M}$. NE was superfused in the bath of the vessel chamber to act on the smooth muscle cells of the microartery. The NE increases the intracellular $\mathrm{Ca}^{2+}$ in the SMC though $\mathrm{IP}_{3}$ pathway thereby leading to vessel constriction. The NE was stored in powdered form at $-20^{\circ} \mathrm{C}$ in a sealed container. The starting solution of $10 \mathrm{mM}$ NE was prepared before every experiment. The solution was then serially diluted to obtain working NE solutions of concentration $0.1 \mu \mathrm{M}, 0.2 \mu \mathrm{M}, 0.4 \mu \mathrm{M}, 1 \mu \mathrm{M}$, $3 \mu \mathrm{M}$ and $10 \mu \mathrm{M}$. These concentrations were used as they provide a broad range of constrictions in the vessels starting from low constriction (at $0.1 \mu \mathrm{M}$ ) to maximum constriction (at around $10 \mu \mathrm{M}$ ). More number of points provides a better curve and more accurate $\mathrm{EC}_{50}$ values. The working solutions were then tested for osmolarity and $\mathrm{pH}$ and were determined to be in working range of $280-300 \mathrm{mOsm}$ and $\mathrm{pH}$ of $7.4 \pm 0.05$. NE was superfused with the help of a peristaltic pump at a flow rate of $5 \mathrm{ml} / \mathrm{min}$ to ensure a complete bath solution $(\sim 5 \mathrm{ml})$ turnover in $1 \mathrm{~min}$. The outlet pump was connected at the outlet port of the vessel chamber to ensure a constant level of bath solution.

\section{Acetylcholine as a vasorelaxant}

Acetylcholine was applied as an agonist to produce vasorelaxation from a concentration range of $1 \mathrm{nM}$ to $10 \mu \mathrm{M}$. Ach stimulates endothelial cells to produce various signaling factors like NO, prostacyclin and EDHF. This endothelial generated signaling is transferred to the underlying SMC thereby causing relaxation. A $10 \mathrm{mM}$ stock solution of Ach was prepared before each experiment. The solution was then serially diluted to obtain working Ach concentrations of $1 \mathrm{nM}, 10 \mathrm{nM}, 30 \mathrm{nM}, 100 \mathrm{nM}, 1 \mu \mathrm{M}, 10 \mu \mathrm{M}$ and 
$100 \mu \mathrm{M}$. These concentrations were used as they provide a broad range of relaxations in the vessels starting from lower relaxation (at $\ln M$ ) to maximum relaxation (at around $100 \mathrm{uM}$ ). More number of points provides a better curve and more accurate EC50 values. The working solutions were checked for osmolarity (280-300) and $\mathrm{pH}(7.4+0.05)$. The working solutions were continually perfused at $370 \mathrm{C}$ through the microartery at approximately $50 \mu \mathrm{L} / \mathrm{min}$ using a $20 \mathrm{mmHg}$ pressure difference across the perfusion chamber as a driving force. The flow rate and pressure difference used here generates a wall shear stress at the vessel wall which lies in the range of physiological pressure (1-10 dynes/cm2) and hence maintains the integrity of the endothelium. Higher pressure gradient can result in higher flow rate, which can damage the endothelial monolayer. Short flow lines ensured a small dead volume and hence rapid switching between agonist and control solution through the microvessel. Extreme care was applied to ensure complete removal of bubbles in the perfusion line as presence of bubbles can also damage the endothelium.

\subsection{BLOCKERS USED}

\section{Indomethacin}

Indomethcain solution $(10 \mu \mathrm{M})$ was perfused through the microvessel to block COX-1 which is responsible for the production of prostacyclin by the endothelium. Indomethcain was perfused for 25-30 mins followed by a 5-10 min washout period. This ensured complete blockade of COX-1. All the Ach solutions were then perfused and diameter responses to different Ach concentrations were obtained to study the contribution of prostacyclin in causing relaxation. 


\section{L-Name}

L-name solution $(350 \mu \mathrm{M})$ was perfused through the microvessel to block the effect of NO in causing vessel relaxation. L-Name blocks eNOS, thereby inhibiting the endothelium from producing NO. L-Name was perfused for 25-30 minutes followed by a wash out period of 5-10 mins. This ensured complete eNOS blockade. All the working solutions of Ach were again perfused and diameter-concentration dose response curves were obtained to study the contribution of NO in causing vasorelaxation.

\section{Apamin}

Apamin solution $(10 \mu \mathrm{M})$ was used to specifically block $\mathrm{SK}_{\mathrm{Ca}}$ channels in the endothelium of the microvessel. The solution was perfused through the artery for 25-30 minutes followed by a 5-10 min washout period. This was used in conjunction with IKca channel blocker (Tram-34) to completely block the EDHF effect. The $\mathrm{K}^{+}$channels cause endothelium-dependent smooth muscle hyperpolarization leading to closure of VGCC thereby causing smooth muscle relaxation. Hence, their blockade should be able to abolish EDHF-mediated relaxation. The $\mathrm{IK}_{\mathrm{Ca}}$ blocker used is described below.

\section{Tram-34}

Tram-34 solution $(0.1 \mu \mathrm{M})$ was used to block $\mathrm{IK}_{\mathrm{Ca}}$ channels in the endothelium of the microvessel. As, the EDHF effect in rat mesenteric arterioles is mediated by calciumactivated potassium channels present in the $\mathrm{EC}$ layer (i.e. $\mathrm{SK}_{\mathrm{Ca}}$ and $\mathrm{IK}_{\mathrm{Ca}}$ in this case), therefore both Apamin and Tram-34 were used to eliminate the EDHF effect in vasorelaxation. Perfusion and washing times used for Tram-34 are similar as for Apamin. Different Ach solutions were then perfused after perfusing both apamin and Tram-34 to obtain diameter- response curves. 


\section{Ouabain}

Ouabain solution $(200 \mathrm{nM})$ was prepared and mixed in equal amounts with various $\mathrm{NE}$ concentrations to have $100 \mathrm{nM}$ ouabain concentration in all the NE solutions. Ouabain was used to block the $\mathrm{Na}^{+} / \mathrm{K}^{+}$ATPase pump in the vascular SM. Different concentrations of NE having $100 \mathrm{nM}$ ouabain were then perfused to obtain dose response curves. Effect of ouabain on Ach-induced relaxation was measured by perfusing Ach solutions ( $1 \mathrm{nM}$ $100 \mu \mathrm{M}$ ) to vessels preconstricted with $0.5 \mu \mathrm{M} \mathrm{NE}$ and $100 \mathrm{nM}$ ouabain.

\section{KB-R7943}

KB-R7943 (2-(2-(4-(4-Nitrobenzyloxy) phenyl) ethyl) isothiourea, methane sulfonate) was stored as a stock solution in DMSO. $4 \mu \mathrm{M}$ of KB-R7943 solution was prepared and mixed with equal amounts of NE solutions to have $2 \mu \mathrm{M}$ of KB-R7943 in all the NE solutions. KB-R7943 was used to block the $\mathrm{Na}^{+} / \mathrm{Ca}^{2+}$ exchanger operating in reverse mode. The effect of KB-R7943 on NE response in presence of ouabain was studied by adding it to the superfusate containing $0.5 \mu \mathrm{M} \mathrm{NE}$ and $1 \mu \mathrm{M}$ Ouabain.

\section{RAT EUTHANASIA MICRODISSECTION AND CANNULATION}

All procedures and protocols used in this study were approved by the institutional animal care and use committee (IACUC) at the Florida International University (approval \# A3096-01). Male Sprague Dawley rats (2-3 month old weighing 200-250 g) were obtained from Harlan (Indiana, USA) and housed at FIU animal care facility. Rats were euthanized with $100 \% \mathrm{CO}_{2}$ in a gas chamber.

Rat dissection was performed under sterile conditions and the mesenteric arcade was excised and immediately transferred to the control solution at $5^{\circ} \mathrm{C}$. Immediate transfer of the mesenteric arcade to the control solution at $5^{\circ} \mathrm{C}$ reduces damage to the 
mesentery. An intact mesenteric arcade was selected and was fixed to a sylgard coated dissection dish using pins (Fig.7). Care was taken to always submerge the mesenteric arcade under cold control solution by continually replacing the control solution in the dissection dish with fresh control solution at $5^{\circ} \mathrm{C}$.

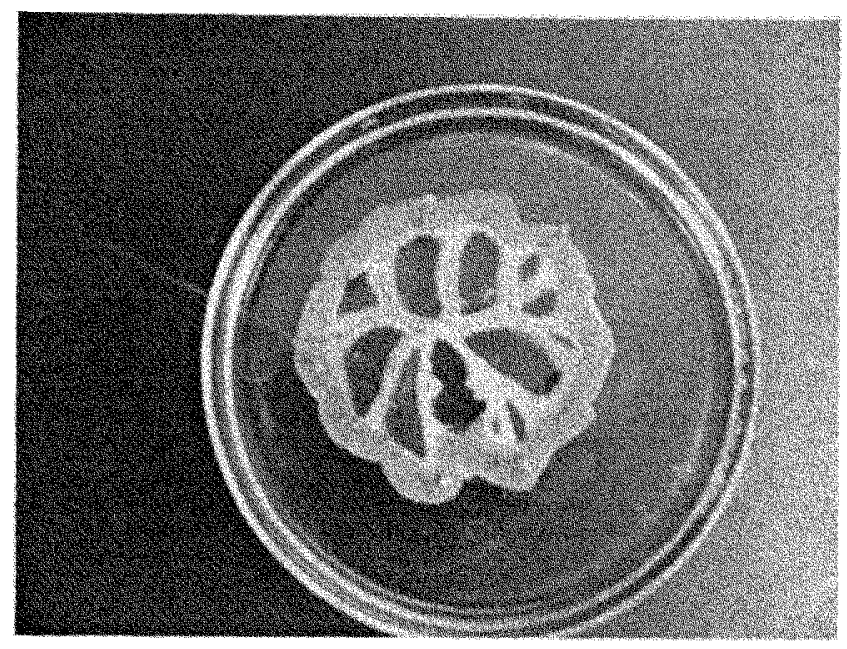

Figure 7: Rat mesenteric arcade spread in control solution at $5^{\circ} \mathrm{C}$.

The mesenteric arcade is placed on a sylgard coated dissection dish and fixed using pins. Microsurgery was performed under dissection microscope to physically remove the fat surrounding the microartery. Care was taken to ensure selection of approximately $0.5 \mathrm{~mm}$ long arteriolar segment without branches or leaks. The microartery was successfully distinguished from a microvein based upon the vessel wall thickness and vessel compliance and isolated. Physical removal of fat and vessel isolation was preferred over chemical digestion of fat. Physical vessel isolation technique is tedious and requires longer period of time but has been determined to be the method of least damage to the microvessel (35). The final cutting of the vessel from the mesentery is extremely critical to experimental success and was performed under fresh cold control 
solution to prevent the microvessel from spasm. The isolated vessel was immediately transferred to the microvessel cannulation chamber containing control solution at $5^{\circ} \mathrm{C}$. Microsutures were obtained from Living Systems Instrumentation, VT, fashioned in to knots and loaded on to the cannulas beforehand. Care was taken to keep the suture length short to prevent them from accidentally touching the microartery during the experiment. Cannulas and perfusion tubing were flushed with control solution at the start of the experiment to prevent air pockets and air bubbles within the perfusion line. Removal of bubbles is imperative for a successful experiment as air pockets can disrupt the endothelial monolayer of the microartery. The system was continually tested for presence of air pockets by observing the response time of the system to a change in servo pressure controller set point. A delayed servo response to a change in set point indicated the presence of air bubble in the lines.

Microvessel was allowed to stabilize to the new environment for 5 minutes. It was lifted from one end and slipped over the glass cannula connected to the servo controlperistaltic pump combination. The cannulated end was secured with the help of two microsutures tied gently around the microvessel (Fig.8). Care was taken to maintain the physiological direction of flow through the microartery. The microartery was always lifted from the ends to prevent any damage to the SMC at the region of interest due to handling. The cannulated end was gradually pressurized up to $5 \mathrm{mmHg}$ to remove the blood inside the vessel lumen. 


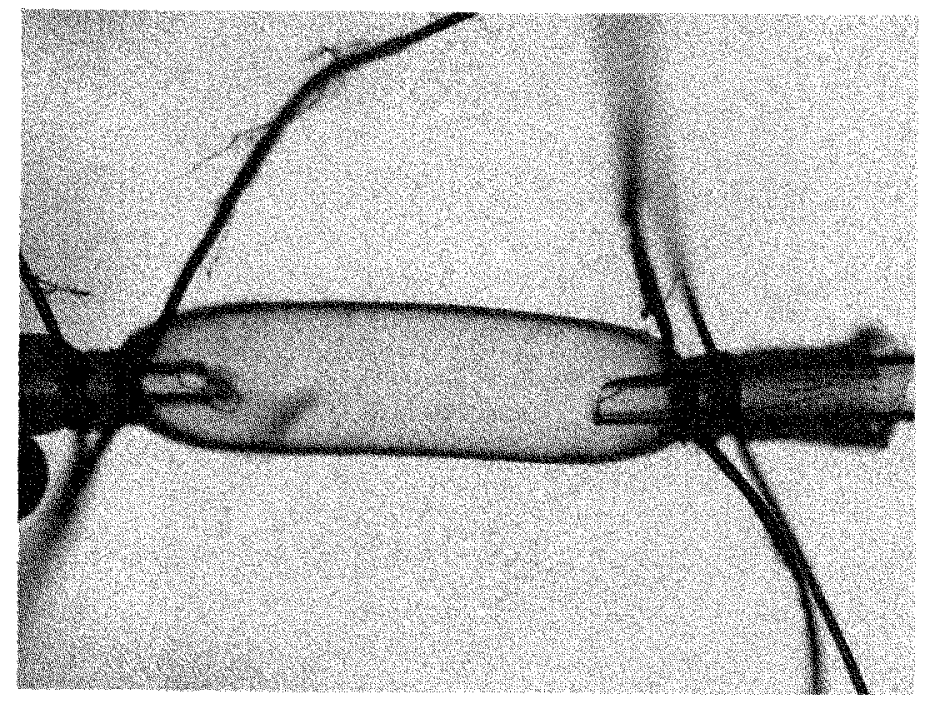

Figure 8: Bright field image of a cannulated rat mesentery microartery secured with the help of two microsutures (imaged using Olympus $4 \mathrm{X}$ objective). The diameter of the vessel pressurized to $50 \mathrm{mmHg}$ is $(\cdots 300 \mu \mathrm{ms})$

Care was taken to maintain extremely low flow rate of control solution through the vessel to avoid erosion of the endothelial monolayer. After removal of intraluminal blood, microvessel perfusion was stopped and the second end was cannulated and secured using two microsutures. Four microsutures are sufficient to withstand a pressure of up to $150 \mathrm{mmHg}$ in the vessel. The microvessel was pressurized to $80 \mathrm{~mm} \mathrm{Hg}$ and then the bend formed was removed by adjusting the cannulas. This is done to pre stretch the microvessel so that it responds maximally to various agonists. The pressure was then reduced to physiological pressure of $50 \mathrm{mmHg}$ and the vessel was tested for leaks by switching the servo controller from automatic to manual mode and observing any changes in the intraluminal pressure. A significant drop in intraluminal pressure indicates a leak. Only vessels without leaks were considered for experimentation. 


\subsection{EXPERIMENTAL SET UP FOR APPLICATION OF AGONISTS TO SMOOTH MUSCLE AND ENDOTHELIUM}

The experimental set-up for superfusing vasoactive agents like NE, Ouabain and KB-R7943 and perfusing agonists and/or blockers like Ach. Indomethacin, L-Name, Apamin and Tram-34 is shown in Fig.9. The set-up established is ideal for experiments involving continuous superfusion and can be adapted depending upon the individual experimental protocol. The present set-up is sufficient for the proposed experiments involving application of NE, Ouabain and KB-R7943 to the microarteries by superfusion and application of Ach, Indomethacin, L-Name, Apamin and Tram-34 to the endothelium by perfusion.

\subsection{BRIGHT FIELD IMAGING, DIAMETER MEASUREMENTS, RECORDING MOVIES FOR VASOMOTION}

Imaging criterion was fixed to ease comparison of data. The microartery was imaged with IPLab3.6.3 software using light from Olympus lamp. The exposure time was set to obtain a clear picture of the vessel. IPLab3.6.3 ratio plus extension was used to acquire images, which were stored for future analysis and post processing. The vessel response to various stimuli was recorded by either taking snapshots or by making a movie with time frames of $5 \mathrm{sec}$. All the vasomotion movies were recorded using a time frame of $1 \mathrm{sec}$ only to measure amplitude and frequency of oscillations. 


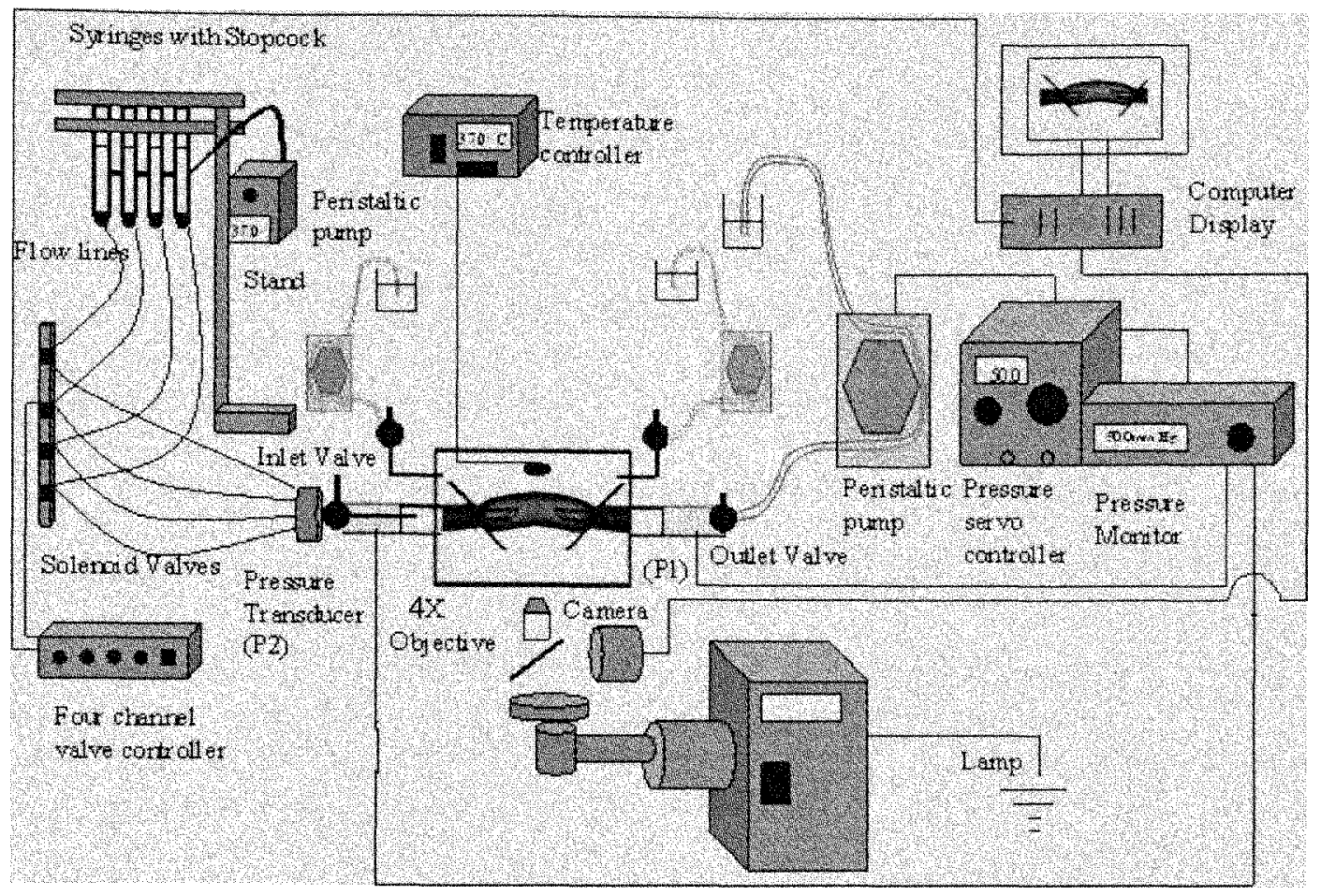

Figure 9: Experimental set-up for application of agonists' through continuous superfusion and perfusion.

\subsection{POST PROCESSING}

Images were also post processed using IPLab3.6.3 to obtain diameter changes at different cross-sections. Diameter measurements were made manually as well as using the script in the software for measuring diameters in bright -field mode. The diameter data was exported to Microsoft Excel for the characterization of the response. The diameter responses were normalized and plotted against the concentration of agonists in a logarithmic scale, $\mathrm{EC}_{50}$ values were then determined using Hill plot equation as described later. 


\subsection{STATISTICS}

Dose response curves were analyzed statistically by using two way analysis of variance (ANOVA) test for multiple comparisons. Constrictions/relaxations were compared at individual agonist concentrations and the points which were determined to be statistically different were shown with a symbol. The two-way ANOVA was used to compare the difference between individual blockers and the Post-Hoc test (Tukey test) was used to determine the significance values for each of the point.

\section{SUMMARY OF EXPERIMENTATION}

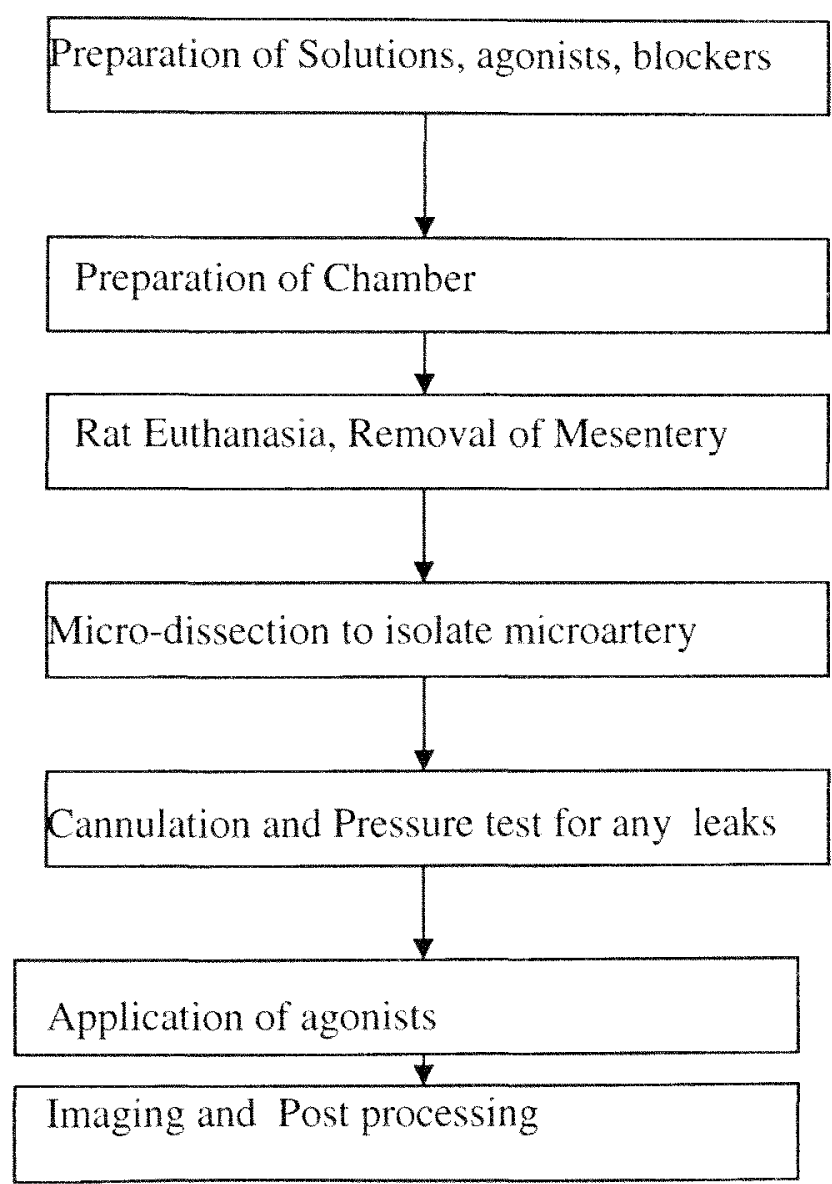




\section{Without Ouabain (Control experiments)}

Dose response curves with NE only (6 rats)

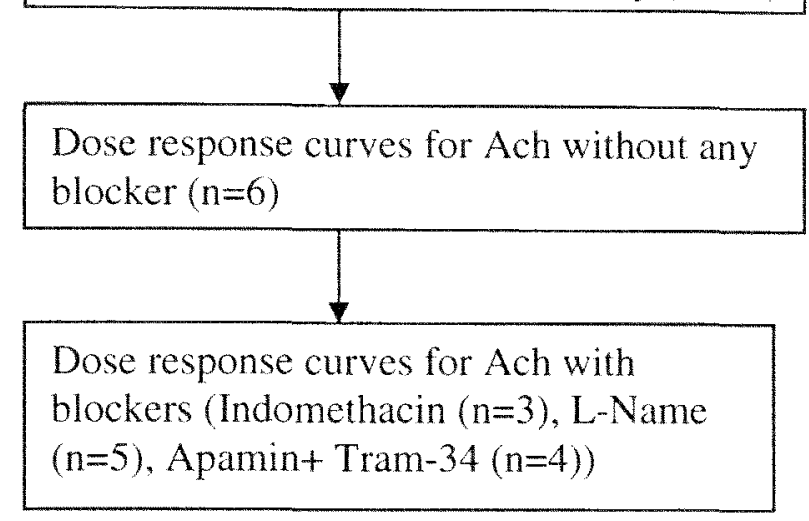

\section{With Ouabain}

\begin{tabular}{|l|}
\hline Dose response curves with NE $(n=4)$ \\
\hline $\begin{array}{l}\text { Dose response curves with Ach without } \\
\text { any blocker as well as with L-Name and } \\
\text { Apamin+Tram-34 }(n=4)\end{array}$
\end{tabular}

\subsection{RESULTS}

\subsection{Pressure vs Diameter}

Increase in intra-luminal pressure causes an increase in microvessel diameter. As shown in Fig 10 a \& b, an increase in pressure leads to a decrease in the slope of the pressure vs diameter curve and at $80 \mathrm{~mm} \mathrm{Hg}$ pressure the slope tends to reach a plateau. Normalized data from 5 separate rat experiments is shown in Fig. 10a whereas average normalized diameter increase is represented in Fig. 10b. On increasing the intra-luminal 
pressure to $80 \mathrm{mmHg}$, the microvessel diameter increased by $44.5( \pm 1.5) \%$ and the slope of the curve approaches a plateau.

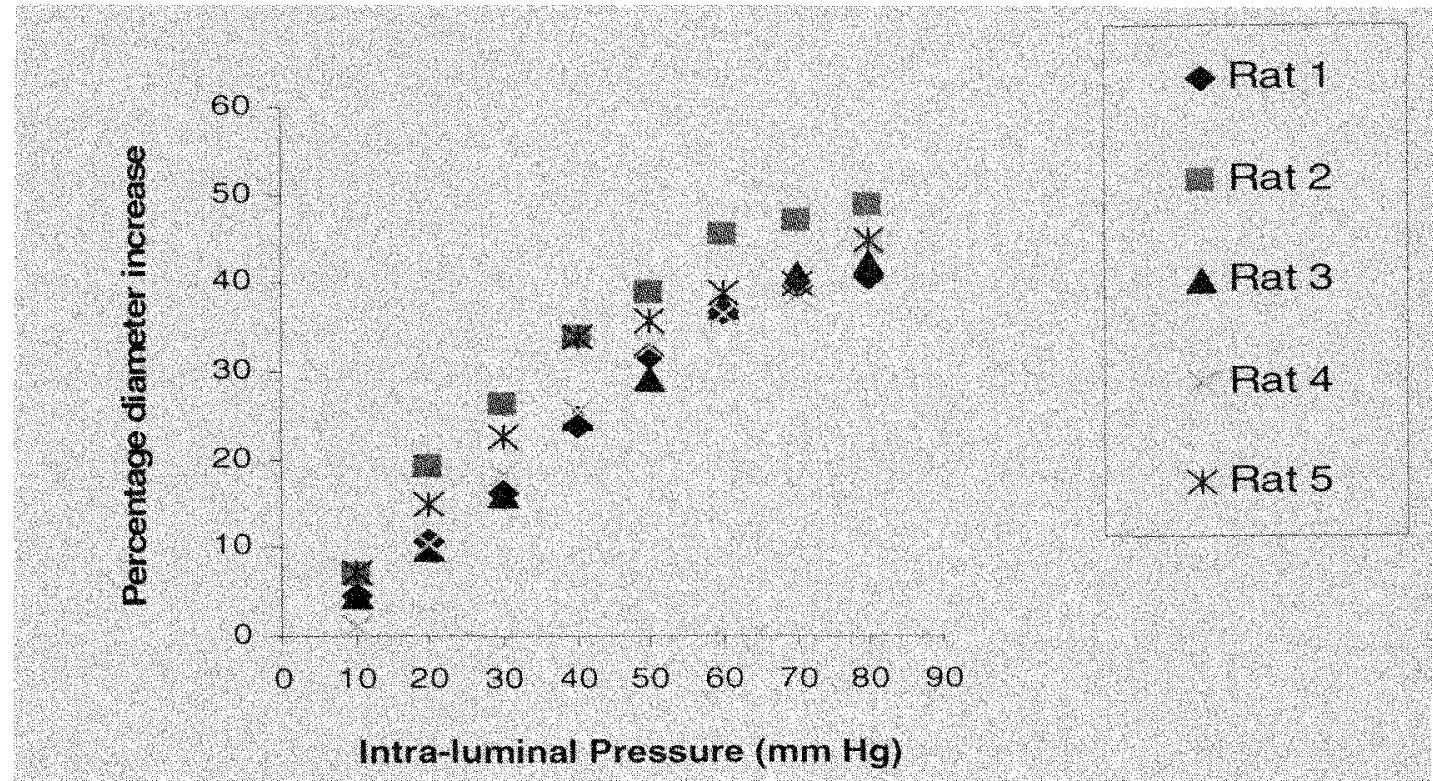

(a)

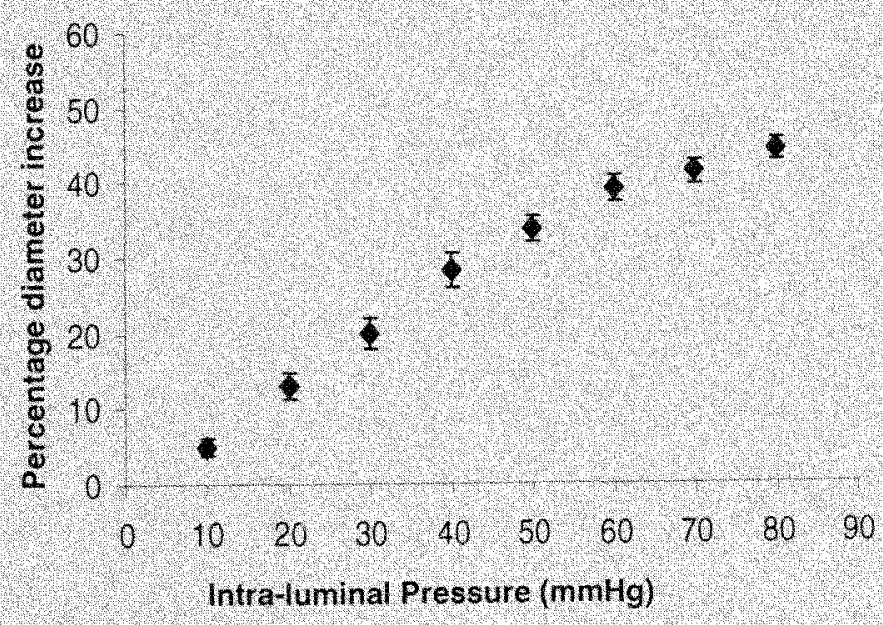

(b)

Figure 10: Diameter response to increase in intra-luminal pressure from 0 to $80 \mathrm{mmHg}$ in isolated intact rat mesenteric arteriole. Vessel diameter tends to plateau as the pressure 
reaches $80 \mathrm{~mm} \mathrm{Hg}$ exhibiting myogenic response. Diameter increase is normalized over basal diameter at $0 \mathrm{mmHg}$.

In (a) raw data $(\mathrm{n}=5)$ is shown whereas in (b) data is shown as percentage mean relaxation $\pm \mathrm{SEM} ; \mathrm{n}=5$.

\subsection{Control studies of vascular reactivity}

\subsubsection{Effect of vasoconstrictor NE on vessel diameter}

Vasoconstriction was obtained upon application of NE showing an intact and functional SM layer. NE concentration in the bath chamber was progressively increased to $0.1 \mu \mathrm{M}, 0.2 \mu \mathrm{M}, 0.4 \mu \mathrm{M}, 1 \mu \mathrm{M}, 3 \mu \mathrm{M}$ and $10 \mu \mathrm{M}$. As the $\mathrm{NE}$ concentration was increased, a higher constriction was observed in the microvessels. A concentrationresponse curve was obtained showing microvessel constriction resulting from different NE concentrations. Fig. 11 a shows raw data obtained from 6 rat experiments whereas Fig. $11 \mathrm{~b}$ shows the mean percentage relaxation $( \pm \mathrm{SEM})$. Constriction was calculated based on the basal diameter of the vessel without NE in the bath solution. The normalized percentage constriction at any NE concentration $C_{i}$ was calculated using the formula:

$\%$ Constriction $($ at $\mathrm{Ci})=\left(\mathrm{D}_{0}-\mathrm{D}_{\mathrm{i}}\right) / \mathrm{D}_{0}$

Where, $D_{i}$ is the vessel diameter at $N E$ concentration $C_{i}$ and $D_{0}$ is the basal diameter of the vessel without $\mathrm{NE}$ in the bath solution.

A maximum constriction $\pm \mathrm{SEM}$ of $46.5( \pm 2.5 \%)$ was obtained at $3 \mu \mathrm{M} \mathrm{NE}$ as shown in Fig. $11 \mathrm{~b}$. The $\mathrm{EC}_{50}$ i.e. the concentration of $\mathrm{NE}$ to obtain $50 \%$ of the maximum constriction was calculated from the dose-response curve using the Hill equation. As the constriction response curve followed a sigmoidal shape, a Hill equation was used to describe the curve:

$\mathrm{R}_{\mathrm{i}}=\mathrm{R}_{\max } \mathrm{C}_{\mathrm{i}}^{\mathrm{n}} /\left(\mathrm{C}_{\mathrm{i}}^{\mathrm{n}}+\mathrm{EC}_{50}{ }^{\mathrm{n}}\right)$ 
Where, $R_{i}$ is the constriction at concentration $C_{i}$ of $N E$ and $R_{\max }$ is the maximum constriction.

The values of hill coefficient $(\mathrm{n})$ and $\mathrm{EC}_{50}$ were calculated by plotting $\log _{10}\left[\mathrm{R}_{\max } /\right.$ $\left.\left(\mathrm{C}_{\mathrm{i}}^{\mathrm{n}}+\mathrm{EC}_{50}{ }^{\mathrm{n}}\right)\right]$ vs $\log _{10}\left[\mathrm{C}_{\mathrm{i}}\right]$ and fitting a line through the curve. The slope of the line provided the value of $n$ whereas the value of $\mathrm{EC}_{50}$ was calculated with the help of the both intercept and slope $\left[E C_{50}=I n t e r c e p t / n\right]$. To further optimize the value of $E_{50}$ obtained from above method, the constriction values corresponding to various concentrations of NE were calculated from the Hill equation (eqn 2) using the values of $\mathrm{C}_{\mathrm{i}}, \mathrm{R}_{\max }, \mathrm{n}$ and $\mathrm{EC}_{50}$. The constriction values obtained experimentally and from the Hill equation were subtracted, squared and the sum of square of errors was calculated. Now, the value of square of sum of error was minimized by changing $\mathrm{EC}_{50}$ and hill coefficient (n). The $\mathrm{EC}_{50}$ values were obtained for individual experiments to obtain the result as average \pm SEM and were found to be $0.46( \pm 0.15) \mu \mathrm{M}$.

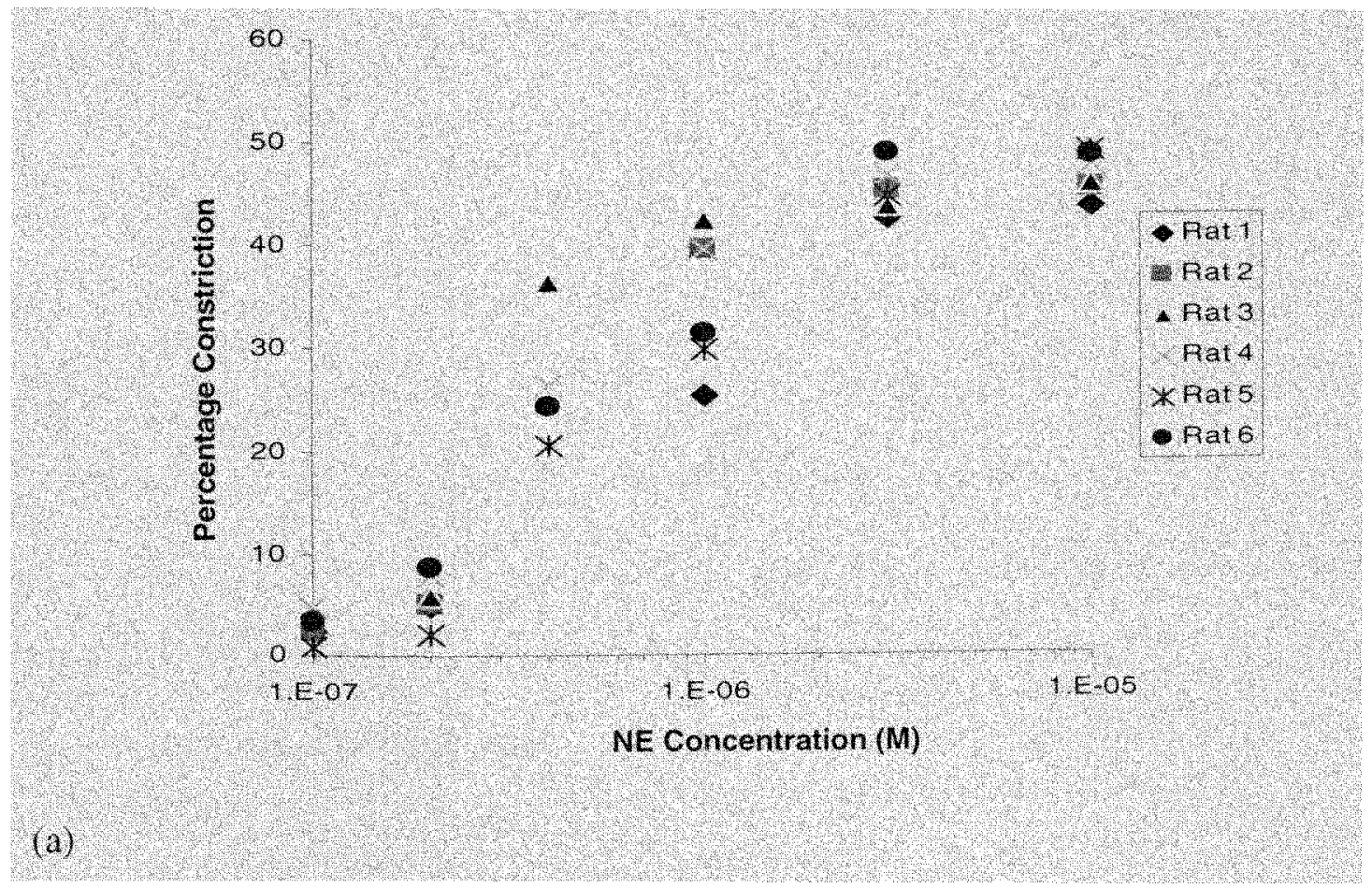




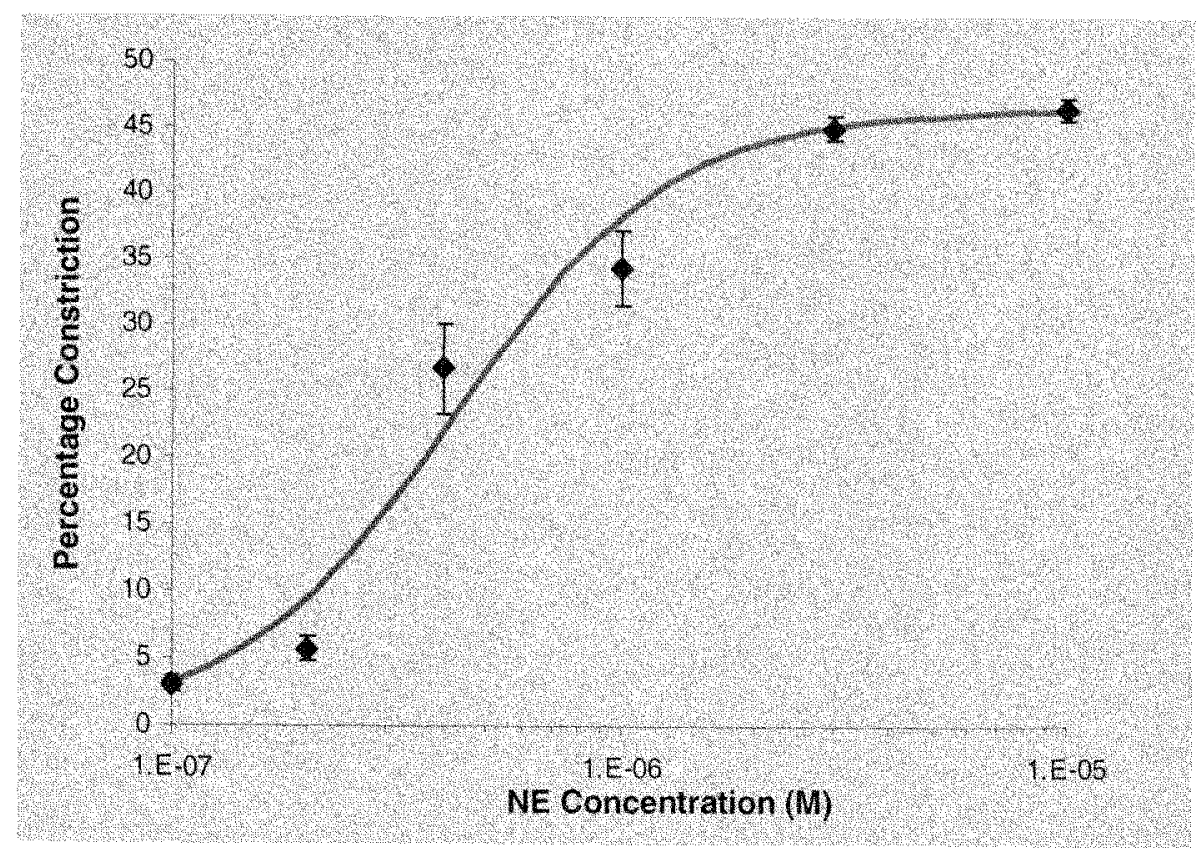

(b)

Figure 11: Concentration-response curve for $\mathrm{NE}$ induced constriction in isolated rat mesenteric rat arterioles. Increase in NE concentration $(0.1 \mu \mathrm{M}-10 \mu \mathrm{M})$ caused an increase in vessel constriction leading to maximum constriction of $46.5 \pm 2.5 \%$ and $\mathrm{EC}_{50}$ of 0.46 $\pm 0.15 \mu \mathrm{M}$. Constriction is normalized over basal diameter i.e. the diameter at $50 \mathrm{mmHg}$ without NE in the chamber bath.

In (a) raw data is shown; $(\mathrm{n}=6)$ whereas in (b) data is expressed as percentage mean constriction \pm SEM; $(n=6)$.

Vasomotion was observed almost every time after NE application showing intact and functional ion channels/gap junctions thereby proving good handling of the vessel. Vasomotion, which is characterized by a rapid oscillation of vessel diameter, occurs on application of vasoconstrictors like $\mathrm{NE}$ and $\mathrm{KCl}$ and is reported as a random event (121). A diameter oscillation is shown in Fig 12 as a function of time from a single experiment. Vasomotion was observed in the NE concentration range $0.4 \mu \mathrm{M}-1 \mu \mathrm{M}$ with an average time period of $4( \pm 1.5)$ seconds. 


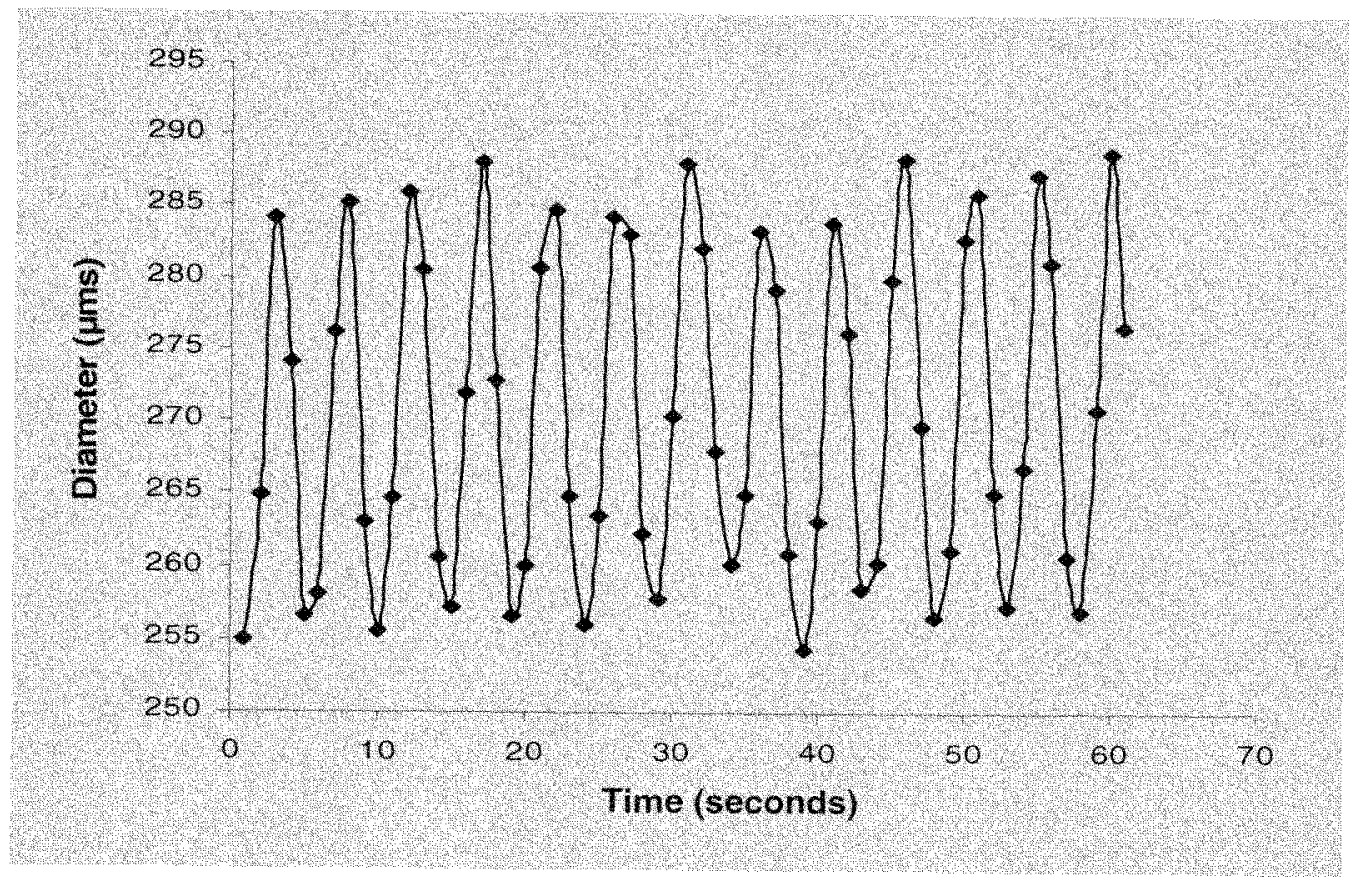

Figure 12: Application of NE in the concentration range $0.4 \mu \mathrm{M}-1 \mu \mathrm{M}$ often resulted in vasomotion. The diameter oscillations observed have an average oscillation period of 4 $( \pm 1.5)$ seconds.

\subsubsection{Acetylcholine-induced Relaxation}

Vasorelaxation was obtained on application of acetylcholine to the arterial endothelium showing an intact and functional endothelium. The microarteries were pressurized to $50 \mathrm{mmHg}$ and preconstricted with $1 \mu \mathrm{M} \mathrm{NE}$. The concentrations of Ach used were $\operatorname{lnM}, 10 \mathrm{nM}, 30 \mathrm{nM}, 100 \mathrm{nM}, 1 \mu \mathrm{M}, 10 \mu \mathrm{M}$ and $100 \mu \mathrm{M}$.

Ach induced a dose-dependent relaxation of the NE preconstricted microvessel as shown in Fig 13. Raw data from 6 different rat experiments is shown in Fig. 13a, whereas an average relaxation-concentration curve is shown in Fig. 13b. All the relaxations were normalized using the formula:

\% Relaxation $($ at $\mathrm{Ci})=\left(\mathrm{D}_{\mathrm{i}}-\mathrm{Do}\right) /(\mathrm{Dt}-\mathrm{Do})$ 
Where, $D_{i}$ is the diameter of the vessel obtained after perfusing concentration $C_{i}$ of Ach, Do is the diameter of vessel after preconstriction with $N E$ and $D_{t}$ is the initial diameter of the vessel before preconstriction.

Ach was able to completely reverse the NE induced constriction, thereby relaxing the vessel to its original diameter. The $\mathrm{EC}_{50}$ value i.e. the concentration of Ach required to relax the vessel to $50 \%$ of its maximum relaxation was obtained following the same method as used for NE-induced constriction (Hill equation) and was found to be $50( \pm 24)$ $\mathrm{nM}$. The maximum relaxation obtained was $95( \pm 4.5) \%$.

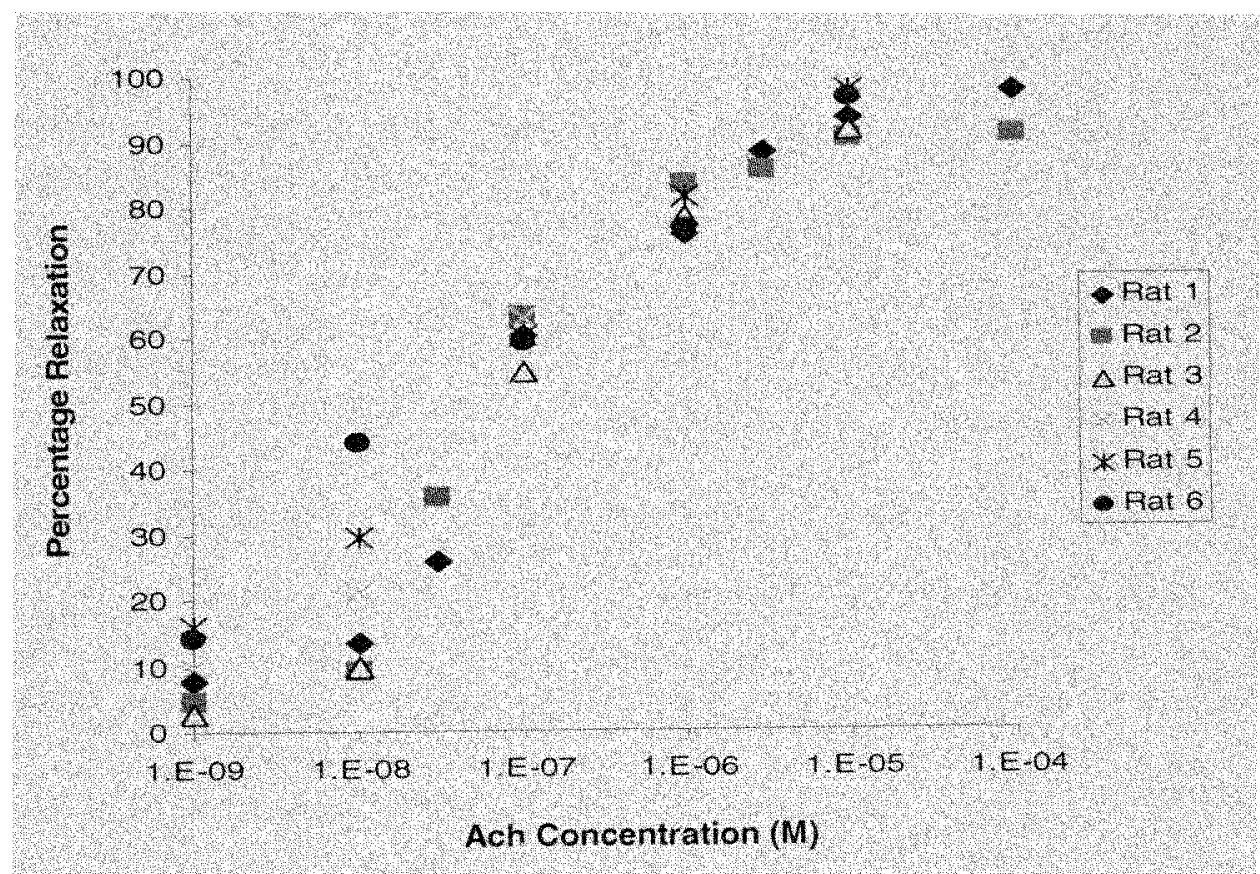

(a) 


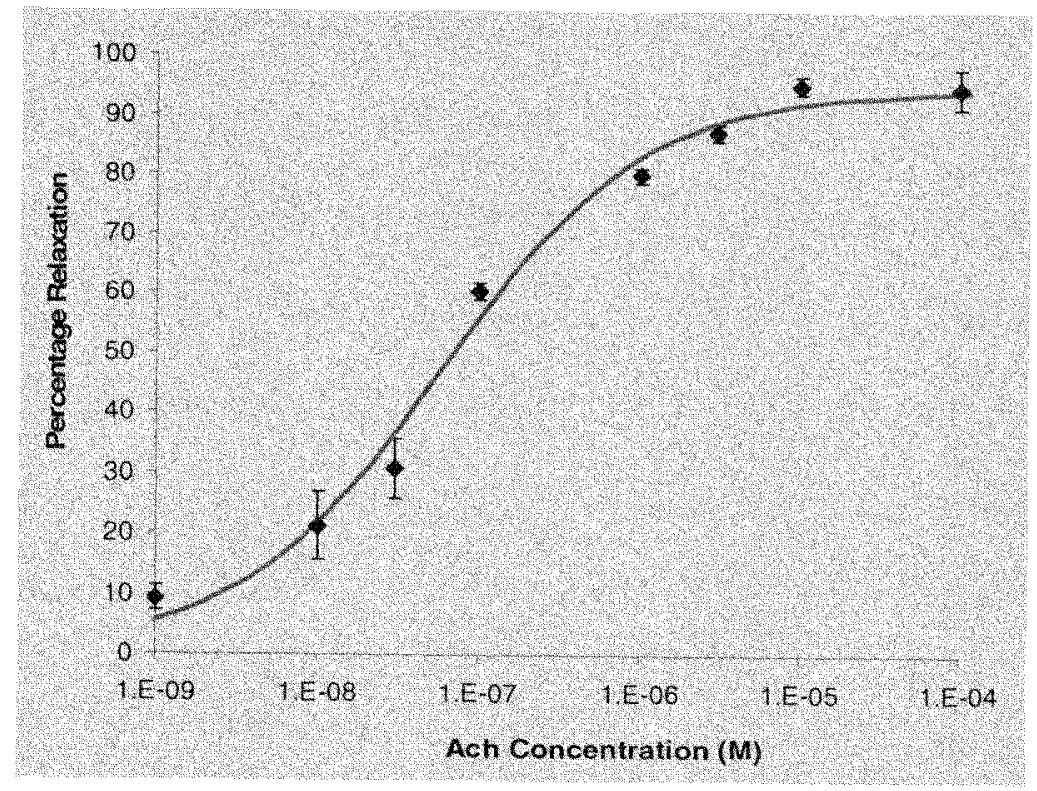

(b)

Figure 13: Concentration response curve for Ach-induced relaxation in isolated intact rat mesenteric arterioles preconstricted with $1 \mu \mathrm{M}$ NE. Ach was able to almost completely reverse NE induced constriction giving a maximum relaxation of $95( \pm 4.5) \%$ and EC50 of $50 \pm 24 \mathrm{nM}$.

In (a) raw data is shown; $(n=6)$ whereas in (b) data is expressed as percentage mean relaxation \pm SEM; $(n=6)$.

\subsubsection{Effect of Indomethacin on Ach induced relaxation.}

Indomethacin solution $(10 \mu \mathrm{M})$ was perfused for 30 minutes to block $\mathrm{COX}-1$ following the same procedure as for Ach. COX-1 is responsible for the production of prostacyclin in the endothelium of rat mesenteric artery and hence its inhibition blocks the prostacyclin pathway of Ach-induced relaxation. Indomethacin was perfused for 30 minutes followed by a 10-15 min wash out period. Different Ach concentrations ( $1 \mathrm{nM}$ to $100 \mu \mathrm{M})$ were again perfused to obtain a concentration response curve of Ach-induced relaxation in the presence of $\mathrm{COX}$ inhibitor. 
The COX blocker had no significant effect on Ach induced relaxation as the Ach was able to almost completely reverse the NE induced constriction even in the presence of indomethacin (Fig 14). The maximum relaxation obtained was $90.5( \pm 1.5) \%$ and the $\mathrm{EC}_{50}$ value obtained in the presence of indomethacin was $75( \pm 17) \mathrm{nM}$. Although the maximum relaxation was slightly impaired, the difference was not statistically significant which was confirmed by two-way ANOVA test for multiple comparisons $(p<0.01)$.

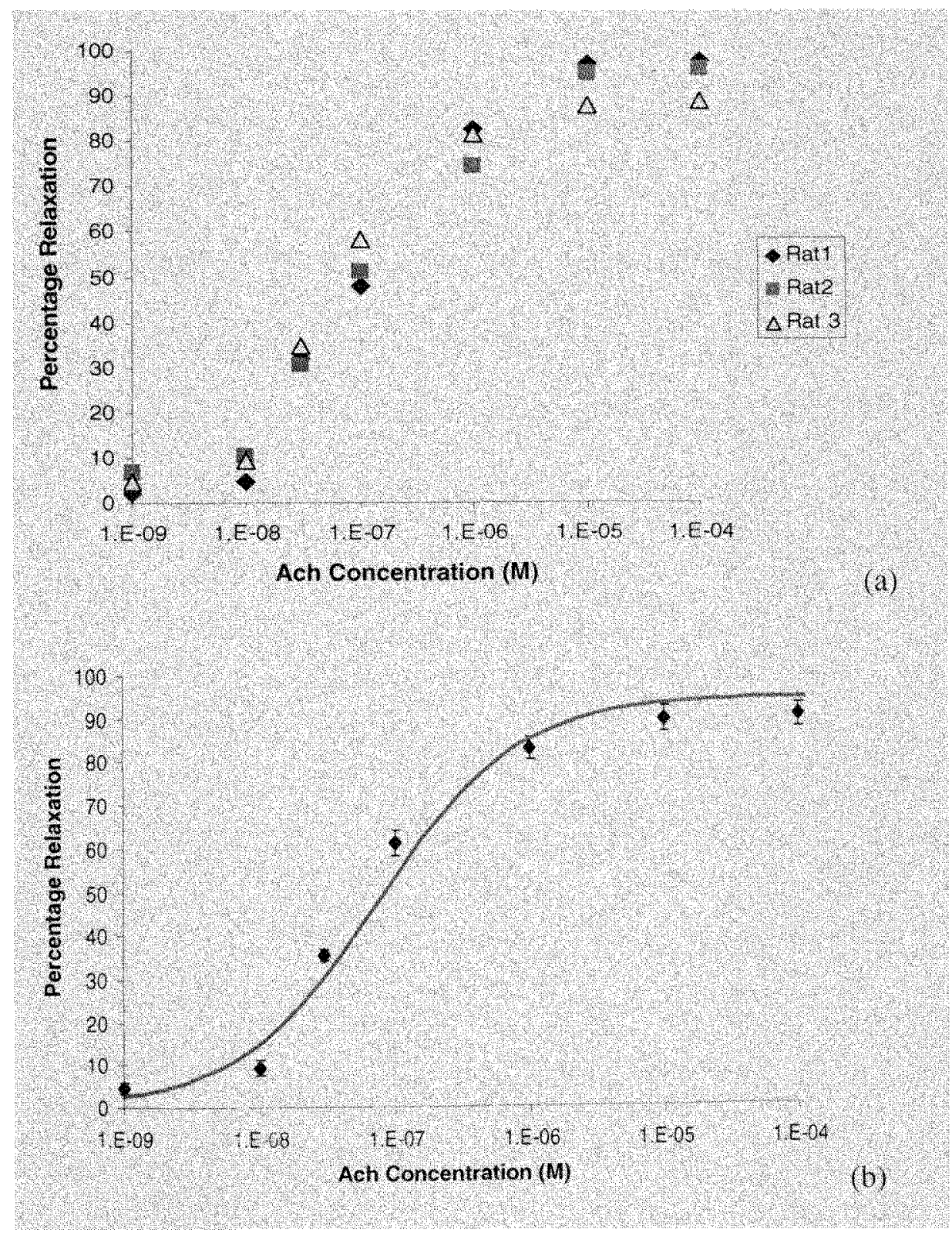


Figure 14: Concentration response curve for Ach-induced relaxation in isolated intact rat mesenteric arterioles preconstricted with $1 \mu \mathrm{M} N E$ in the presence of COX blocker indomethacin. Ach evoked relaxation was not significantly affected in the presence of indomethacin. The maximum relaxation observed in presence of indomethacin was $90.5( \pm 1.5) \%$ whereas $\mathrm{EC}_{50}$ in this case was $75 \pm 17 \mathrm{nM}$.

In (a) raw data is shown; $(n=3)$ whereas in (b) data is expressed as percentage mean relaxation \pm SEM; $(n=3)$.

\subsubsection{Effect of eNOS blockade on Ach-induced relaxation}

Endothelial nitric oxide synthase blocker (L-Name, $350 \mu \mathrm{M}$ ) was used to block the NO production in the arterial endothelium. L-Name solution was perfused for 30 minutes followed by a 10-15 minute washout period. All the concentrations of Ach were again perfused to obtain the concentration -response curves as shown in Fig15. NOS blockade had a significant effect on the Ach-induced relaxation. The maximum relaxation was impaired in comparison to control conditions thereby showing a major role of $\mathrm{NO}$ in Ach-induced relaxation. The maximum relaxation obtained in the presence of L-Name was $54.5( \pm 3.5) \%$ whereas the $\mathrm{EC}_{50}$ value for this curve was found to be $45( \pm 32) \mathrm{nM}$.

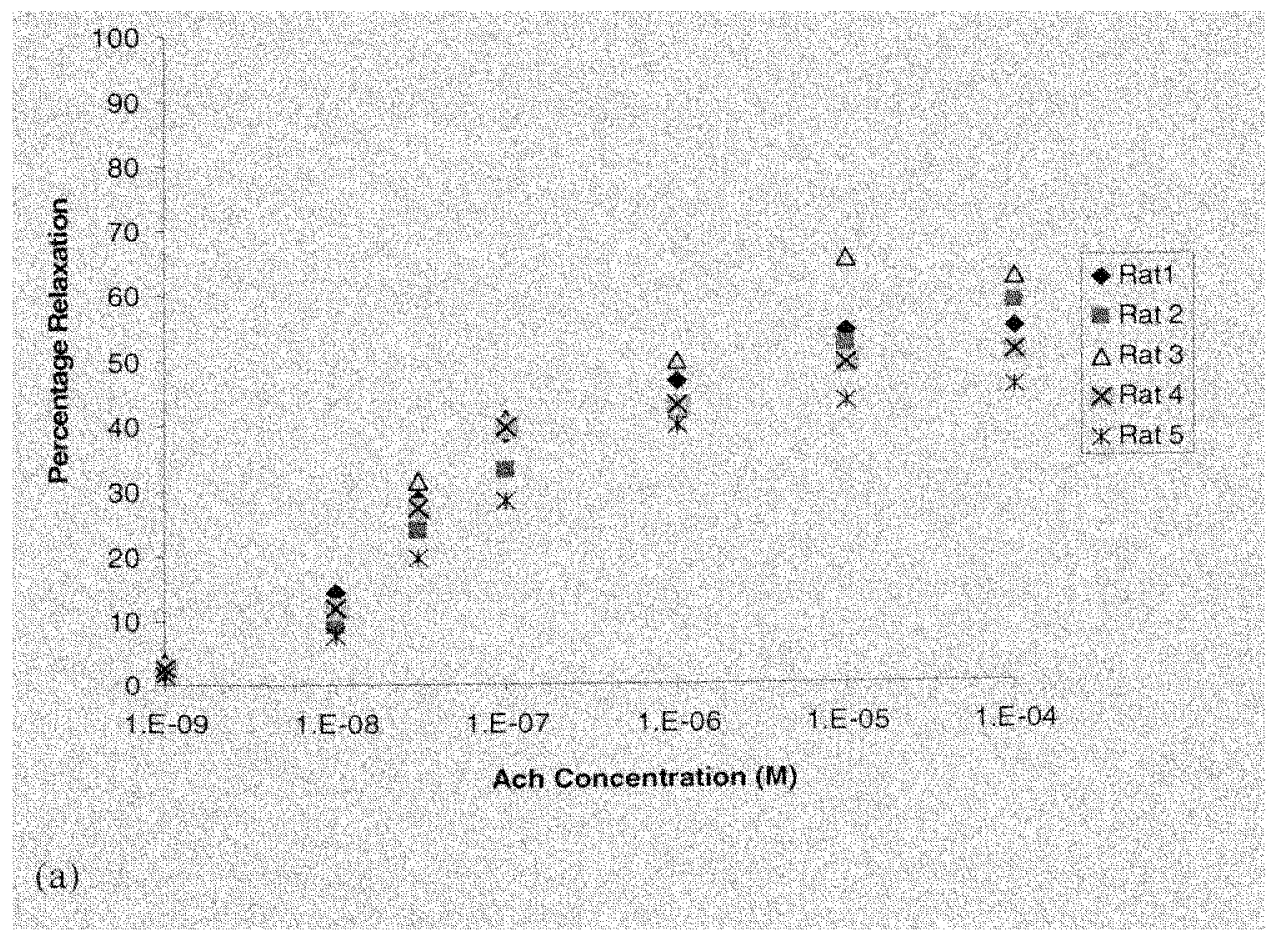




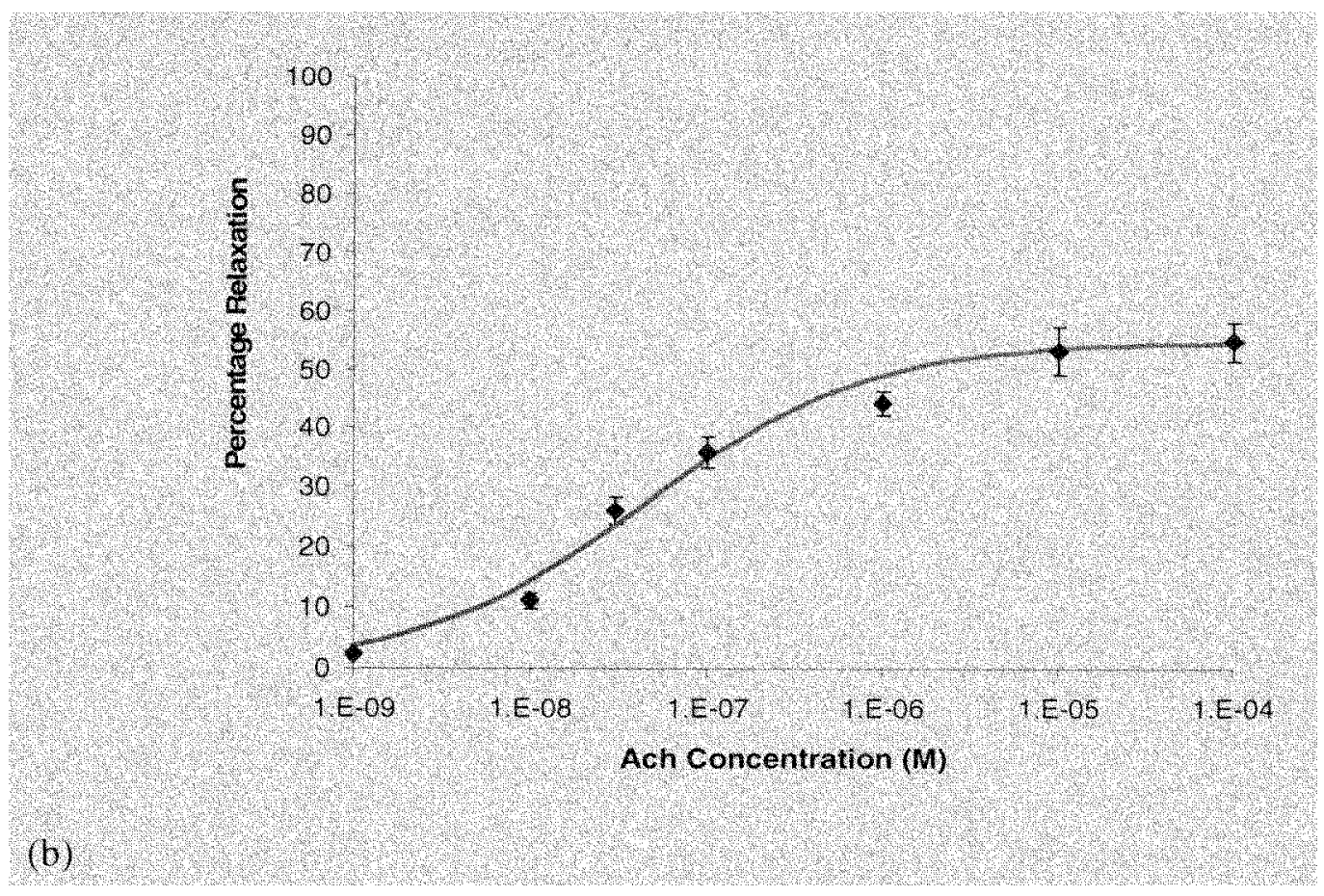

Figure 15: Concentration response curve for Ach-induced relaxation in isolated intact rat mesenteric arterioles preconstricted with $1 \mu \mathrm{M} \mathrm{NE}$ in the presence of e-NOS blocker, $L$ Name. Ach evoked relaxation was significantly affected in the presence of L-Name. The maximum relaxation observed in presence of $\mathrm{L}-\mathrm{Name}$ was $54.5( \pm 3.5) \%$ whereas $\mathrm{EC}_{50}$ in this case was not affected significantly $(45 \pm 32 \mathrm{nM})$.

In (a) raw data is shown; $(n=5)$ whereas in (b) data is expressed as percentage mean relaxation $\pm \operatorname{SEM} ;(n=5)$.

\subsubsection{Effect of blocking EDHF pathway in Ach-induced relaxation}

Selective potassium channel blockers were used to block the EDHF pathway in Ach induced vasodilation. As discussed earlier, in rat mesenteric arteries, EDHF exerts its effect through potassium channels present in EC ( rat mesenteric arterial EC contains only $\mathrm{IK}_{\mathrm{Ca}}$ and $\mathrm{SK}_{\mathrm{Ca}}$ ) and hence specific blockers for $\mathrm{IK}_{\mathrm{Ca}}(\mathrm{Tram}-34,0.1 \mu \mathrm{M})$ and $\mathrm{SK}_{\mathrm{Ca}}$ (Apamin, 10 MM) were perfused for 30 minutes each followed by a washout for 10-15 minutes. Since, the same vessel has been perfused with Indomethacin and L-Name, the perfusion of Apamin and Tram-34 results in the blockage of all the three pathways. All the Ach solutions were again perfused to obtain the concentration-response to Ach 
induced vasodilation. The potassium channel blockers almost completely abolished the Ach-induced relaxation as shown in Fig 16. The maximum relaxation obtained was 13.5 $( \pm 3.5)$. Fig. $16 \mathrm{c}$ shows the effect of blocking all the pathways on Ach-induced relaxation.

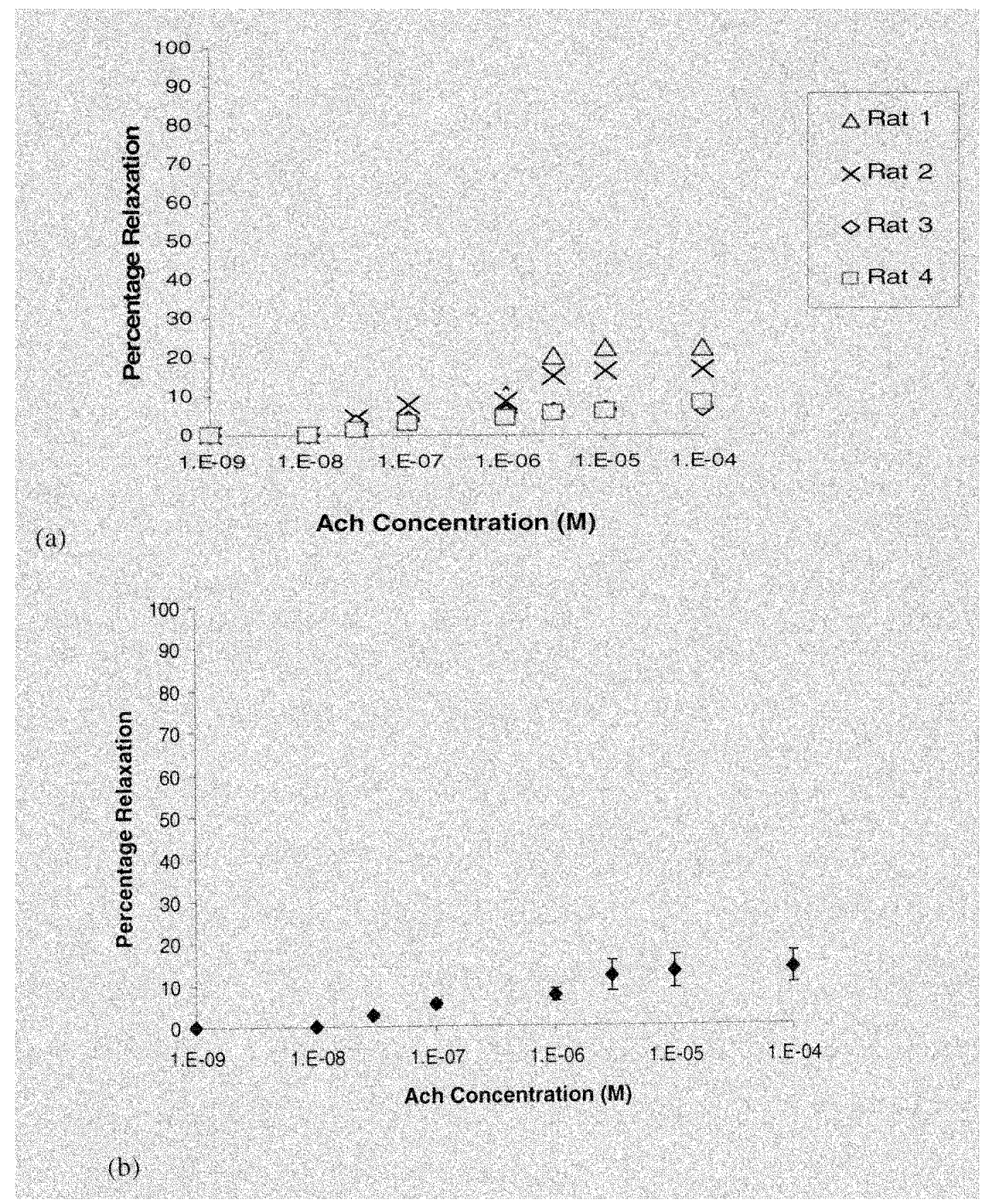




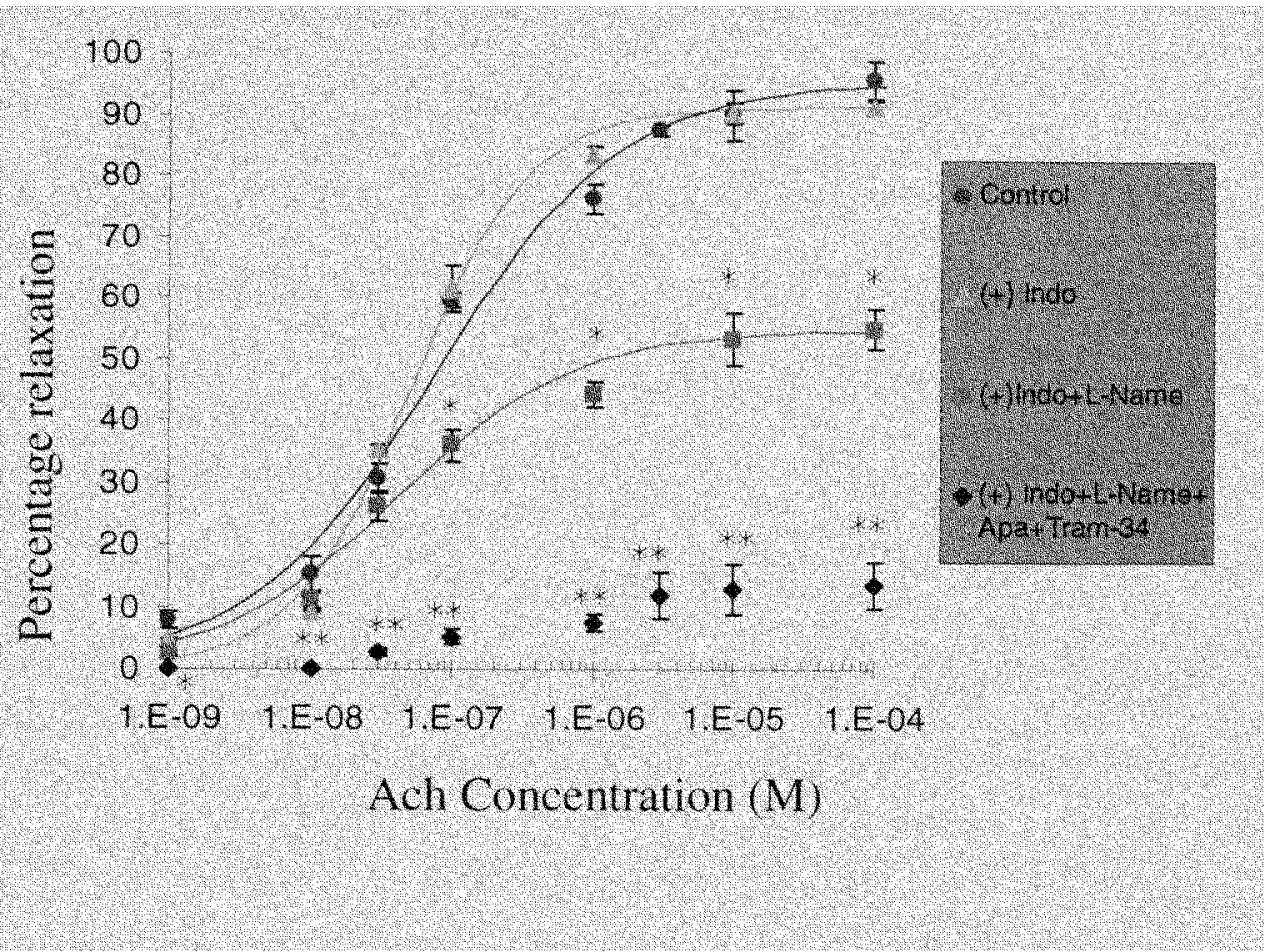

Figure 16: Concentration-response curve for Ach-induced relaxation in isolated intact rat mesenteric arterioles preconstricted with $1 \mu \mathrm{M} N E$ after blocking all the three pathways. In (a) raw data is shown; $(n=4)$ giving concentration response to Ach-induced dilation in the presence of blockers Indomethacin, L-Name, apamin and Tram-. Blockade of all the three pathways almost abolished the Ach-induced dilation. In (b) the data is expressed as percentage mean relaxation \pm SEM; $(n=4)$. In (c) the contribution of all the pathways is shown. $(\mathrm{p}<0.01)(*)$ different from control and $(* *)$ different from Indo+L-name.

\subsection{Effect of Ouabain on Vascular Reactivity}

Ouabain (used to block the $\mathrm{Na}^{+} / \mathrm{K}^{+}$ATPase pump) was superfused along with $\mathrm{NE}$ to study its affect on NE induced vasoconstriction. The effect of ouabain on NE-induced constriction and vasomotion was recorded. Ach-induced relaxation was also examined to study the effect of ouabain on vascular reactivity. Different blockers (L-Name, Apamin and Tram-34) were also applied in the presence of ouabain and their effect on Achinduced relaxation was recorded and compared with control experiments. 


\subsubsection{Effect of Ouabain on NE induced constriction-response curve}

Addition of $1 \mu \mathrm{M}$ ouabain to NE preconstricted vessel caused a significant constriction $(47.4 \mu \mathrm{m})$ as shown in Fig. 17a. However, the effect of $100 \mathrm{nM}$ ouabain on the steadystate diameter of the microvessel was not significant. Ouabain (100nM) was superfused along with different $\mathrm{NE}$ concentrations $(0.1 \mu \mathrm{M}$ to $10 \mu \mathrm{M})$ to determine the effect of ouabain on NE induced concentration-response curve in rat mesenteric arterioles. The NE induced vasomotion did not abolish in the presence of oubain as shown in Fig. 17b and the resulting time period of oscillation was $4.7 \pm 1.5 \mathrm{~s}$. Fig. $17 \mathrm{c}$ shows raw data obtained from 4 rats $(n=4)$ illustrating the concentration response of NE in the presence of ouabain. Fig. $17 \mathrm{~d}$ illustrates the data as percentage mean constriction \pm SEM whereas Fig. 17e shows comparison of NE induced vasoconstriction in presence and absence of ouabain. The maximum constriction obtained in presence of ouabain increased to $50( \pm 2)$ \% compared to a maximum constriction of $46.5( \pm 2.5) \%$ obtained in the absence of ouabain. The $\mathrm{EC}_{50}$ obtained in presence of ouabain was $0.53( \pm 0.10) \mu \mathrm{M}$ compared to $0.46( \pm 0.15) \mu \mathrm{M}$ (which was obtained in the absence of ouabain).

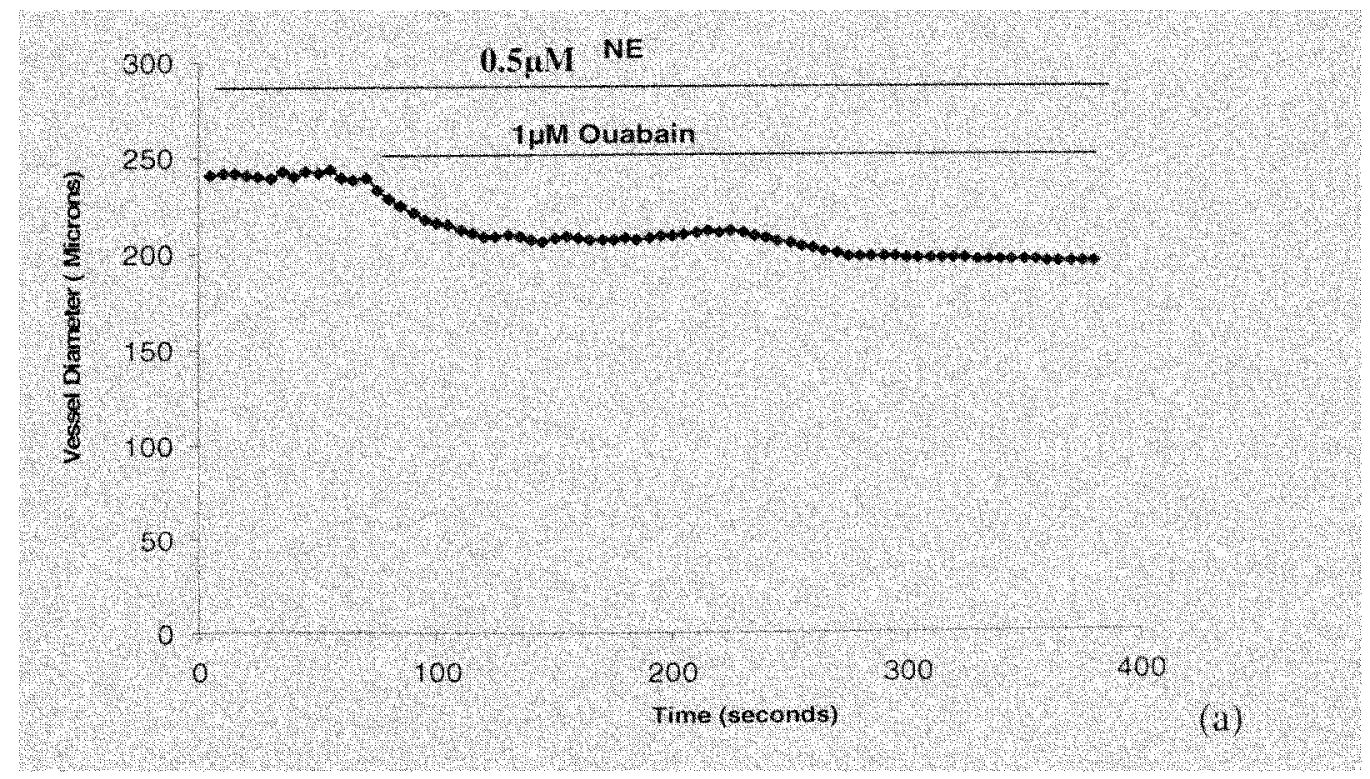




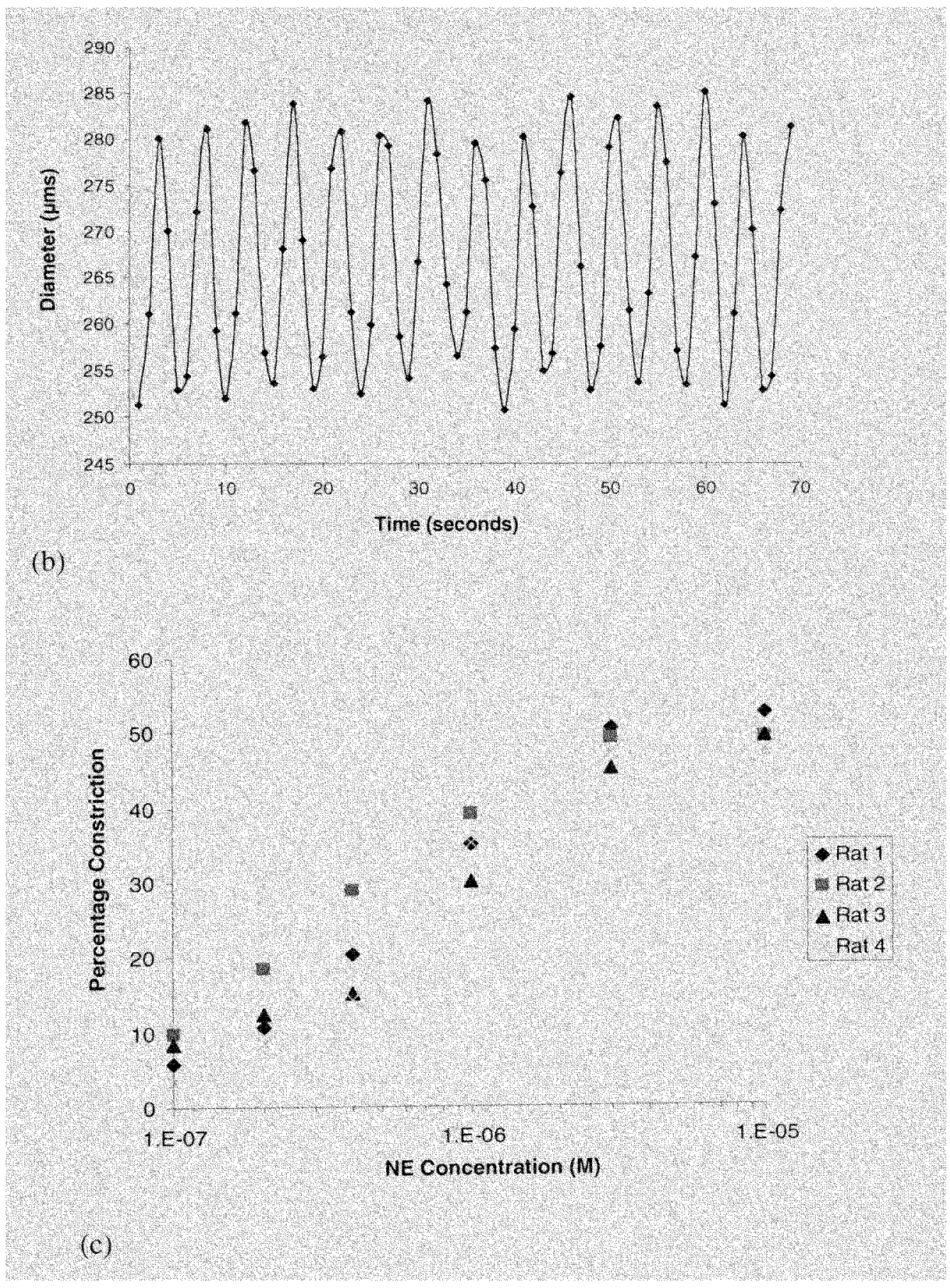




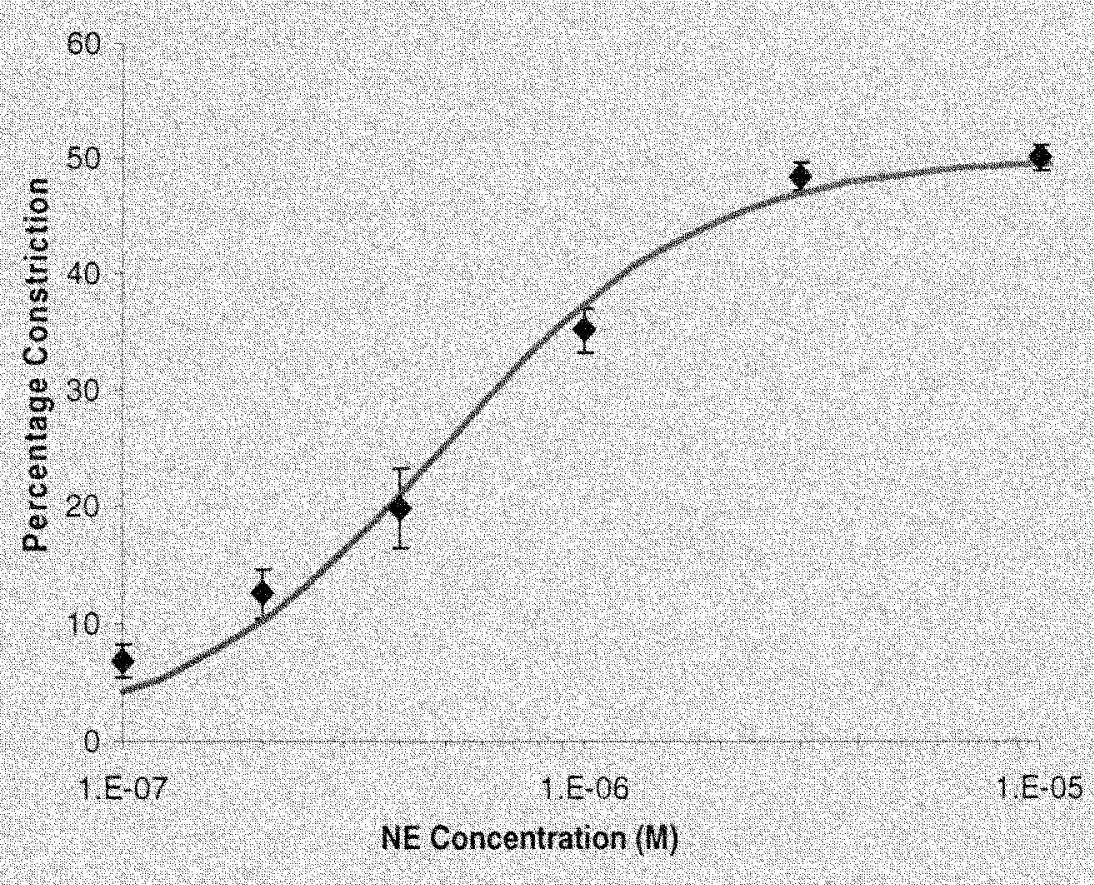

(d)

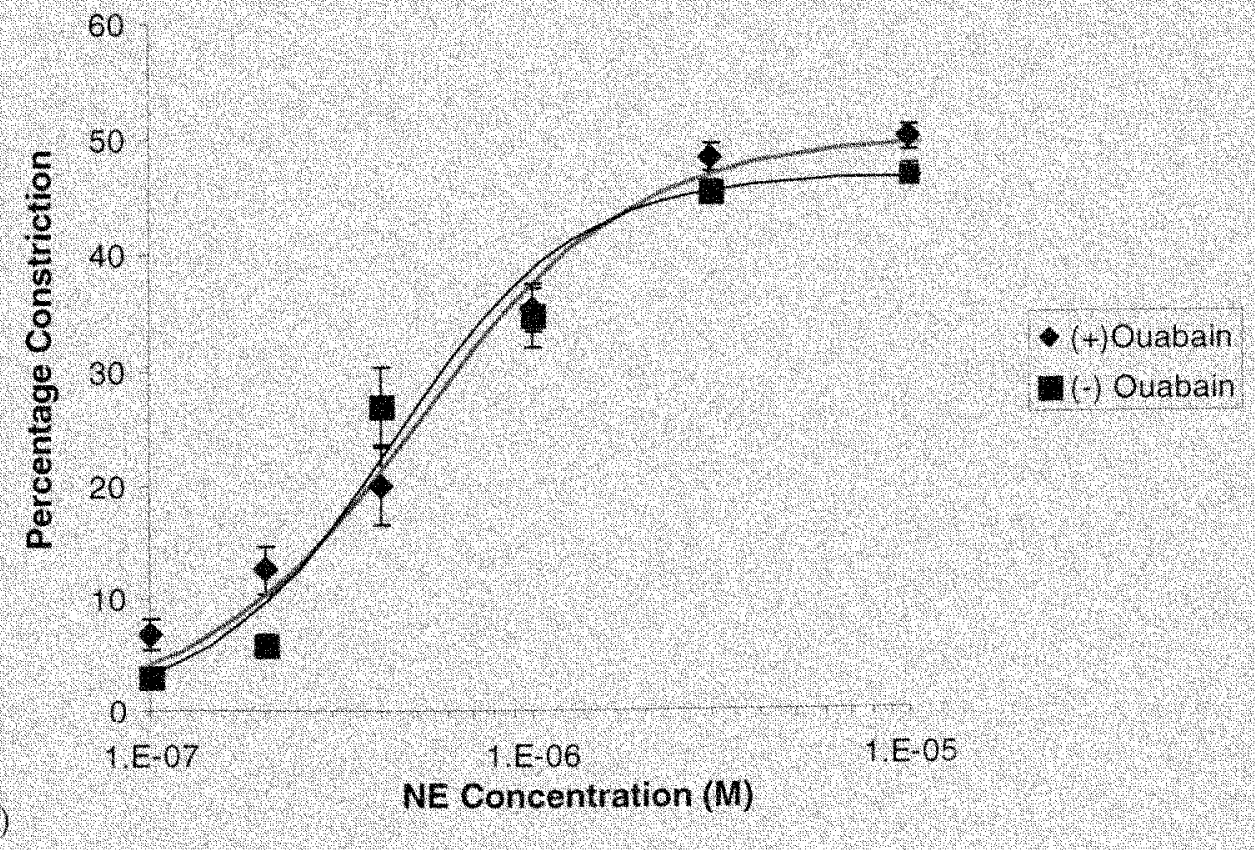


Figure 17: Effect of ouabain on NE induced vasoconstriction in isolated rat mesenteric artery.

In (a) diameter response on adding $1 \mu \mathrm{M}$ ouabain (in the presence of $0.5 \mu \mathrm{M} N E$ ) is shown. (b) shows the effect of ouabain on NE induced vasomotion. In (c) raw data; $(n=4)$ showing the NE induced concentration-dose response in the presence of $100 \mathrm{nM}$ ouabain is illustrated and (d) demonstrates the data as percentage mean constriction $\pm \operatorname{SEM}(n=4)$. In (e) comparison of NE induced concentration- response in the presence and absence of ouabain is shown. Although, the NE induced constriction was slightly increased in the presence of ouabain, there was no statistical difference.

\section{Effect of NCX Blockade on NE induced vasoconstriction}

Blockade of $\mathrm{Na}^{+} / \mathrm{Ca}^{2+}$ exchanger with $2 \mu \mathrm{M} \mathrm{KB}-\mathrm{R} 7943$ (added to the superfusion, in the continuous presence of NE and ouabain) resulted in a biphasic response. At first, the addition of KB-R7943 caused an initial constriction as shown in Fig. 18a. This was followed by a relaxation after a certain time lapse. The time lapse between the constriction and relaxation was approximately 100 seconds. Concerning vasomotion, the oscillation period increased to 8 seconds as shown in Fig. $18 \mathrm{~b}$.

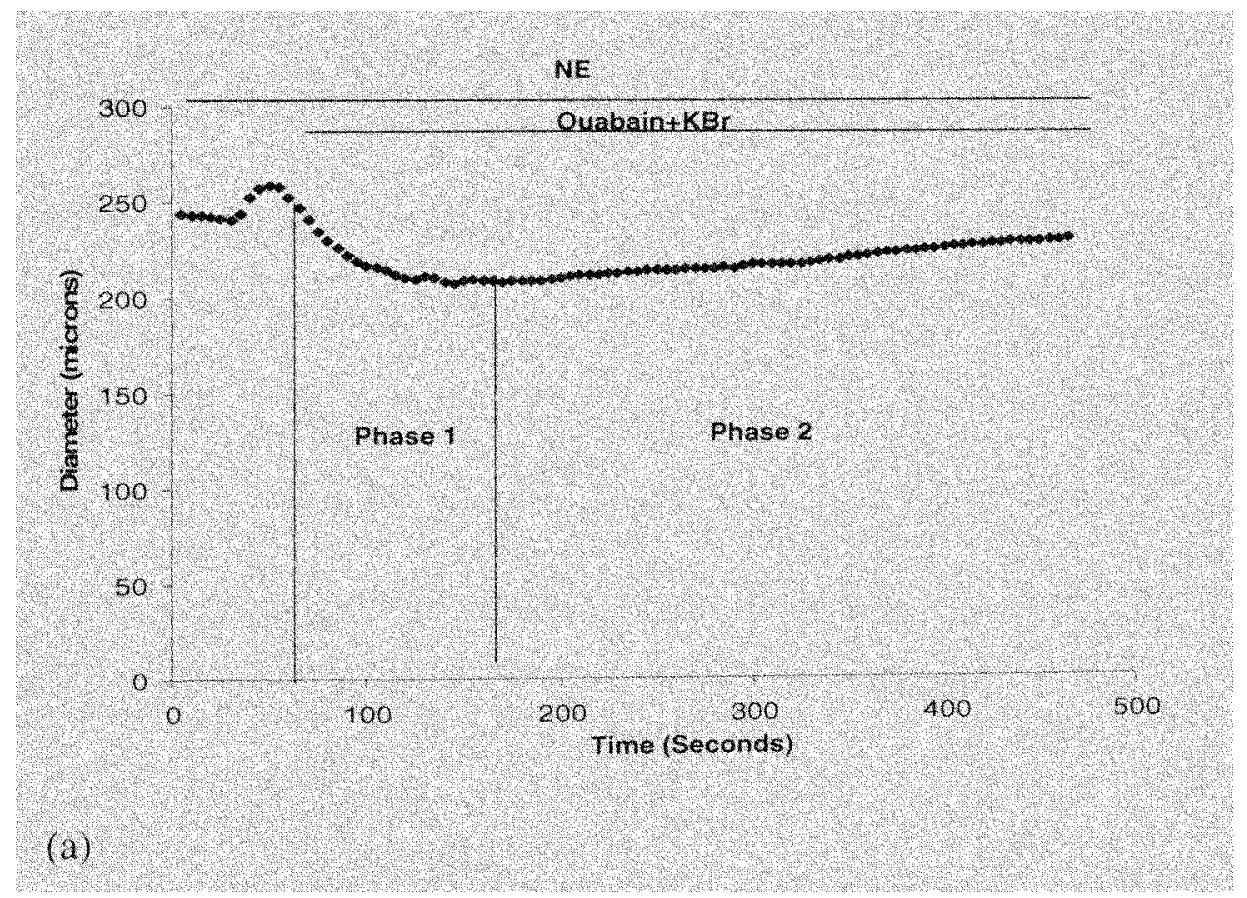




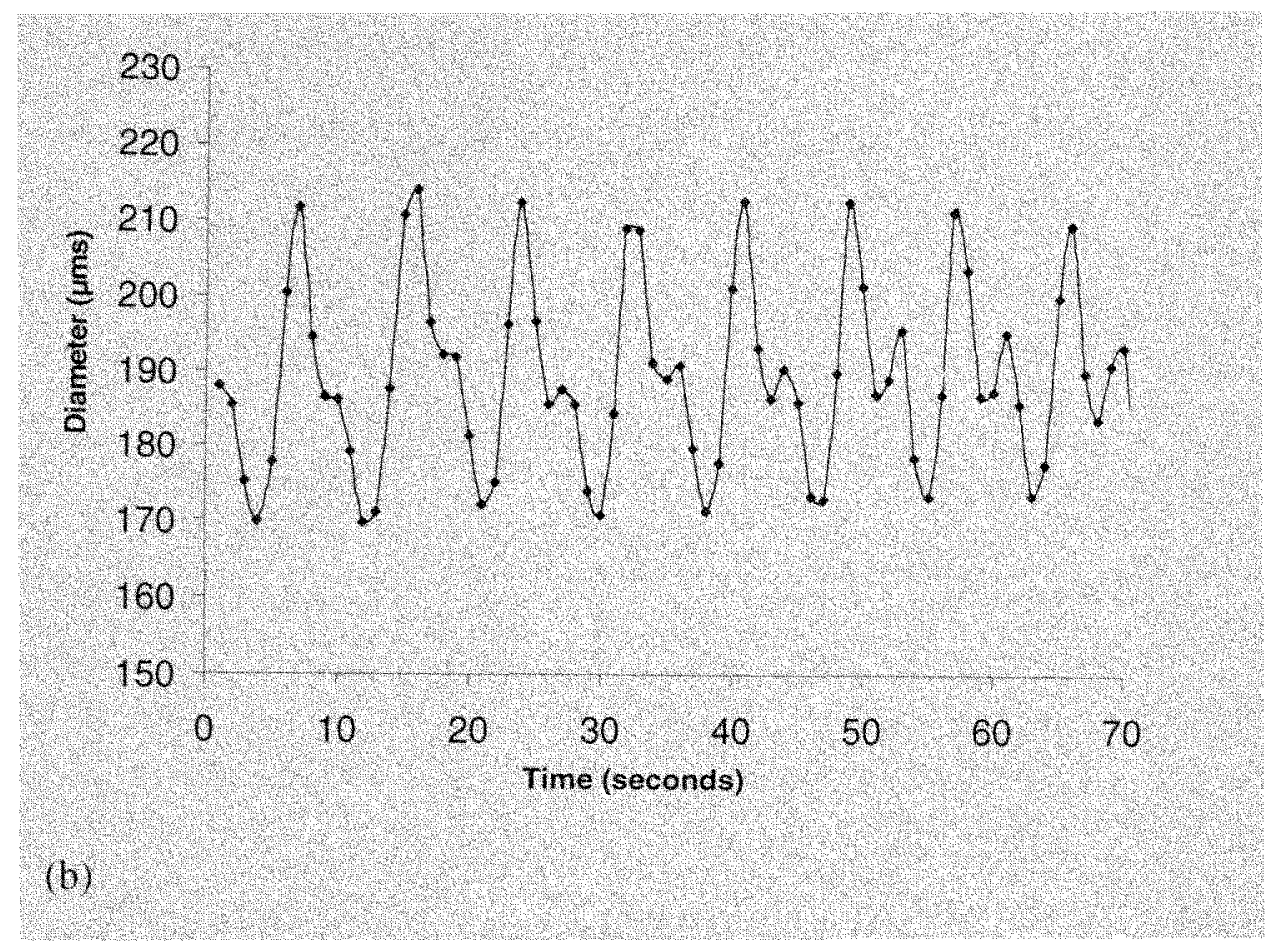

Figure 18: Effect of NCX blockade with $2 \mu \mathrm{M}$ KB-R7943 on NE induced constriction in the presence of ouabain.

In (a) transient response from a single experiment is shown. The vessel constricts initially after addition of $2 \mu \mathrm{M} \mathrm{KBr}$ and $1 \mu \mathrm{M}$ ouabain in the presence of $0.5 \mu \mathrm{M} \mathrm{NE}$ followed by a relaxation. In (b) the effect of KB-R7943 on NE induced vasomotion is shown. The time period of diameter oscillation increases to 8 seconds.

\subsubsection{Ach-induced dilation in the presence of Ouabain}

All the concentrations of Ach solutions ( $\operatorname{lnM}$ to $100 \mu \mathrm{M})$ were perfused through the isolated intact rat mesenteric arteries preconstricted with $0.5 \mu \mathrm{M} \mathrm{NE}$ and $100 \mathrm{nM}$ ouabain. The effect of $\mathrm{Na}^{+} / \mathrm{K}^{+}$ATPase blocker on Ach mediated dilations was studied in vessels presconstricted to approximately $50 \%$ of its initial diameter. Raw data from 4 rats is shown in Fig. 19a whereas data as percentage mean relaxation \pm SEM is shown in Fig. $19 \mathrm{~b}$. Presence of ouabain significantly impaired Ach induced vasodilation to $29.5( \pm 2.2)$ $\%$ compared to $95 \pm 4.5 \%$ relaxation (in ouabain absence). Fig. $19 \mathrm{c}$ shows a comparison of the Ach-induced dilation in the presence and absence of ouabain. The values of 
relaxations which were statistically different are shown on the curve. The $\mathrm{EC}_{50}$ obatined with ouabain was $10( \pm 3) \mathrm{nM}$ which was statistically reduced compared to the $\mathrm{EC}_{50}$ in ouabain absence $(50 \pm 24 \mathrm{nM})$.

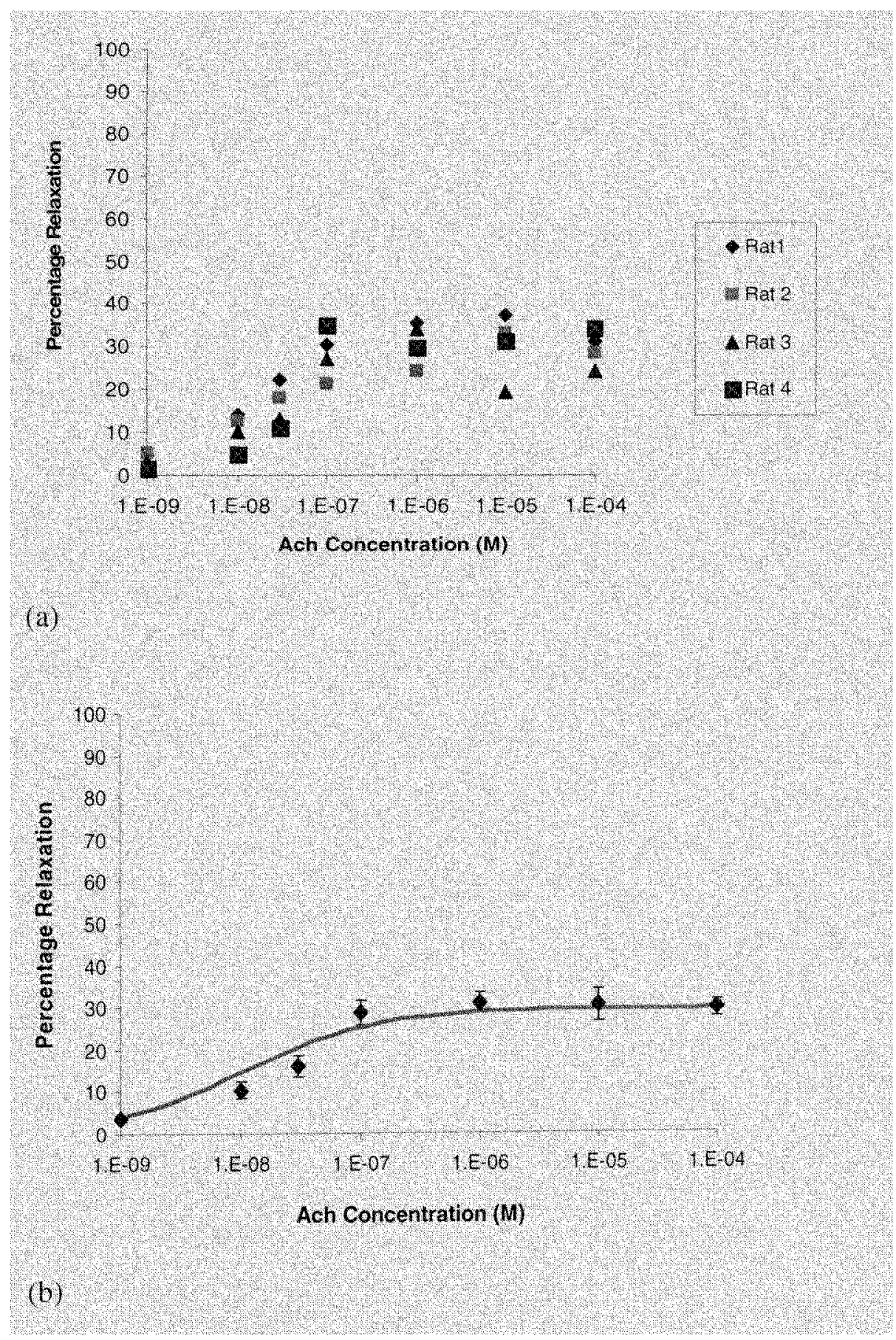




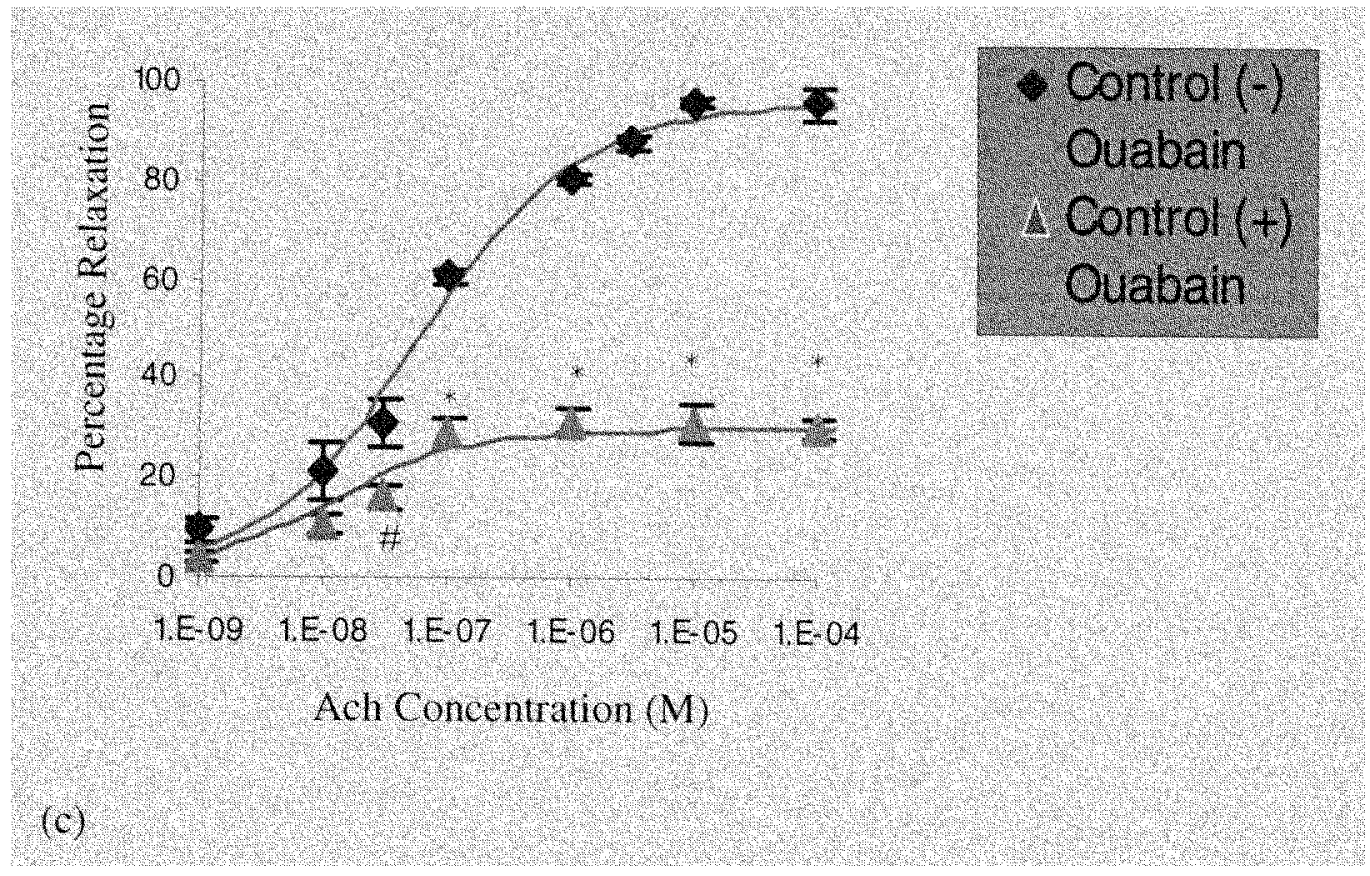

Figure 19: Ach induced relaxation response in isolated intact rat mesenteric arterioles preconstricted with $0.5 \mathrm{uMNE}$ and $100 \mathrm{nM}$ ouabain.

In (a) raw data is shown; $(n=4)$ whereas in (b) the data is expressed as percentage mean relaxation $\pm S E M ;(n=4)$. (c) shows a comparison of Ach-induced dilation in the presence and absence of ouabain. $*(p<0.01)$ and $\#(p<0.05)$.

\section{Effect of L-Name on Ach-induced dilation in presence of Ouabain}

The effect of eNOS blockade on Ach induced relaxation response in the presence of ouabain was studied in rat mesenteric vessels. eNOS blockade did not significantly effect Ach induced relaxation in the presence of ouabain. The maximum relaxation obtained in this case was $30.5( \pm 2.5) \%$ and the $\mathrm{EC}_{50}$ reduced to $82( \pm 3) \mathrm{nM}$. Fig. 20 a shows raw data from four rat experiments showing Ach induced relaxation response in the presence of L-Name whereas in Fig. $20 \mathrm{~b}$ the data is expressed as percentage mean relaxation \pm SEM. Fig. 20c shows the comparison of Ach induced relaxation response with and without eNOS blockade in the presence of ouabain. 


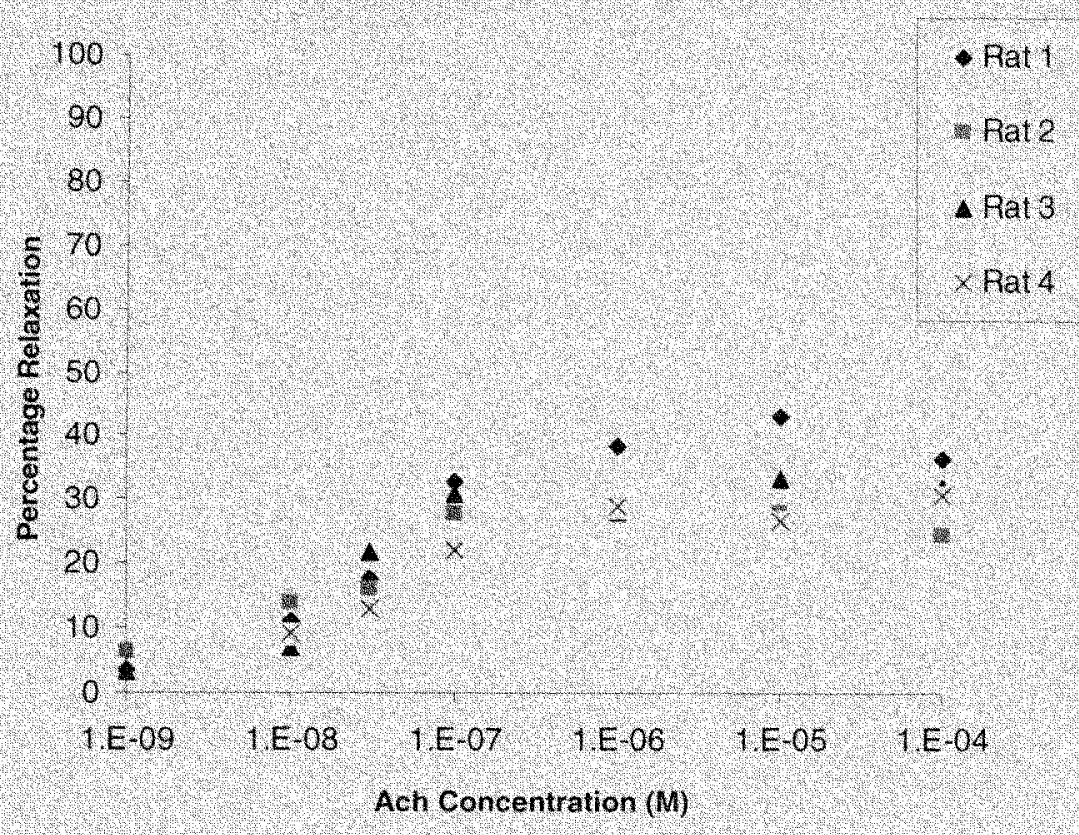

(a)

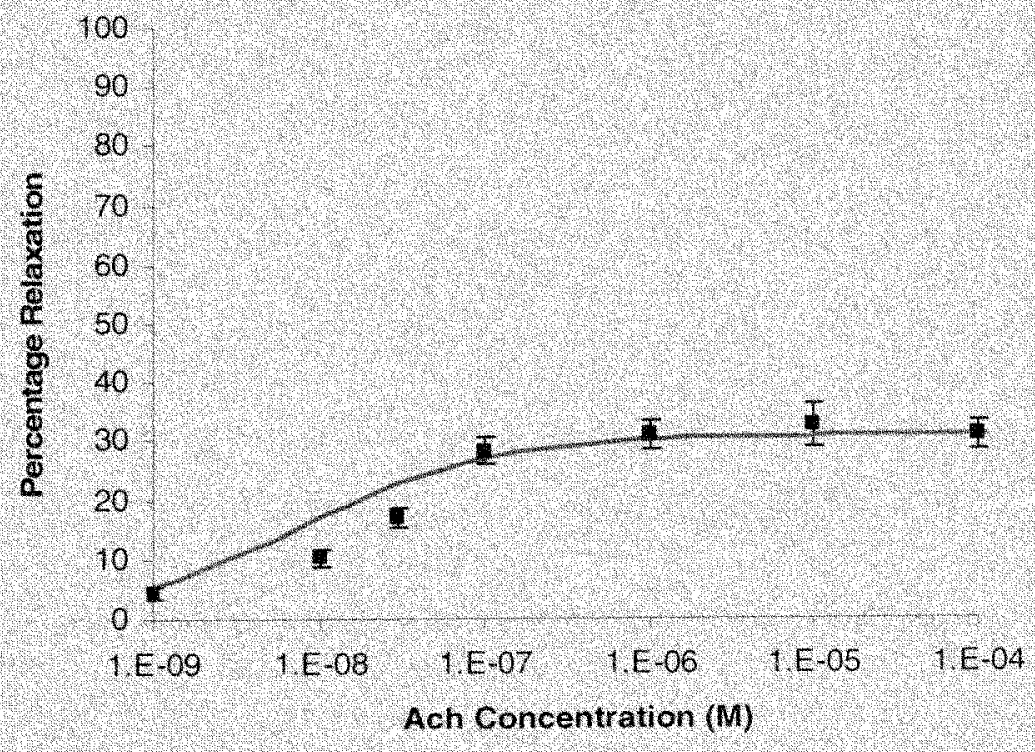

(b) 


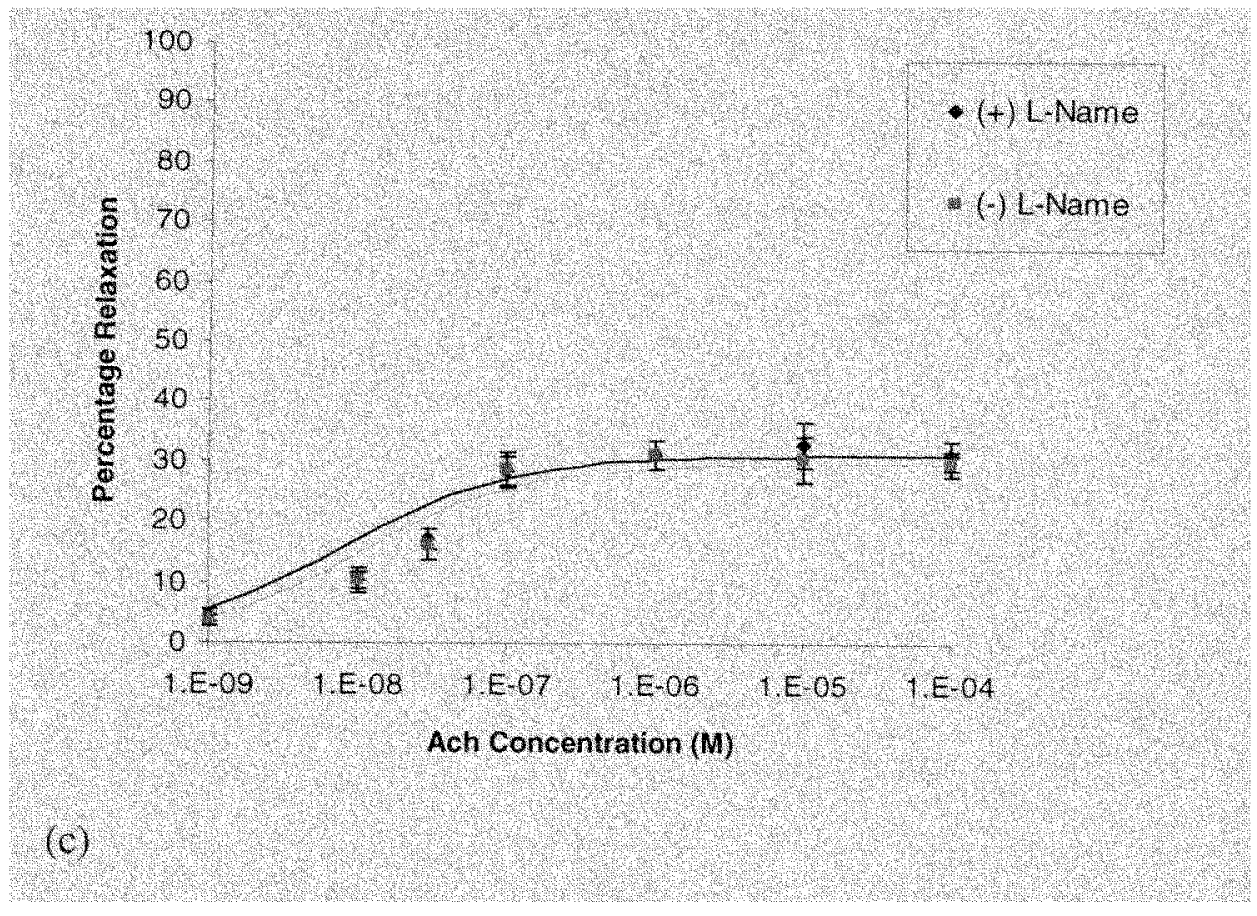

Figure 20: Effect of NOS blockade on Ach-induced relaxation response in the presence of 100nM Ouabain.

In (a) raw is shown $(n=4)$ whereas in (b) the data is expressed as percentage mean relaxation \pm SEM $(n=4)$. (c) shows the comparison of Ach relaxation response with and without NOS blockade in the presence of ouabain. The eNOS blockade (in the presence of ouabain) did not affect the Ach induced dilation significantly.

\subsubsection{Effect of EDHF blockade on Ach induced relaxation in presence of Ouabain}

The blockade of NO as well as EDHF pathways was again performed as done before for control studies and the Ach induced relaxation response was studied in presence of $\mathrm{Na}^{+} / \mathrm{K}^{+}$ATPase blocker, Ouabain. Similar protocol was followed to block the $\mathrm{SK}_{\mathrm{Ca}}$ and $\mathrm{IK}_{\mathrm{Ca}}$ channels in the rat mesenteric arteriolar endothelium as used earlier for control studies. The $\mathrm{SK}_{\mathrm{Ca}}$ and $\mathrm{IK}_{\mathrm{Ca}}$ channels were blocked in the presence of L-Name. Since prostacyclin was not found to play a significant role in Ach induced dilation, indomethacin was not used in this case. Raw data from four rat experiments is shown in Fig. $21 \mathrm{a}$ whereas data is expressed as percentage mean relaxation \pm SEM in Fig. $21 \mathrm{~b}$. 
Blockade of EDHF pathway nearly abolished the Ach induced vasodilation. The maximum relaxation obtained in this case was $9( \pm 3.5) \%$. Fig. $21 \mathrm{c}$ shows the comparison of blockade of all the pathways on Ach-induced dilation in the presence of ouabain.

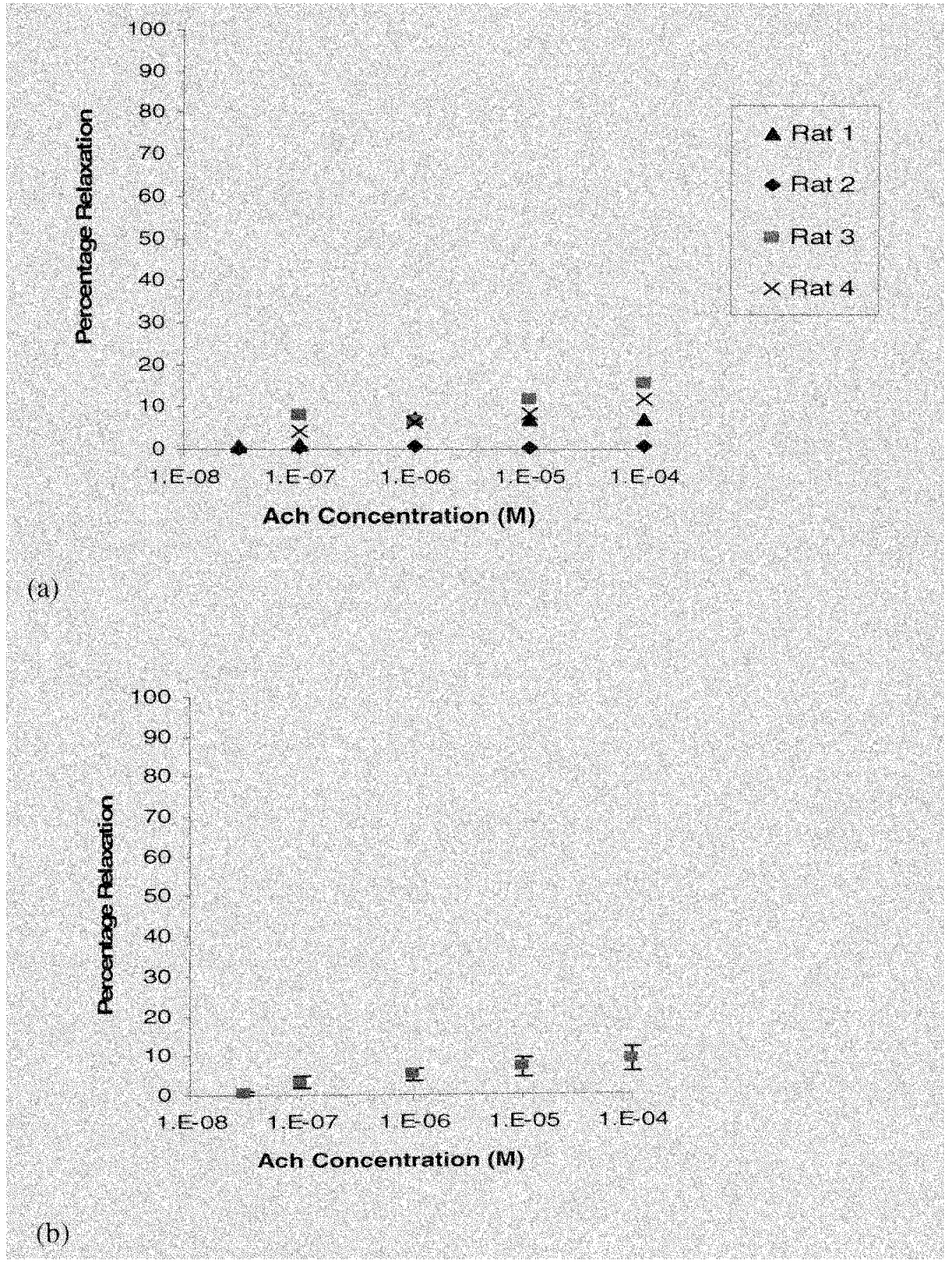




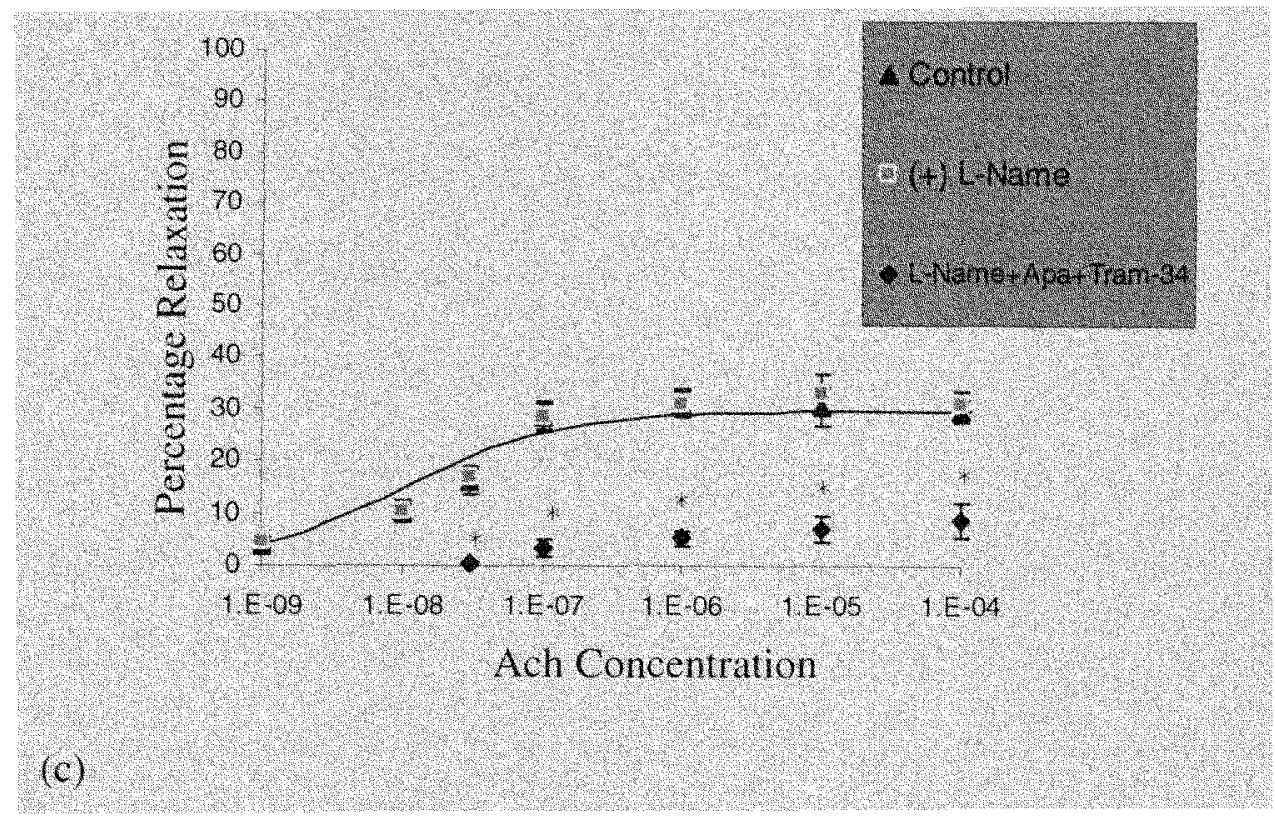

Figure 21: Effect of eNOS and EDHF blockade on Ach-induced relaxation in isolated intact rat mesenteric arterioles preconstricted with $0.5 \mathrm{uM} \mathrm{NE}$ and $100 \mathrm{nM}$ ouabain.

In (a) raw data is shown $(n=4)$ whereas in (b) data is expressed as percentage mean relaxation $\pm S E M(n=4)$. (c) shows a comparison of blocking all the relaxation pathways on Ach-induced relaxation in the presence of ouabain. Points that are significantly different from control are denoted with $*(\mathrm{p}<0.01)$.

\subsection{DISCUSSION}

\section{Pressure vs. Diameter}

The percentage increase in resting diameter of the vessels was plotted as a function of intra-luminal pressure. In this study, we found that on increasing the intraluminal pressure to $80 \mathrm{mmHg}$, the microvessel relaxed by $44.5(+1.5) \%$ as well as the slope of the curve almost reached a plateau at $80 \mathrm{mmHg}$. This finding is consistent with other studies who have reported the diameter increases as a function of intra-luminal pressure in isolated cannulated rat mesenteric arteries $(5,111)$. 


\section{NE induced Vasoconstriction}

NE increases the $\mathrm{SMC} \mathrm{Ca}{ }^{2+}$ through $\mathrm{IP}_{3}$ pathway thereby causing constriction. In this study, NE induced a dose dependent constriction in rat mesenteric arterioles showing an intact and functional SM layer. Few studies have previously reported NE induced constriction response curves $(5,111,112)$. This study reports a maximum constriction of $46.5( \pm 1.5 \%)$ and $\mathrm{EC}_{50}$ of $0.46 \pm 0.15 \mu \mathrm{M}$ which is in close agreement with previous studies of Poureguard et al who reported a maximum constriction of $40( \pm 5 \%)$ and an $\mathrm{EC}_{50}$ of $0.72( \pm 0.1) \mu \mathrm{M}(112)$. Also the maximum constriction was observed at $3 \mu \mathrm{M} \mathrm{NE}$ which is in close agreement with Poureguard's study. However, some studies have reported a higher maximum constriction of up to $80 \%$ as well as a higher $\mathrm{EC}_{50}$ of the order of $3.35 \mu \mathrm{M}(85)$.

Schuster et al (121) has reported that in-vitro observation of vasomotion is highly dependent on the proper handling of the vessel. The occurrence of vasomotion is highly dependent on the integrity and functionality of ion channels and gap junctions present in SMC which can be easily disrupted during the dissection and cannulation of the vessels. In this study, we observed vasomotion almost every time thus ensuring good vessel handling. In this study, vasomotion was observed at $\mathrm{NE}$ concentration range of $0.4 \mu \mathrm{M}$ to $1 \mu \mathrm{M}$ which is in agreement with Schuster's findings. The time period of diameter oscillations observed in this study was $4.0( \pm 1.5)$ seconds which is in close agreement with a time period of $5.0( \pm 1.1)$ seconds as observed by Schuster et al (121).

\section{Ach induced relaxation responses}

Ach induces vasorelaxation by stimulating endothelial mediated release of NO, prostacyclin and EDHF. Various studies have been performed to study the relative 
contribution of NO, prostacyclin and EDHF in vasodilation of rat mesenteric arterioles. Dose-dependent diameter response curves to different Ach concentrations have been widely published in literature as Ach causes relaxation involving all the three pathways. In most of the studies, various groups preconstricted the mesenteric arterioles to approximately $50 \%$ of maximum constriction using NE or a similar vasoconstrictor thereafter perfusing different Ach solutions with concentrations ranging from $\operatorname{lnM}$ to $100 \mu \mathrm{M}$.

However, to study the contribution of individual pathway, different blockers have been used to block individual pathways. NO synthase blocker L-Name has been widely used to inhibit the production of NO in the endothelium, Indomethacin is used as a COX1 blocker to inhibit prostacyclin induced dilation and $\mathrm{K}_{\mathrm{Ca}}$ channel blockers are used to inhibit the EDHF effect. In rat mesenteric arterioles, the endothelium is found to contain $\mathrm{IK}_{\mathrm{Ca}}$ and $\mathrm{SK}_{\mathrm{Ca}}$ only. Thus specific blockers for $\mathrm{SK}_{\mathrm{Ca}}$ (Apamin) and $\mathrm{IK}_{\mathrm{Ca}}(\mathrm{Tram}-34,39)$ have been used to prevent vasodilation due to hyperpolarization. Other studies in rat mesenteric arterioles have also used a cocktail of apamin and charybdotoxin (blocker of $I K_{\mathrm{Ca}}$ and $\left.\mathrm{BK}_{\mathrm{Ca}}\right)$ to abolish EDHF effect.

From past literature, Ach is able to completely reverse the NE induced constriction in almost all the studies performed on rat vessels $(16,17,23,32,34,37,46$, $62,64,77,78,105,106,125,129)$. These studies report a maximum relaxation in the range $(85-100) \%$ and $\mathrm{EC}_{50}$ values in the range $(30-155) \mathrm{nM}$ This study reports a complete relaxation of $\mathrm{NE}$ induced constriction, thus supporting all the previous published data. The $\mathrm{EC}_{50}$ value for Ach induced relaxation was found to be $50 \pm 24 \mathrm{nM}$ which is in close agreement with the $\mathrm{EC}_{50}$ values published before. However, some 
variation in $\mathrm{EC}_{50}$ values is expected due to different levels of preconstrictions used in various studies.

Contribution of prostacyclin in Ach induced vasodilation was studied by blocking COX-1 using indomethacin $(10 \mu \mathrm{M})$. Previous experimental studies on rat mesenteric arteries show that prostacyclin does not have a significant contribution in Ach induced dilation $(16,17,23,32,34,37,46,62,64,77,78,105,106,125,129)$. These studies have obtained maximum relaxation in the presence of Indomethacin in the range (90-100) $\%$ and an $\mathrm{EC}_{50}$ in the range quite similar to control conditions (49-185) nM. The results of this study are consistent with these findings as the maximum relaxation produced in the presence of indomethacin was found to be $90.5( \pm 1.5) \%$ whereas $\mathrm{EC}_{50}$ value was also not significantly affected $(75 \pm 17 \mathrm{nM})$. However, very few studies (83) have reported a significant effect of indomethacin in rat mesenteric arterioles (maximum relaxation $60.5+4.5)$

However, blocking NO synthase using L-Name $(350 \mu \mathrm{M})$ has shown to have a significant effect on Ach induced relaxation thereby providing evidence of a significant role endothelial-derived NO in causing vasodilation in rat mesenteric arteries. Previous experimental studies on rat microvessels have reported a significant decrease in Ach induced dilation in the presence of L-Name $(16,17,23,32,34,37,46,62,64,77,78$, $105,106,125,129)$. These studies have reported a maximum relaxation after eNOS blockade in the range (48-82) \% and an $\mathrm{EC}_{50}$ value between $(65-300) \mathrm{nM}$. In this study, presence of $\mathrm{L}-\mathrm{Name}$ reduced the Ach-induced maximum relaxation to $54.5( \pm 3.5) \%$ whereas the $\mathrm{EC}_{50}$ value was also not significantly affected $(45 \pm 32 \mathrm{nM})$. 
EDHF-mediated responses involve an increase in the intracellular EC calcium concentration causing the opening of calcium-activated potassium channels $\left(\mathrm{SK}_{\mathrm{Ca}}\right.$ and $\mathrm{IK}_{\mathrm{Ca}}$ only in case of rat mesenteric arterioles) present in the endothelial cells leading to their hyperpolarization. This results in an endothelium-dependent hyperpolarization of the smooth muscle cells, causing vessel relaxation by decreasing the concentration of cytoplasmic free $\mathrm{Ca}^{2+}$ by closure of voltage-operated $\mathrm{Ca}^{2+}$ channels in the smooth muscle cell membrane. Thus, blockade of $\mathrm{SK}_{\mathrm{Ca}}$ and $\mathrm{IK}_{\mathrm{Ca}}$ should eliminate EDHF-mediated relaxation in rat mesenteric arterioles. Various studies have been performed using a cocktail of apamin $(10 \mu \mathrm{M})$ along with either of Tram-34, Tram-39, Charybdotoxin or Iberiotoxin. Perfusing these blockers in the presence of L-Name and Indomethacin has been found to almost completely abolish the vasodilation $(16,32,34,37,46,62,64,77$, $78,105,106,125)$. These studies have reported a maximum relaxation in the range $(0-12)$ $\%$. In this study, we found a maximum relaxation of $13.5( \pm 3.5)$. Although the relaxation was greatly reduced, it wasn't completely abolished. This may be due to incomplete blockade of $\mathrm{K}^{+}$channels or involvement of some other pathway.

Table 3 shows a comparison of the results of this study with previous reports for Achinduced dilation (in the presence of various blockers) in the absence of ouabain.

\begin{tabular}{|l|c|c|}
\hline & \% Maximum Relaxation & \\
\hline & Previous Studies & This Study \\
Control & $(85-100) \%$ & $(95 \pm 4.5) \%$ \\
Indomethacin & $(90-100) \%$ & $(90.5 \pm 1.5) \%$ \\
Indo+L-Name & $(48-82) \%$ & $(53.5 \pm 3.5) \%$ \\
All Blockers & $(0-12) \%$ & $(13.5 \pm 3.5) \%$ \\
\hline
\end{tabular}


$\mathrm{EC}_{50}(\mathrm{nM})$

\begin{tabular}{|l|c|c|}
\hline & Previous Studies & This Study \\
\hline Control & $(30-155)$ & $(50 \pm 24)$ \\
Indomethacin & $(49-185)$ & $(75 \pm 15)$ \\
Indo+L-Name & $(65-300)$ & $(45 \pm 22)$ \\
\hline
\end{tabular}

Table 3: A comparison of $\%$ maximum relaxation and $\mathrm{EC}_{50}$ values obtained in this study with previous reports for Ach-induced dilation in rat vessels (in the absence of ouabain).

\section{Effect of Ouabain on NE induced Vasoconstriction}

Cardiotonic steroids, including the adrenal cortical hormone ouabain, have been proposed to play a role in some forms of hypertension as its production is reported to increase in the state of hypertension. Ouabain may affect microcirculatory vascular resistance through inhibition of the $\mathrm{Na}^{+} / \mathrm{K}^{+}$ATPase; leading to an accumulation of $\mathrm{Na}^{+}$ inside the cell, reversal of the $\mathrm{Na}^{+} / \mathrm{Ca}^{2+}$ exchanger ( $\mathrm{NCX}$ ), and accumulation of $\mathrm{Ca}^{2+}$ in the cytosol. In this study, we tested the effect of ouabain on NE induced vasoconstriction. There haven't been any studies reporting concentration-response curves to NE induced constriction in the presence of ouabain. The concentration of ouabain used in this study $(100 \mathrm{nM})$ is higher than the physiological/pathological levels in the body (1pm-10nM). Using lower ouabain concentrations has experimental limitations as its effect cannot be seen on vessel diameter responses. Also, using supra-physiological concentration provides a good tool to study the effects of ouabain on all the pathways involved in regulating vessel diameter. The maximum constriction obtained in presence of ouabain increased to $50( \pm 2) \%$ compared to a maximum constriction of $46.5( \pm 2.5) \%$ obtained in the absence of ouabain. 
Although, the increase caused due to ouabain is not statistically significant, it is important to note that blood pressure is inversely proportional to the fourth power of vessel diameter and hence small changes in diameter can significantly affect blood pressure. In this study, vasomotion did not abolish in the presence of $1 \mu \mathrm{M}$ ouabain which is in contradiction with some studies (53), but consistent with others (121). The abolishment of vasomotion observed by some groups could be due to a difference in the tissue studied or partially impaired vessel leading to abolishment of vasomotion.

\section{Effect of NCX blocker}

The $\mathrm{Na}^{+} / \mathrm{Ca}^{2+}$ exchanger was blocked using $2 \mu \mathrm{M} \mathrm{KB}-\mathrm{R} 7943$ solution. Addition of KB-R7943 $(2 \mu \mathrm{M})$ along with ouabain $(1 \mu \mathrm{M})$ to NE preconstricted vessel gave a bi-phasic response, with at first as expected for a blockade of $\mathrm{Na}^{+} / \mathrm{K}^{+}$ATPase pump, caused an initial constriction due to ouabain effect (an increase in $\mathrm{SMC} \mathrm{Na}^{+}$leading to reversal in direction of NCX thereby causing SMC Ca ${ }^{2+}$ increase). However, after some time (100s) the NCX blocker effect becomes predominant leading to a relaxation (As KB-R7943 blocks the NCX operating in reverse mode, thereby reducing SMC $\mathrm{Ca}^{2+}$ ). However again, the diameter oscillations were not abolished and resulted in a higher time period as reported by Schuster (108).

\section{Effect of $\mathrm{Na}^{+} / \mathrm{K}^{+}$ATPase blockade on Ach-induced vasodilation}

Effect of $\mathrm{Na}^{+} / \mathrm{K}^{+}$ATPase pump blockade on Ach-induced dilation has an important significance in understanding the role of ouabain in hypertension. Very few studies have been performed to study this effect and hence very limited data is available in the literature. Some studies found an impairment in relaxation to Ach in some vascular beds $(30,137)$ whereas some tissues did not exhibit any difference $(18,128)$. There is no 
data on ouabain effect on Ach-induced dose curve in rat mesenteric arteries which is provided by this study. Interpretation of experimental findings is complicated by inherited limitations in traditional studies of vascular reactivity. Chang et al. (15) point out that the vast majority of experimental studies utilize isolated vascular rings of large vessels and not vessels from the microcirculation, where blood flow and pressure is mostly controlled. Large arteries may behave significantly different than resistance arterioles. In this study, presence of $100 \mathrm{nM}$ ouabain along with $0.5 \mu \mathrm{M} \mathrm{NE}$ was able to significantly impair Ach-induced relaxation $(\mathrm{p}<0.01)$. The maximum relaxation was obtained as $29.5( \pm 2.5) \%$ compared to $95( \pm 4.5) \%$ obtained without ouabain.

One of the limitations of this study was the use of high concentration of ouabain. The pathological concentration of ouabain is $\sim 10 \mathrm{nM}$ whereas the concentration of ouabain used in this study was $100 \mathrm{nM}$. Lower concentrations of ouabain did not induce any measurable difference in NE-induced constriction and hence this study utilized a higher concentration to study its effect. However, the effect of $10 \mathrm{nM}$ ouabain on Achinduced relaxation should be studied in future.

The mechanism of ouabain-induced inhibition of relaxation remains controversial. To test the hypothesis that ouabain impairs the NO mediated vasodilation, L-Name was perfused to block the NO production followed by application of different Ach concentrations. Surprisingly, there was no significant difference in the presence and absence of L-Name, thus confirming the significant effect of ouabain on NO pathway in Ach-mediated vasodilation in rat mesenteric arterioles.

The ouabain-induced compromise in NO-mediated relaxation can be due to many reasons. Firstly, ouabain may impair the ability of endothelium to produce NO thereby 
compromising its effect. This can be verified by studying relaxation on perfusing exogenous NO solutions or studying the NO production by loading NO-sensitive dye DAF-FM to check for NO production in the presence of ouabain.

A second explanation can be due to $\mathrm{SMC} \mathrm{Ca}{ }^{2+}$. NO causes relaxation by opening the $\mathrm{BK}_{\mathrm{Ca}}$ channels (directly or indirectly) and thereby causing SMC hyperpolarization. The resulting hyperpolarization results in the closure of VGCC thereby inhibiting $\mathrm{Ca}^{2+}$ entry into SMC. However in the presence of ouabain, $\mathrm{Na}^{+} / \mathrm{K}^{+}$ATPase blockade causes an increase in $\mathrm{SMC} \mathrm{Na}{ }^{+}$resulting in a reduced $\mathrm{Ca}^{2+}$ efflux through $\mathrm{NCX}$ leading to an inversion of $\mathrm{NCX}$ thereby causing $\mathrm{Ca}^{2+}$ entry. Thus, in this scenario, although NO inhibits $\mathrm{Ca}^{2+}$ entry through VGCC, SMC $\mathrm{Ca}^{2+}$ continues to increase because of the reverse operating mode of NCX thereby inhibiting relaxation. To test this hypothesis, more studies need to be performed by applying NCX blocker (KB-R9743) and perfusing Ach in presence of ouabain. A restored relaxation on application of KB-R7943 will provide strong evidence supporting the above hypothesis.

Ouabain induced impaired relaxation can also be attributed to a loss of $\mathrm{K}^{+}$ gradient in SMC. As the $\mathrm{Na}^{+} / \mathrm{K}^{+}$ATPase pump blockade leads to a reduced intracellular $\mathrm{K}^{+}$(along with increased $\mathrm{Na}^{+}$), this reduced $\mathrm{K}^{+}$can impair the ability of the SMC to hyperpolarize. As discussed earlier, NO exerts its effect by hyperpolarizing SMC (i.e.by opening $\mathrm{BK}_{\mathrm{Ca}}$ channels leading to loss of intracellular $\mathrm{K}^{+}$). Reduced intracellular $\mathrm{K}^{+}$ concentration due to oubain can lead to a reduced SMC hyperpolarization which in turn may lead to delayed or partial inhibition of VGCC (thereby increasing SMC $\mathrm{Ca}^{2+}$ ). Thus NO effect can be compromised again and hence more studies need to be performed by 
monitoring the SMC membrane potential during Ach perfusion in the presence of ouabain.

The relaxation observed after eNOS blockade shows the contribution of EDHF-mediated relaxation. In this study, ouabain was also found to impair EDHF-mediated relaxation although partially. Since, EDHF produces relaxation by hyperpolarizing SMC, we can suggest from the above two findings that ouabain plays a role in compromising SMC hyperpolarization. However, more significant loss of NO mediated relaxation may be due to combined effect of less SMC hyperpolarization and NO production by the endothelium.

Thus, further studies needs to be carried out to study the action mechanism of ouabain which can lead to design preliminary clinical studies to find a treatment of ouabain induced hypertension.

\subsection{Conclusion}

This study has been successful in establishing a system for in-vitro experimentation on isolated microvessels. The study investigated vascular reactivity by studying the effects of vasoconstrictor $\mathrm{NE}$ and vasorelaxant Ach in the presence and absence of adrenal cortical hormone, ouabain. NE resulted in a dose dependent constriction of the microvessel with and without ouabain. However, the maximum constriction was slightly but not significantly increased in the presence of ouabain. This suggests that high ouabain levels do not increase the sensitivity of microvessels to vasoconstrictors significantly. Ach was able to completely reverse the NE induced constriction in the absence of ouabain. Prostanoids did not play a significant role in Ach mediated vasodilation whereas 
NO and EDHF contributed almost equally in the absence of ouabain. Ach-induced relaxation was significantly impaired in the presence of ouabain. The NO pathway was significantly impaired in the presence of ouabain whereas the EDHF pathway was partially compromised. Thus during ouabain-induced hypertension, high ouabain levels lead to higher blood pressure as the arteriolar diameters are smaller. Ouabain impairs relaxation to vasodilators much more significantly than enhance constriction to vasoconstrictors. 


\section{REFERENCES}

1. Adams DJ and Hill MA. Potassium channels and membrane potential in the modulation of intracellular calcium in vascular endothelial cells. J Cardiovasc Electrophysiol 15: 598-610, 2004.

2. Angus JA and Cocks TM. Vasodilatation and the discovery of endotheliumderived relaxing factor. Med J Alist 146: 250-253, 1987.

3. Ashida T, Kawano Y, Yoshimi H, Kuramochi M, and Omae T. Effects of dietary salt on sodium-calcium exchange and ATP-driven calcium pump in arterial smooth muscle of Dahl rats. J Hypertens 10: 1335-1341, 1992.

4. Ashida T, Kuramochi M, and Omae T. Increased sodium-calcium exchange in arterial smooth muscle of spontaneously hypertensive rats. Hypertension 13: 890-895, 1989.

5. Bakker EN, Buus CL, VanBavel E, and Mulvany MJ. Activation of resistance arteries with endothelin-1: from vasoconstriction to functional adaptation and remodeling. $J$ Vasc Res 41: 174-182, 2004.

6. Ballou DP, Zhao Y, Brandish PE, and Marletta MA. Revisiting the kinetics of nitric oxide (NO) binding to soluble guanylate cyclase: the simple NO-binding model is incorrect. Proc Natl Acad Sci U S A 99: 12097-12101, 2002.

7. Baron A, Frieden M, and Beny JL. Epoxyeicosatrienoic acids activate a highconductance, $\mathrm{Ca}(2+)$-dependent $\mathrm{K}+$ channel on pig coronary artery endothelial cells. $J$ Physiol 504 ( Pt 3): 537-543, 1997.

8. Beny JL and Brunet PC. Electrophysiological and mechanical effects of substance $\mathrm{P}$ and acetylcholine on rabbit aorta. J Physiol 398: 277-289, 1988.

9. Berridge MJ, Lipp P, and Bootman MD. The versatility and universality of calcium signalling. Nat Rev Mol Cell Biol 1: 11-21, 2000.

10. Blaustein MP. Sodium ions, calcium ions, blood pressure regulation, and hypertension: a reassessment and a hypothesis. Am J Physiol 232: C165-173, 1977.

11. Brock TG, McNish RW, and Peters-Golden M. Arachidonic acid is preferentially metabolized by cyclooxygenase- 2 to prostacyclin and prostaglandin E2. $J$ Biol Chem 274: 11660-11666, 1999.

12. Budel S and Beny JL. The role of the sodium-calcium exchanger for calcium extrusion in coronary arteries, Life Sci 67: 549-557, 2000. 
13. Bunting S, Gryglewski R, Moncada S, and Vane JR. Arterial walls generate from prostaglandin endoperoxides a substance (prostaglandin $\mathrm{X}$ ) which relaxes strips of mesenteric and coeliac ateries and inhibits platelet aggregation. Prostaglandins 12: 897$913,1976$.

14. Catella-Lawson F, McAdam B, Morrison BW, Kapoor S, Kujubu D, Antes L, Lasseter KC, Quan H, Gertz BJ, and FitzGerald GA. Effects of specific inhibition of cyclooxygenase- 2 on sodium balance, hemodynamics, and vasoactive eicosanoids. $J$ Pharmacol Exp Ther 289: 735-741, 1999.

15. Chang IIR, Lee RP, Wu CY, and Chen HI. Nitric oxide in mesenteric vascular reactivity: a comparison between rats with normotension and hypertension. Clin Exp Pharmacol Physiol 29: 275-280, 2002.

16. Chauhan S, Rahman A, Nilsson H, Clapp L, MacAllister R, and Ahluwalia A. NO contributes to EDHF-like responses in rat small arteries: a role for NO stores. Cardiovascular Research 57: 207-216, 2003.

17. Chen G and Cheung DW. Modulation of endothelium-dependent hyperpolarization and relaxation to acetylcholine in rat mesenteric artery by cytochrome P450 enzyme activity. Circ Res 79: 827-833, 1996.

18. Chen G, Hashitani H, and Suzuki H. Endothelium-dependent relaxation and hyperpolarization of canine coronary artery smooth muscles in relation to the electrogenic Na-K pump. Br J Pharmacol 98: 950-956, 1989.

19. Chen G, Suzuki H, and Weston AH. Acetylcholine releases endotheliumderived hyperpolarizing factor and EDRF from rat blood vessels. Br J Pharmacol 95 : $1165-1174,1988$.

20. Chen G, Yamamoto Y, Miwa K, and Suzuki H. Hyperpolarization of arterial smooth muscle induced by endothelial humoral substances. Am J Physiol 260: H1888$1892,1991$.

21. Chen PY and Sanders PW. L-arginine abrogates salt-sensitive hypertension in Dahl/Rapp rats. J Clin Invest 88: 1559-1567, 1991.

22. Cherian L, Goodman JC, and Robertson CS. Brain nitric oxide changes after controlled cortical impact injury in rats. J Neurophysiol 83: 2171-2178, 2000.

23. Clark SG and Fuchs LC. Role of nitric oxide and Ca++-dependent K+ channels in mediating heterogeneous microvascular responses to acetylcholine in different vascular beds. J Pharmacol Exp Ther 282; 1473-1479, 1997. 
24. Cohen RA and Vanhoutte PM. Endothelium-dependent hyperpolarization. Beyond nitric oxide and cyclic GMP. Circulation 92: 3337-3349, 1995.

25. Condorelli $\mathbf{P}$ and George SC. In vivo control of soluble guanylate cyclase activation by nitric oxide: a kinetic analysis. Biophys $J$ 80: $2110-2119,2001$.

26. Cowan CL and Cohen RA. Two mechanisms mediate relaxation by bradykinin of pig coronary artery: NO-dependent and -independent responses. Am J Physiol 261: H830-835, 1991.

27. Davis MJ and Hill MA. Signaling mechanisms underlying the vascular myogenic response. Physiol Rev 79: 387-423, 1999.

28. de la Sierra A, Lluch MM, Coca A, Aguilera MT, Giner V, Bragulat E, and Urbano-Marquez A. Fluid, ionic and hormonal changes induced by high salt intake in salt-sensitive and salt-resistant hypertensive patients. Clin Sci (Lond) 91: 155-161, 1996.

29. De Mey JG, Claeys M, and Vanhoutte PM. Endothelium-dependent inhibitory effects of acetylcholine, adenosine triphosphate, thrombin and arachidonic acid in the canine femoral artery. J Pharmacol Exp Ther 222: 166-173, 1982.

30. De Mey JG and Vanhoutte PM. Interaction between $\mathrm{Na}, \mathrm{K}+$ exchanges and the direct inhibitory effect of acetylcholine on canine femoral arteries. Circ Res 46: 826-836, 1980.

31. Dedkova EN, Ji X, Lipsius SL, and Blatter LA. Mitochondrial calcium uptake stimulates nitric oxide production in mitochondria of bovine vascular endothelial cells. Am J Physiol Cell Physiol 286: C406-415, 2004.

32. Ding $\mathbf{H}$, Kubes $\mathbf{P}$, and Triggle $\mathbf{C}$. Potassium- and acetylcholine-induced vasorelaxation in mice lacking endothelial nitric oxide synthase. $\mathrm{Br} J$ Pharmacol 129: 1194-1200, 2000.

33. Dora KA, Doyle MP, and Duling BR. Elevation of intracellular calcium in smooth muscle causes endothelial cell generation of NO in arterioles. PNAS 94:6529$6534,1997$.

34. Doughty JM, Plane F, and Langton PD. Charybdotoxin and apamin block EDHF in rat mesenteric artery if selectively applied to the endothelium. Am J Physiol Heart Circ Physiol 276: H1107-1112, 1999.

35. Duling BR, Gore RW, Dacey RG, Jr., and Damon DN. Methods for isolation, cannulation, and in vitro study of single microvessels. Am J Physiol 241: H108-116, 1981. 
36. Earley S, Heppner TJ, Nelson MT, and Brayden JE. TRPV4 forms a novel $\mathrm{Ca} 2+$ signaling complex with ryanodine receptors and $\mathrm{BKCa}$ channels. Circ Res 97 : $1270-1279,2005$.

37. Edwards G, Dora KA, Gardener MJ, Garland CJ, and Weston AH. K+ is an endothelium-derived hyperpolarizing factor in rat arteries. Nature 396: 269-272, 1998.

38. Ellis A and Triggle CR. Endothelium-derived reactive oxygen species: their relationship to endothelium-dependent hyperpolarization and vascular tone. Can $J$ Physiol Pharmacol 81: 1013-1028, 2003.

39. Faraci FM, Sobey CG, Chrissobolis S, Lund DD, Heistad DD, and Weintraub NL. Arachidonate dilates basilar artery by lipoxygenase-dependent mechanism and activation of $\mathrm{K}(+)$ channels. Am J Physiol Regul Integr Comp Physiol 281: R246-253, 2001.

40. Feletou M, Bonnardel E, and Canet E. Bradykinin and changes in microvascular permeability in the hamster cheek pouch: role of nitric oxide. $\mathrm{Br} J$ Pharmacol 118: 1371-1376, 1996.

41. Figueroa XF, Isakson BE, and Duling BR. Connexins: gaps in our knowledge of vascular function. Physiology (Bethesda) 19:277-284, 2004.

42. Fleming I. Cytochrome P450 2C is an EDHF synthase in coronary arteries. Trends Cardiovasc Med 10: 166-170, 2000.

43. Fleming 1. Cytochrome P450 epoxygenases as EDHF synthase(s). Pharmacol Res 49: 525-533, 2004.

44. Fleming I and Busse R. Vascular cytochrome P450 in the regulation of renal function and vascular tone: EDHF, superoxide anions and blood pressure. Nephrol Dial Transplant 16: 1309-1311, 2001.

45. Fleming WW. The electrogenic Nat, Kt-pump in smooth muscle: physiologic and pharmacologic significance. Annu Rev Pharmacol Toxicol 20: 129-149, 1980.

46. Fujii K, Ohmori S, Tominaga M, Abe I, Takata Y, Ohya Y, Kobayashi K, and Fujishima M. Age-related changes in endothelium-dependent hyperpolarization in the rat mesenteric artery. Am J Physiol 265: H509-516, 1993.

47. Furchgott RF. Endothelium-derived relaxing factor: discovery, early studies, and identification as nitric oxide. Biosci Rep 19:235-251, 1999.

48. Furchgott RF and Zawadzki JV. The obligatory role of endothelial cells in the relaxation of arterial smooth muscle by acetylcholine. Nature 288: 373-376, 1980. 
49. Gladwin MT, Crawford JH, and Patel RP. The biochemistry of nitric oxide, nitrite, and hemoglobin: role in blood flow regulation. Free Radical Biology and Medicine 36: 707-717, 2004.

50. Gollasch M, Lohn M, Furstenau M, Nelson MT, Luft FC, and Haller II. Ca2+ channels, $\mathrm{Ca} 2+$ sparks, and regulation of arterial smooth muscle function. $Z$ Kardiol 89 Suppl 2: 15-19, 2000.

51. Gonzalez-Fernandez $\mathbf{J M}$ and Ermentrout $\mathbf{B}$. On the origin and dynamics of the vasomotion of small arteries. Math Biosci 119: 127-167, 1994.

52. Goto $\mathbf{A}$ and Yamada K. Putative roles of ouabainlike compound in hypertension: revisited. Hypertens Res 23 Suppl: S7-13, 2000.

53. Gustafsson H. Vasomotion and underlying mechanisms in small arteries. An in vitro study of rat blood vessels. Acta Physiol Scand Suppl 614: 1-44, 1993.

54. Guyton AC and Coleman TG. Quantitative analysis of the pathophysiology of hypertension. 1969. J Am Soc Nephrol 10: 2248-2258, 1999.

55. Hamlyn JM, Blaustein MP, Bova S, DuCharme DW, Harris DW, Mandel F, Mathews WR, and Ludens JH. Identification and characterization of a ouabain-like compound from human plasma. Proc Natl Acad Sci U SA 88: 6259-6263, 1991.

56. Hamlyn JM, Hamilton BP, and Manunta P. Endogenous ouabain, sodium balance and blood pressure: a review and a hypothesis. J Hypertens 14: 151-167, 1996.

57. Hasegawa T, Masugi F, Ogihara T, and Kumahara Y. Increase in plasma oubainlike inhibitor of $\mathrm{Na}+\mathrm{K}+$-ATPase with high sodium intake in patients with essential hypertension. J Clin Hypertens 3: 419-429, 1987.

58. Hasunuma K, Yamaguchi T, Rodman DM, O'Brien RF, and McMurtry IF. Effects of inhibitors of EDRF and EDHF on vasoreactivity of perfused rat lungs. Am $J$ Physiol 260: L97-104, 1991.

59. Hayakawa H, Coffee K, and Raij L. Endothelial dysfunction and cardiorenal injury in experimental salt-sensitive hypertension: effects of antihypertensive therapy. Circulation 96: 2407-2413, 1997.

60. Hayakawa $\mathbf{H}$ and $\mathbf{R a i j} \mathbf{L}$. The link among nitric oxide synthase activity, endothelial function, and aortic and ventricular hypertrophy in hypertension. Hypertension 29: 235-241, 1997.

61. Hecker M. Endothelium-Derived Hyperpolarizing Factor-Fact or Fiction? News Physiol Sci 15: 1-5, 2000. 
62. Hinton JM and Langton PD. Inhibition of EDHF by two new combinations of

$\mathrm{K}+$-channel inhibitors in rat isolated mesenteric arteries. 138: 1031-1035, 2003.

63. Hu $\mathbf{L}$ and Manning RD, Jr. Role of nitric oxide in regulation of long-term pressure-natriuresis relationship in Dahl rats. Am J Physiol 268: H2375-2383, 1995.

64. Hwa JJ, Ghibaudi L, Williams P, and Chatterjee M. Comparison of acetylcholine-dependent relaxation in large and small arteries of rat mesenteric vascular bed. Am J Physiol 266: H952-958, 1994.

65. Iftinca M, Waldron GJ, Triggle CR, and Cole WC. State-dependent block of rabbit vascular smooth muscle delayed rectifier and Kv1.5 channels by inhibitors of cytochrome P450-dependent enzymes. J Pharmacol Exp Ther 298: 718-728, 2001.

66. Ignarro LJ, Buga GM, Wood KS, Byrns RE, and Chaudhuri G. Endotheliumderived relaxing factor produced and released from artery and vein is nitric oxide. ProC Natl Acad Sci U S A 84: 9265-9269, 1987.

67. Ignarro LJ, Byrns RE, Buga GM, and Wood KS. Endothelium-derived relaxing factor from pulmonary artery and vein possesses pharmacologic and chemical properties identical to those of nitric oxide radical. Circ Res 61: 866-879, 1987.

68. Iwamoto T, Kita S, Zhang J, Blaustein MP, Arai Y, Yoshida S, Wakimoto K, Komuro I, and Katsuragi T. Salt-sensitive hypertension is triggered by $\mathrm{Ca} 2+$ entry via $\mathrm{Na}+/ \mathrm{Ca} 2+$ exchanger type-1 in vascular smooth muscle. Nat Med 10: 1193-1199, 2004.

69. Jackson PA and Duling BR. Myogenic response and wall mechanics of arterioles. Am J Physiol 257: H1147-1155, 1989.

70. Jackson WF. Ion Channels and Vascular Tone. Hypertension 35: 173-178, 2000.

71. Jaggar JH, Wellman GC, Heppner TJ, Porter VA, Perez GJ, Gollasch M, Kleppisch T, Rubart M, Stevenson AS, Lederer WJ, Knot HJ, Bonev AD, and Nelson MT. Ca2+ channels, ryanodine receptors and $\mathrm{Ca}(2+)$-activated $\mathrm{K}+$ channels: a functional unit for regulating arterial tone. Acta Physiol Scand 164: 577-587, 1998.

72. Juhaszova M and Blaustein MP. Distinct distribution of different Na+ pump alpha subunit isoforms in plasmalemma. Physiological implications. Ann N Y Acad Sci 834: 524-536, 1997.

73. Kagota S, Tamashiro A, Yamaguchi $Y$, Nakamura K, and Kunitomo M. Excessive salt or cholesterol intake alters the balance among endothelium-derived factors released from renal arteries in spontaneously hypertensive rats. $J$ Cardiovasc Pharmacol 34: $533-539,1999$. 
74. Kalebic T, Garbisa S, Glaser B, and Liotta LA. Basement membrane collagen: degradation by migrating endothelial cells. Science 221: 281-283, 1983.

75. Kalluri R. Basement membranes: structure, assembly and role in tumour angiogenesis. Nat Rev Cancer 3: 422-433, 2003.

76. Kuriyama H and Suzuki H. The effects of acetylcholine on the membrane and contractile properties of smooth muscle cells of the rabbit superior mesenteric artery. $\mathrm{Br} J$ Pharmacol 64: 493-501, 1978.

\section{Lacy PS, Pilkington G, Hanvesakul R, Fish HJ, Boyle JP, and Thurston H.} Evidence against potassium as an endothelium-derived hyperpolarizing factor in rat mesenteric small arteries. Br J Pharmacol 129: 605-611, 2000.

78. Lagaud GJ, Skarsgard PL, Laher I, and van Breemen C. Heterogeneity of endothelium-dependent vasodilation in pressurized cerebral and small mesenteric resistance arteries of the rat. J Pharmacol Exp Ther 290: 832-839, 1999.

79. Lamboley M, Schuster A, Beny JL, and Meister JJ. Recruitment of smooth muscle cells and arterial vasomotion. Am J Physiol Heart Circ Physiol 285: H562-569, 2003.

80. Leblanc $\mathbf{N}$ and Hume JR. Sodium current-induced release of calcium from cardiac sarcoplasmic reticulum. Science 248: 372-376, 1990.

81. Liao Y, Day KH, Damon DN, and Duling BR. Endothelial cell-specific knockout of connexin 43 causes hypotension and bradycardia in mice. Proc Natl Acad Sci U S A 98: 9989-9994, 2001

82. Liou JY, Shyue SK, Tsai MJ, Chung CL, Chu KY, and Wu KK.

Colocalization of prostacyclin synthase with prostaglandin H synthase-1 (PGHS-1) but not phorbol ester-induced PGHS-2 in cultured endothelial cells. I Biol Chem 275: 15314$15320,2000$.

83. Liu Y, Jones AW, and Sturek M. Attenuated Ca2+response to acetylcholine in endothelial cells from aorta of aldosterone-salt hypertensive rats. Am J Hypertens 8: 404$408,1995$.

84. Lluch MM, de la Sierra A, Poch E, Coca A, Aguilera MT, Compte M, and Urbano-Marquez A. Erythrocyte sodium transport, intraplatelet $\mathrm{pH}$, and calcium concentration in salt-sensitive hypertension. Hypertension 27: 919-925, 1996.

85. Looft-Wilson RC, Matthes RD, and Gisolfi CV. Heat acclimation does not alter rat mesenteric artery response to norepinephrine. J Appl Physiol 86: 536-540, 1999. 
86. Manunta P, Stella P, Rivera R, Ciurlino D, Cusi D, Ferrandi M, Hamlyn JM, and Bianchi G. Left ventricular mass, stroke volume, and ouabain-like factor in essential hypertension. Hypertension 34: 450-456, 1999.

87. Margulis A and Sitaramayya A. Rate of deactivation of nitric oxide-stimulated soluble guanylate cyclase: influence of nitric oxide scavengers and calcium. Biochemistry 39: $1034-1039,2000$.

88. Marrelli SP, Eckmann MS, and Hunte MS. Role of endothelial intermediate conductance $\mathrm{KCa}$ channels in cerebral EDHF-mediated dilations. An $J$ Physiol Heart Circ Physiol 285: H1590-1599, 2003.

89. Matlib MA, Schwartz A, and Yamori Y. A Na+-Ca2+exchange process in isolated sarcolemmal membranes of mesenteric arteries from WKY and SHR rats. Am $J$ Physiol 249: C166-172, 1985.

90. Matsuda T, Arakawa N, Takuma K, Kishida Y, Kawasaki Y, Sakaue M, Takahashi K, Takahashi T, Suzuki T, Ota T, Hamano-Takahashi A, Onishi M, Tanaka Y, Kameo K, and Baba A. SEA0400, a novel and selective inhibitor of the $\mathrm{Na}+\mathrm{Ca}$ + exchanger, attenuates reperfusion injury in the in vitro and in vivo cerebral ischemic models. J Pharmacol Exp Ther 298: 249-256, 2001.

91. McAdam BF, Catella-Lawson F, Mardini IA, Kapoor S, Lawson JA, and FitzGerald GA. Systemic biosynthesis of prostacyclin by cyclooxygenase (COX)-2: the human pharmacology of a selective inhibitor of COX-2. Proc Natl Acad Sci U SA 96: $272-277,1999$.

92. Mensah GA. Clinical hypertension. Cardiol Clin 20: xiii-xiv, 2002.

93. Michel CC and Curry FE. Microvascular permeability. Physiol Rev 79: 703$761,1999$.

94. Miyoshi A, Suzuki H, Fujiwara M, Masai M, and Iwasaki T. Impairment of endothelial function in salt-sensitive hypertension in humans. Am J Hypertens 10: 10831090, 1997.

95. Moncada $\mathbf{S}$ and Vane JR. Pharmacology and endogenous roles of prostaglandin endoperoxides, thromboxane A2, and prostacyclin. Phamacol Rev 30: 293-331, 1978.

96. Najibi S, Cowan CL, Palacino JJ, and Cohen RA. Enhanced role of potassium channels in relaxations to acetylcholine in hypercholesterolemic rabbit carotid artery. Am J Physiol 266: H2061-2067, 1994.

97. Nakanishi K, Hara N, and Nagai $\mathbf{Y}$. Salt-sensitive hypertension in conscious rats induced by chronic nitric oxide blockade. Am J Hypertens 15: 150-156, 2002. 
98. Nelson LD, Mashburn NA, and Bell PD. Altered sodium-calcium exchange in afferent arterioles of the spontaneously hypertensive rat. Kidney $\operatorname{lnt} 50$ : 1889-1896, 1996.

99. Nelson LD, Unlap MT, Lewis JL, and Bell PD. Renal arteriolar Na+/Ca2+ exchange in salt-sensitive hypertension. Am J Physiol 276: F567-573, 1999.

100. Nelson MT and Quayle JM. Physiological roles and properties of potassium channels in arterial smooth muscle. Am J Physiol 268: C799-822, 1995.

101. Nikitina EI, Kochemasova NG, Taranenko VM, and Shuba MF. [Mechanism of the relaxant action of noradrenaline on coronary artery smooth muscle cells]. Biull Eksp Biol Med 91: 517-520, 1981.

102. Nilius $\mathbf{B}$ and Droogmans $\mathbf{G}$. Ion channels and their functional role in vascular endothelium. Physiol Rev 81: 1415-1459, 2001.

103. Nilsson H and Aalkjaer C. Vasomotion: mechanisms and physiological importance. Mol Interv 3: 79-89, 51, 2003.

104. Olesen SP and Bundgaard M. ATP-dependent closure and reactivation of inward rectifier $\mathrm{K}+$ channels in endothelial cells. Circ Res 73: 492-495, 1993.

105. Onaka U, Fujii K, Abe I, and Fujishima M. Antihypertensive treatment improves endothelium-dependent hyperpolarization in the mesenteric artery of spontaneously hypertensive rats. Circulation 98: 175-182, 1998.

106. Ozkan MH and Uma S. Inhibition of acetylcholine-induced EDHF response by elevated glucose in rat mesenteric artery. Life Sciences 78: 14-21, 2005.

107. Palmer RM, Ferrige AG, and Moncada S. Nitric oxide release accounts for the biological activity of endothelium-derived relaxing factor. Nature 327: 524-526, 1987.

108. Payne GW, Madri JA, Sessa WC, and Segal SS. Histamine inhibits conducted vasodilation through endothelium-derived $\mathrm{NO}$ production in arterioles of mouse skeletal muscle. Faseb J 18: 280-286, 2004.

109. Pedroletti C, Lundahl J, Alving K, and Hedlin G. Exhaled nitric oxide in asthmatic children and adolescents after nasal allergen challenge. Pediatr Allergy Immunol 16: 59-64, 2005.

110. Peng H, Matchkov V, Ivarsen A, Aalkjaer C, and Nilsson H. Hypothesis for the initiation of vasomotion Circ Res 88: 810-815, 2001. 
111. Pourageaud $\mathbf{F}$ and De Mey JG. Structural properties of rat mesenteric small arteries after 4-wk exposure to elevated or reduced blood flow. Am J Physiol 273:

H1699-1706, 1997.

112. Pourageaud F and De Mey JGR. Vasomotor responses in chronically hyperperfused and hypoperfused rat mesenteric arteries. Am J Physiol Heart Circ Physiol 274: H1301-1307, 1998.

113. Proud D. Nitric oxide and the common cold. Curr Opin Allergy Clin Immunol 5: $37-42,2005$.

114. Quilley J and McGiff JC. Is EDHF an epoxyeicosatrienoic acid? Trends Pharmacol Sci 21: 121-124, 2000.

115. Raij L. Nitric oxide, salt sensitivity, and cardiorenal injury in hypertension. Semin Nephrol 19: 296-303, 1999.

116. Rapoport RM and Murad F. Effect of ouabain and alterations in potassium concentration on relaxation induced by sodium nitroprusside. Blood Vessels 20: 255-264, 1983.

117. Rapoport RM, Schwartz K, and Murad F. Effect of sodium-potassium pump inhibitors and membrane-depolarizing agents on sodium nitroprusside-induced relaxation and cyclic guanosine monophosphate accumulation in rat aorta. Circ Res 57: 164-170, 1985.

118. Richard V, Tanner FC, Tschudi M, and Luscher TF. Different activation of Larginine pathway by bradykinin, serotonin, and clonidine in coronary arteries. $A m J$ Physiol 259: H1433-1439, 1990.

119. Rubanyi GM, Lorenz RR, and Vanhoutte PM. Bioassay of endotheliumderived relaxing factor(s): inactivation by catecholamines. Am J Physiol 249: H95-101, 1985.

120. Rubanyi GM and Vanhoutte PM. Nature of endothelium-derived relaxing factor: are there two relaxing mediators? Circ Res 61: 1161-67, 1987.

121. Schuster A, Lamboley M, Grange C, Oishi H, Beny JL, Stergiopulos N, and Meister JJ. Calcium dynamics and vasomotion in rat mesenteric arteries. I Cardiovasc Pharmacol 43: 539-548, 2004.

122. Segal SS, Damon DN, and Duling BR. Propagation of vasomotor responses coordinates arteriolar resistances. Am J Physiol 256: H832-837, 1989. 
123. Segal SS and Duling BR. Conduction of vasomotor responses in arterioles: a role for cell-to-cell coupling? Am J Physiol 256: H838-845, 1989.

124. Segal SS and Duling BR. Flow control among microvessels coordinated by intercellular conduction. Science 234: 868-870, 1986.

\section{Shimokawa H, Yasutake H, Fujii K, Owada MK, Nakaike R, Fukumoto Y,} Takayanagi T, Nagao T, Egashira K, Fujishima M, and Takeshita A. The importance of the hyperpolarizing mechanism increases as the vessel size decreases in endotheliumdependent relaxations in rat mesenteric circulation. J Cardiovasc Pharmacol 28: 703 $711,1996$.

126. Smith WL, DeWitt DL, and Garavito RM. Cycloox ygenases: structural, cellular, and molecular biology. Annu Rev Biochem 69: 145-182, 2000.

127. Stone JR and Marletta MA. Spectral and kinetic studies on the activation of soluble guanylate cyclase by nitric oxide. Biochemistry 35: 1093-1099, 1996.

128. Suzuki H. The electrogenic Na-K pump does not contribute to endotheliumdependent hyperpolarization in the rabbit ear artery. Eur J Pharmacol 156: 295-297, 1988.

129. Tomioka H, Hattori Y, Fukao M, Sato A, Liu M, Sakuma I, Kitabatake A, and Kanno M. Relaxation in different-sized rat blood vessels mediated by endotheliumderived hyperpolarizing factor: importance of processes mediating precontractions. $J$ Vasc Res 36: 311-320, 1999.

130. Tran QK, Ohashi K, and Watanabe H. Calcium signalling in endothelial cells. Cardiovasc Res 48: 13-22, 2000.

131. Urakami-Harasawa L, Shimokawa H, Nakashima M, Egashira K, and Takeshita A. Importance of endothelium-derived hyperpolarizing factor in human arteries. J Clin Invest 100: 2793-2799, 1997.

132. van Hinsbergh WM. Endothelial permeability for macromolecules. Mechanistic aspects of pathophysiological modulation. Arterioscler Thromb Vasc Biol 17: 1018-1023, 1997.

133. Vane JR and Botting RM. Pharmacodynamic profile of prostacyclin. Am J Cardiol 75: 3A-10A, 1995.

134. Wei CM, Hu S, Miller VM, and Burnett JC, Jr. Vascular actions of C-type natriuretic peptide in isolated porcine coronary arteries and coronary vascular smooth muscle cells. Biochem Biophys Res Commun 205: 765-771, 1994. 
135. Weston AH, Richards GR, Burnham MP, Feletou M, Vanhoutte PM, and Edwards G. $\mathrm{K}+$-induced hyperpolarization in rat mesenteric artery: identification, localization and role of $\mathrm{Na} / \mathrm{K}+-\mathrm{ATPases}$. Br J Pharmacol 136: 918-926, 2002.

136. Wier WG. Calcium transients during excitation-contraction coupling in mammalian heart: aequorin signals of canine Purkinje fibers. Science 207: 1085-1087, 1980.

137. Woolfson RG and Poston L. Effect of ouabain on endothelium-dependent relaxation of human resistance arteries. Hypertension 17: 619-625, 1991.

138. Xia XM, Fakler B, Rivard A, Wayman G, Johnson-Pais T, Keen JE, Ishii T, Hirschberg B, Bond CT, Lutsenko S, Maylie J, and Adelman JP. Mechanism of calcium gating in small-conductance calcium-activated potassium channels. Nature 395: 503-507, 1998.

139. Xie Q, Zhang Y, Zhai C, and Bonanno JA. Calcium influx factor from cytochrome P-450 metabolism and secretion-like coupling mechanisms for capacitative calcium entry in corneal endothelial cells. J Biol Chem 277: 16559-16566, 2002.

140. You J, Johnson TD, Marrelli SP, and Bryan RM, Jr. Functional heterogeneity of endothelial P2 purinoceptors in the cerebrovascular tree of the rat. Am J Physiol 277: H893-900, 1999.

141. Zhao Y, Brandish PE, Ballou DP, and Marletta MA. A molecular basis for nitric oxide sensing by soluble guanylate cyclase. Proc Natl Acad Sci U S A 96: 14753$14758,1999$. 